\title{
Local predictors of anti-A $\beta$ therapy efficacy revealed by quantitative whole-brain microscopy
}

Authors: Daniel Kirschenbaum ${ }^{1 \S}$, Fabian F. Voigt ${ }^{2 \S}$, Ehsan Dadgar-Kiani ${ }^{3 \S}$, Francesca Catto ${ }^{1 \S}$, Chiara Trevisan ${ }^{1}$,

Oliver Bichsel ${ }^{1}$, Hamid Shirani ${ }^{4}$, K. Peter R. Nilsson ${ }^{4}$, Karl Joachim Frontzek ${ }^{1}$, Paolo Paganetti ${ }^{5}$, Fritjof Helmchen ${ }^{2}$, Jin Hyung Lee ${ }^{3,6 *+} \&$ Adriano Aguzzi ${ }^{1 *+}$

${ }^{1}$ Institute of Neuropathology, University Hospital Zurich, University of Zurich, Schmelzbergstrasse $12, \mathrm{CH}-$ 8091 Zurich, Switzerland

${ }^{2}$ Laboratory of Neural Circuit Dynamics, Brain Research Institute, University of Zurich Winterthurerstrasse 190, CH-8057 Zurich, Switzerland

Neuroscience Center Zurich, University of Zurich \& ETH Zurich, Winterthurerstrasse 190, CH-8057 Zurich, Switzerland

${ }^{3}$ Department of Bioengineering, Stanford University, Stanford, CA 94305, USA

${ }^{4}$ Department of Physics, Chemistry and Biology, Division of Chemistry, Linköping University, SE-581 83 Linköping, Sweden

${ }^{5}$ Laboratory for Biomedical Neurosciences, Neurocenter of Southern Switzerland, Ente Cantonale Ospedaliero, $\mathrm{CH}-6807$ Torricella-Taverne, Switzerland

Faculty of Biomedical Neurosciences, Università della Svizzera Italiana, CH-6900 Lugano, Switzerland ${ }^{6}$ Neurology and Neurological Sciences, Neurosurgery, and Electrical Engineering, Stanford University

${ }^{8}$ Co-first authors; equal contribution

${ }^{+}$Co-last authors; equal contribution

*Correspondence: adriano.aguzzi@usz.ch, lijinhy@stanford.edu 
bioRxiv preprint doi: https://doi.org/10.1101/2021.01.15.426090; this version posted July 14, 2021. The copyright holder for this preprint (which was not certified by peer review) is the author/funder, who has granted bioRxiv a license to display the preprint in perpetuity. It is made available under aCC-BY-ND 4.0 International license.

One sentence summary: $3 \mathrm{D}$ microscopy of $A \beta$ plaques reveals that Alzheimer's disease therapeutics have regiospecific effects that can be mapped to distinct genetic networks. 


\section{Abstract:}

Genetic and biochemical evidence implicates amyloid- $\beta(A \beta)$ in Alzheimer's disease, yet many anti-A $\beta$ treatments are clinically ineffective. Regional heterogeneity of efficacy may contribute to these disappointing results. Here we mapped the regiospecificity of various anti-A $\beta$ treatments by high-resolution light-sheet imaging of amyloid plaques in electrophoretically clarified brains of Thy1-APP mice overexpressing A $\mathrm{B}$. We found that $A \beta$ plaques in whole brains progressed from $1.2 * 10^{6}$ to $2.5 * 10^{6}$ (standard deviation $\pm 1.6 * 10^{5}$ and $\pm 4.3 * 10^{5}$ respectively) over a 9-month period. We then assessed the regiospecific plaque clearance in mice subjected to $\beta$-secretase inhibition, amyloid intercalation by polythiophenes, or anti-A $\beta$ antibodies. Each treatment showed unique spatiotemporal $A \beta$ clearance signatures, with polythiophenes emerging as potent anti-A $\beta$ compounds with promising pharmacokinetic properties. We then interrogated genes matching regiospecific $A \beta$ clearance by aligning voxels that showed drug effectiveness to spatial-transcriptomics atlases. Bace1 and Thy1 expression matched the regiospecific efficacy of BACE inhibition, confirming the validity of our analyses. Voxels cleared by polythiophenes correlated with transcripts encoding synaptic proteins, whereas voxels cleared by BACE inhibition correlated with oligodendrocyte-specific genes. The restricted regional susceptibility of $A \beta$ plaques to specific treatments may contribute to the clinical failure of anti-A $\beta$ therapies. The striking regiospecificity of the treatments studied suggests that combinatorial regimens may improve functional outcomes. 


\section{Introduction}

Pathological protein aggregation typically occurs in distinct microanatomical locales and gives rise to specific clinical pictures $(1,2)$, yet the determinants of this specificity are poorly understood. In Alzheimer's disease $(A D)$, the most prevalent neurodegenerative disease (3), deposition of amyloid- $\beta$ (A $\beta$ ) plaques occurs stereotypically in a well-characterized sequence (4-6). The plaque load of AD patients can be effectively reduced by quenching $A \beta$ production (7), by reducing the propagation of $A \beta$ aggregates (8), or by enhancing $A \beta$ catabolism (9). The clinical efficacy of $A \beta$ removal is still debated $(10,11)$, perhaps because intervention is too late to be efficacious (12). It is also conceivable that anti-A $\beta$ drugs remove plaques differentially in distinct CNS regions, some of which may not coincide with the areas that matter most to proper brain functioning.

To challenge the latter hypothesis, we developed a high-throughput quantitative 3D histology (Q3D) platform for optically clarifying, staining, imaging and quantifying $A \beta$ plaques in whole brains of mice. $A \beta$ plaques were electrophoretically stained in cleared brains and imaged with a mesoscale selective plane illumination microscope (mesoSPIM) (13). We tested the effects of the polythiophene LIN5044 which intercalates with amyloids and is therapeutic in prion diseases $(14,15)$, the BACE1 inhibitor NB-360 $(16,17)$, and the $\beta 1$ antibody (18) in APPPS1 mice (19). We found that each drug acted onto distinct, largely non-overlapping brain regions. The alignment of whole-brain treatment maps to a spatial transcriptomics atlas allowed us to identify local transcriptional signatures correlating with the effectiveness of each drug. 


\section{Results}

\section{Rapid tissue clearing and staining platform}

Detergent-mediated lipid extraction from hydrogel-embedded tissues is facilitated by electrophoretic mobilization of detergent molecules $(20,21)$ in a buffer-filled container. However, the electrical resistivity of 4\% paraformaldehyde-fixed PBS-soaked brain tissue is 4-fold higher than that of PBS (Figure S1E). Therefore, any buffer surrounding the specimen short-circuits its electrophoresis. We resolved this issue by constructing a focused electrophoretic clearing (FEC) device that uncouples buffer recirculation in the anodic and cathodic circuits with an insulating layer (Figure 1A and S1). By forcing the electrical current to traverse the tissue specimen (130 mA in constant-current, $39.5^{\circ} \mathrm{C}$ ), FEC reduced the clearing time from $48-120$ with CLARITY to 6-14 hours $(20,21)$ (Figure 1B-D and S1G).

For $A \beta$ plaque staining of intact mouse brains by electrophoresis, we constructed buffer-filled chambers hosting the electrodes. Their inner faces were cast with $10 \%$ polyacrylamide in tris-tricine buffer and functioned as electrically conductive contact surfaces. The sample was mounted with a holder between the two polyacrylamide walls. This allowed electrophoresis to occur through the buffers, the gels and the tissue specimen; spanning $10 \mathrm{~cm}$ between the two electrodes (Figure S2A-B). The electric resistance of the electrophoretic system $\left(20 \mathrm{~V}, 20^{\circ} \mathrm{C}\right)$ increased from initially $\sim 2 \mathrm{k} \Omega$ to $\sim 20 \mathrm{k} \Omega$ after 2 hours (Figure S2C). 


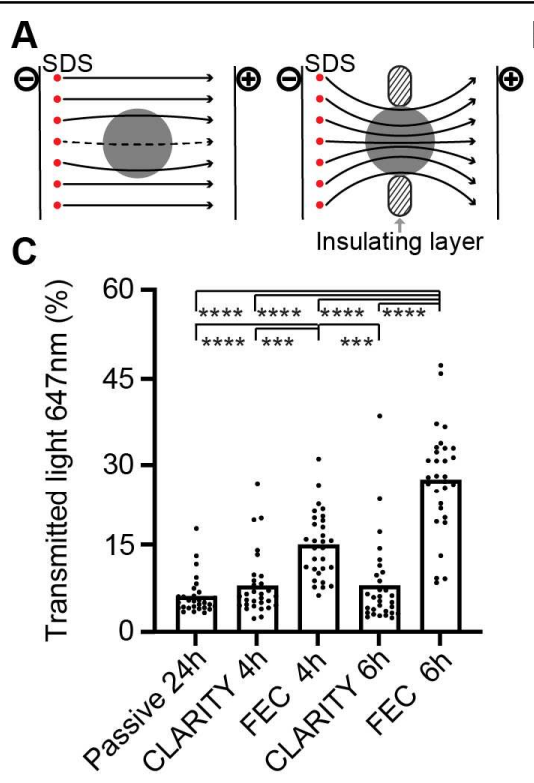

B
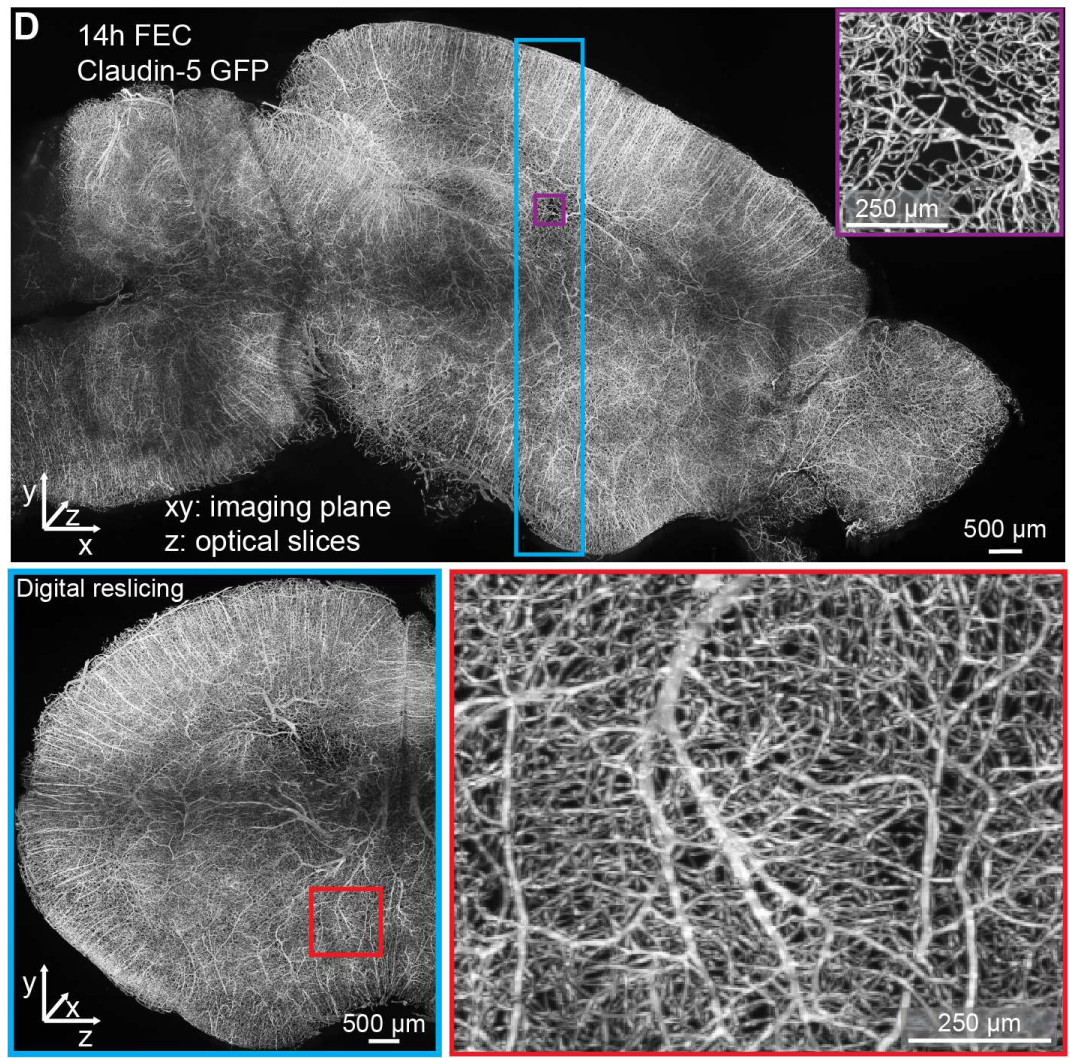

\section{Figure 1}

Figure 1. Focused electrophoresis improves tissue clearing efficiency. (A) Schematics of focused electrophoretic clearing (FEC). An insulating layer constrains the electrical field through the tissue. (B) Comparison of mouse brains cleared by FEC ( $6 \mathrm{hrs}$ ) and passive ( 3 days). Passive clearing was incomplete even after 3 days. (C) Light transmittance of tissue increased more rapidly with FEC than with CLARITY. Each datapoint plotted is the mean from three neighboring transmittance readings (hence resulting in 10 datapoints from the 30 measurements/brain) (One-way ANOVA $* * * p<0.001, * * * * p<0.0001$ ). (D) The brain vasculature of Claudin5-GFP mice after 14 hours of clearing was imaged sagittally by mesoSPIM. Digital reslicing and visualization by maximum-intensity projection demonstrates that focused clearing resulted in highly uniform signals. Darkened areas are due to stitching/vignetting artifacts. 
We then ran native-gel electrophoreses of proteins with various charges at different $\mathrm{pH}$ and ionic strengths.

Tris-tricine (50 mM each) at pH 8.5 yielded the best results (Figure S2D-G). As expected, the electrophoretic mobility of proteins was influenced by the charge of covalently coupled fluorophores (Figure S2D-G). The polythiophenes qFTAA $(616.5 \mathrm{~g} / \mathrm{mol}, \mathrm{m} / \mathrm{z}=205.5)$ and hFTAA $(948.9 \mathrm{~g} / \mathrm{mol}, \mathrm{m} / \mathrm{z}=237.125)$ were dissolved in agarose $\left(600 \mu \mathrm{l}\right.$, congealing temperature $\left.26-30^{\circ} \mathrm{C}\right)$ and cast on the acrylamide-tissue interface in order to confine them to the smallest possible volume. Under these conditions, the dye front traversed the entire brain within 2 hours.

An uneven passage of the dye front through the brain may lead to local inhomogeneities of plaque detection, particularly at gel-liquid interfaces. To investigate this question, a hydrogel-embedded and cleared APPPS1 brain was electrophoretically stained with polythiophenes ( 2 hours) and cut into $500-\mu \mathrm{m}$ sagittal sections with a vibratome. Free-floating sections were imaged with a fluorescent stereomicroscope. Then, the sections were passively re-stained with the same polythiophene dyes using a well-established protocol (22, 23) and images were acquired again. The numbers of $A \beta$ plaques were 3085 and 3061 plaques before and after re-staining, respectively, and their morphology was very similar (Figure 2A). Hence the sensitivity and spatial homogeneity of electrophoretic plaque staining of whole brains was not inferior to that of conventional histochemical slice staining. Slight differences in plaque counts and morphology were a result of physical distortions of the slices during passive staining, and due to focal shifts during re-imaging of the free-floating slices. 


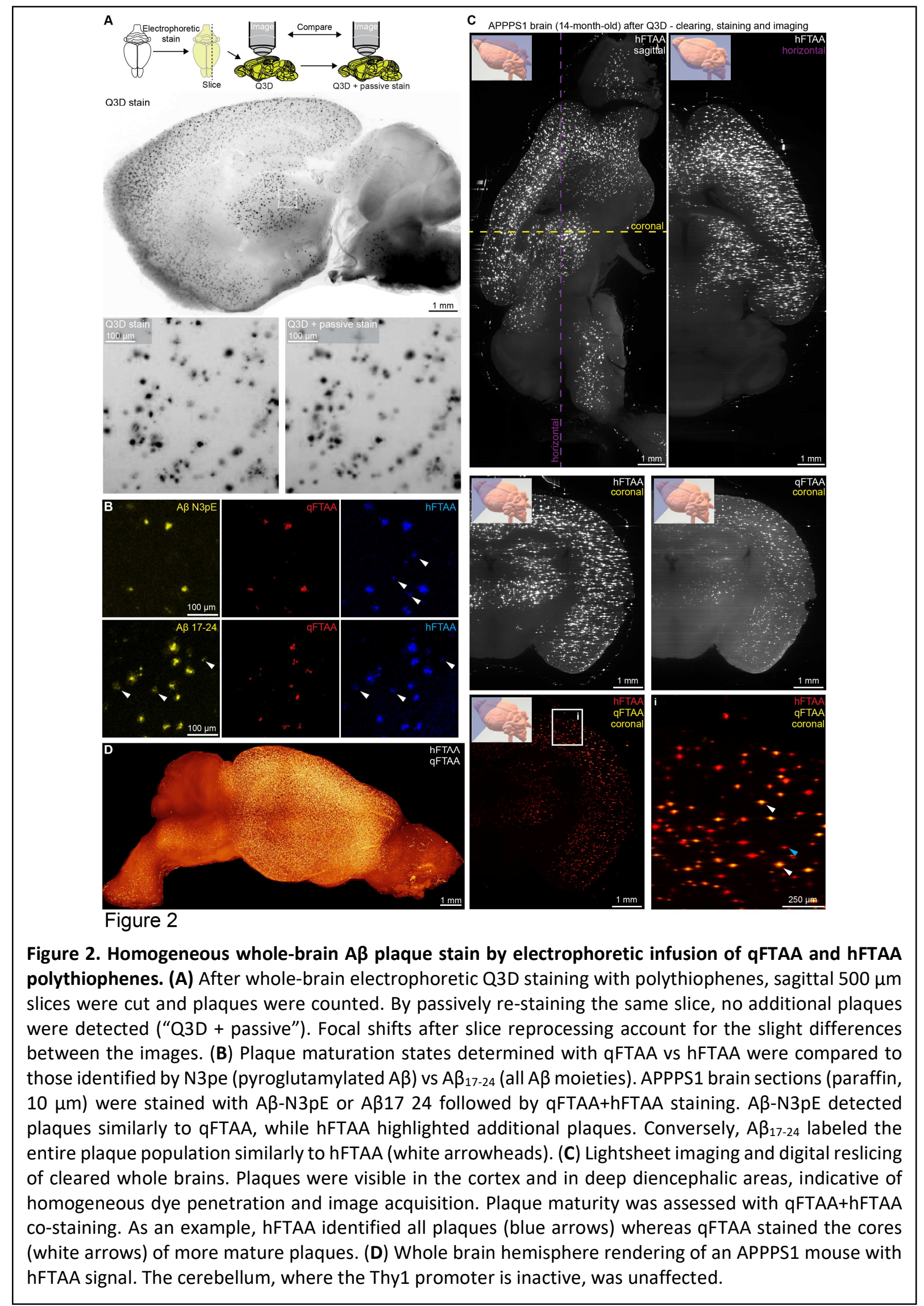


Antibody A $17-24$ recognizes early plaques and stains their entire surface, whereas N3pE labels plaques which accumulate at later stages (24). Likewise, the polythiophene hFTAA stains the entire area of early plaques whereas qFTAA stains the cores of plaques in older mice. The qFTAA/hFTAA ratio correlates with plaque compactness (22) and is used as a proxy for their maturity. We stained histological sections ( $3 \mu \mathrm{m})$ from paraffin-embedded APPPS1 brains with AB17-24 or N3pE, followed by staining with qFTAA and hFTAA. The hFTAA and AB17-24 signals were largely superimposable and identified more plaques than qFTAA and $\mathrm{N} 3 p E$, which stained selectively the cores of a subset of plaques (Figure $2 \mathrm{~B}-\mathrm{C}$ ). Most $\mathrm{A} \beta 17-24^{+} \mathrm{N} 3 \mathrm{pE}-$ plaques were $\mathrm{hFTAA}^{+} \mathrm{qFTAA}^{-}$, suggesting that they contained less mature amyloid.

\section{Evaluation of anti-AB therapies by Q3D}

Groups of 2-month old or 11-month old APPPS1 mice (30 and 25 mice/group, henceforth referred to as "young" and "old", respectively) were treated for 90 days with the BACE1 inhibitor NB360 (0.5 g inhibitor/kg

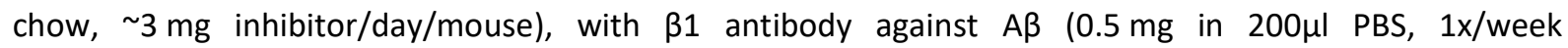
intraperitoneally), or with the amyloid-binding compound LIN5044 (0.4 mg in $100 \mu \mathrm{l} \mathrm{PBS,} \mathrm{1x/week}$ intraperitoneally) (Table S1). Control treatments included control food chow and intraperitoneally injected recombinant pooled IgG or PBS, respectively (Figure 3A). Mice were sacrificed one week after the last administration of LIN5044 or $\beta 1$; the NB360 chow was provided without interruption. Brains were subjected to clearing, staining, and imaging. Raw data volumes were transformed to the coordinate space of the Allen Brain Atlas (25) and anatomically registered. We then performed automated plaque segmentation and regional quantification of plaque pathology (Figure 3, 4A, S3-4, Table S2). Voxel-level plaque counts, mean size, and maturity (qFTAA/hFTAA ratio) were determined for each treatment group (Figure S4A-C, Table S3). The 40 brain regions displaying the most significant treatment effect were plotted for plaque count, mean size and maturity. Corresponding voxels of brains treated with anti- $A \beta$ compounds and their respective controls were compared pairwise by inferential statistics (Figure S4D). This allowed us to identify "Significantly Altered Voxels" (SAV) across entire brain volumes. SAV heatmaps were digitally resliced into coronal and sagittal sections. 


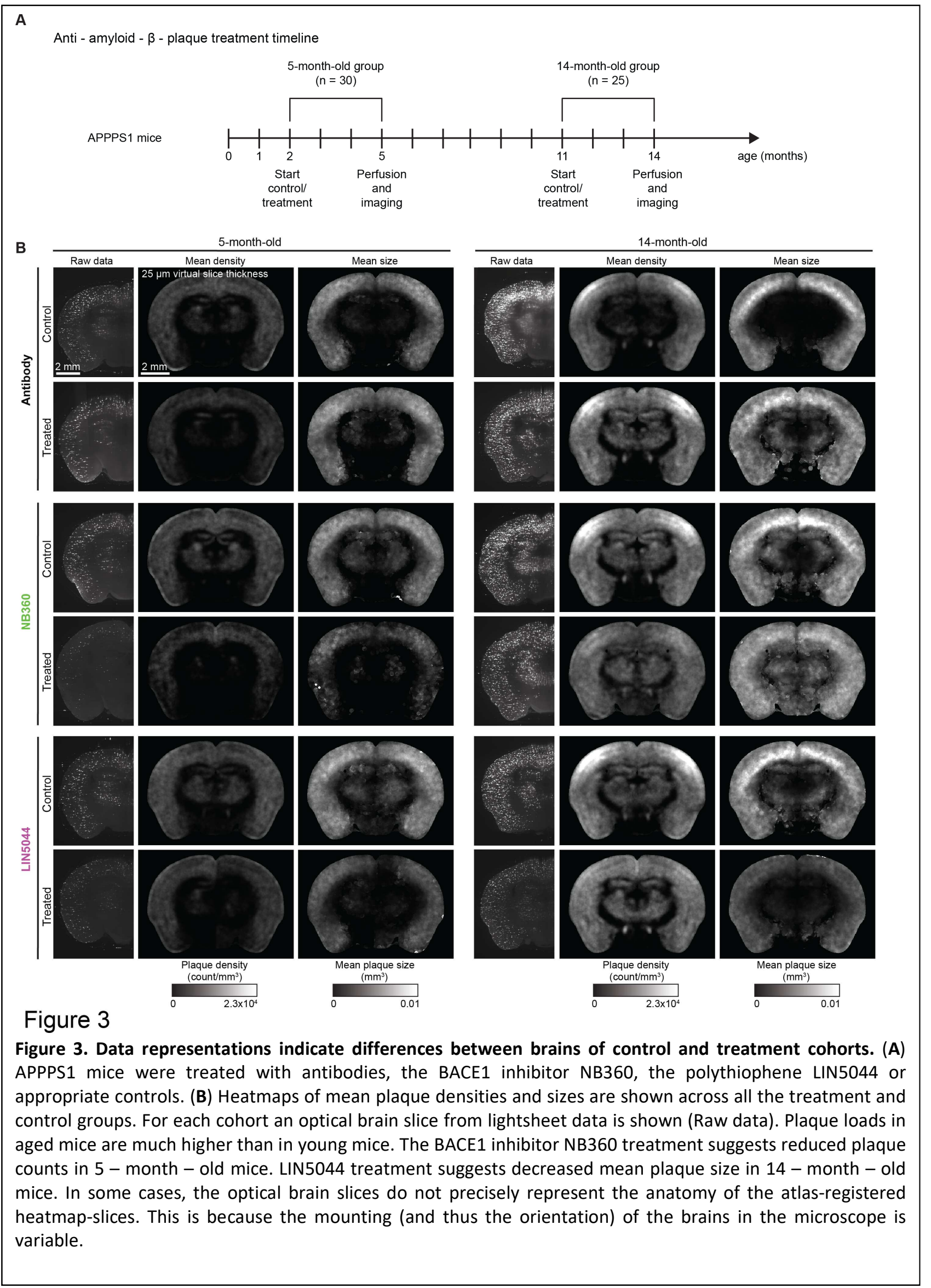




\section{Correlation of local efficacy with neuroanatomical areas}

The effects of the $\beta 1$ antibody were surprisingly small. In young mice, the increase in plaque density was slightly reduced (gustatory areas and claustrum: $p=0.014$ ) whereas size was marginally increased (claustrum: $p=0.044$ ), and plaque maturity was unaffected. In old mice there was no significant effect (Figure S5, S6A-D, S7A-D, S8A-D). In contrast, NB360 robustly quenched the increase in plaque density and (to a lesser extent) size in 5-month-old mice. The effect on plaque density was most pronounced in subcortical areas (claustrum: $p=0.004$ ) and in ventral and posterior cortical areas including the perirhinal and posterolateral visual area (both $p=0.004$ ), whereas the effect on plaque size was particularly strong in the amygdala and piriform area (both $p=0.024$ ) (Figure 4-5, S9A-B, 10A-B). Plaque maturity (based on the qFTAA/hFTAA fluorescent ratio) was increased in superficial cortical areas (e.g. olfactory areas $p=0.011$ ) but decreased in deep subcortical structures (e.g. amygdala $p=0.017$ ) (Figure 4B, D and S11A-B). In old mice, NB360 had no significant effect on plaque density, size and maturity (Figure 4, S9C-D, 10C-D, 11C-D).

LIN5044 acted primarily on plaque size, but only marginally on plaque density of old mice (Figure 3-4, S12AD, 13A-D). Plaques were smaller in subcortical areas (medial septal complex and amygdala: $p=0.0048$ and 0.012 respectively) and cortical areas with a rostro-dorsal emphasis (supplemental somatosensory area: $p=0.0067)$. The effect of LIN5044 on mean plaque size was more pronounced in old mice, but the spatial distribution of the treatment effect was similar in young and old mice (Figure 4, S13A, C). In contrast, the effect of LIN5044 on plaque density in young mice was less conspicuous (Figure 4, S12A, C).

LIN5044 treatment may influence the fluorescent spectra of plaques and distort maturity analyses. We therefore measured plaque spectra of APPPS1 mice 3 days after a single injection of LIN5044 or PBS. The emission spectra of plaques were not influenced (Figure S14A). In contrast, the cohorts treated for 3 months with LIN5044 showed a massive shift towards increased plaque maturity in old mice (retrosplenial area: $p=$ 0.0014) and to a lesser extent in young mice (supplemental somatosensory area: $p=0.026$ ) (Figure S14B-G). 


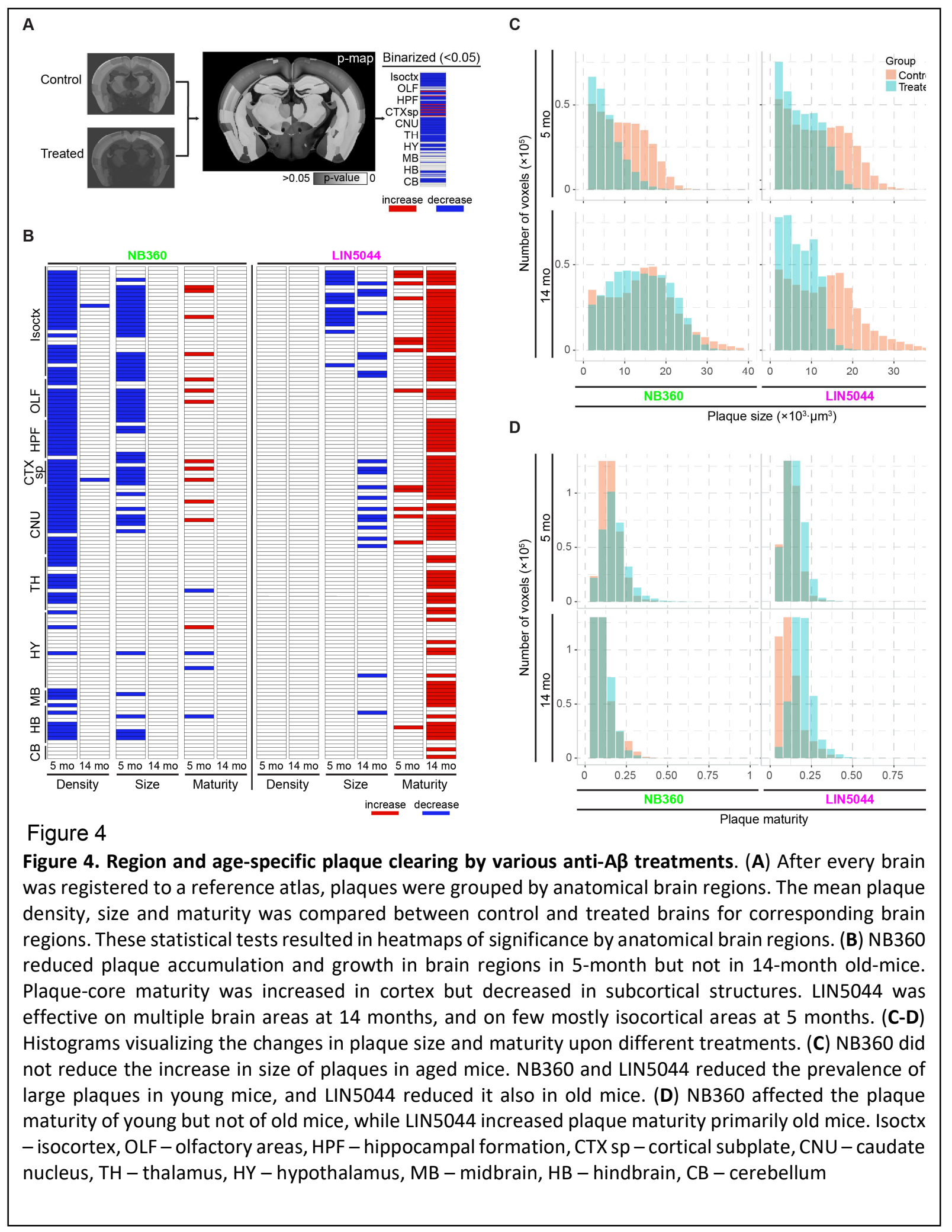




\section{Regional drug - effect analysis based on voxel-level probability distribution}

We decomposed atlas-registered brains into spatially registered cubic voxels $\left(15^{\prime} 625 \mu \mathrm{m}^{3}\right)$ and generated descriptive statistics of plaque density, size and maturity for each voxel. We then assessed the effects of each treatment arm at the single-voxel level (Figure 3, 5A-B, S3-S4). We found that the locales of treatment effectiveness did not coincide with neuroanatomically defined regions. Indeed, assignment by neuroanatomical boundaries failed to capture peaks of regiospecific therapeutic efficacy and overestimated the volume of treatment-affected brain tissue (Figure 5C, S15E). Remarkably, voxel-level heatmaps of pvalues showed that BACE1 inhibition reduced the increase in plaque counts most effectively in the posterior and ventral telencephalon (Figure 5A, S9E), whereas LIN5044 reduced the increase in the size of plaques primarily in rostro-dorsal areas (Figure 5A, S13E-F). These effects were symmetric across the midline and showed sharp boundaries lining the deep cortical layers (LIN5044), the thalamus, and CA3 (NB360) (Figure S9E, S10E and S13F). The $\beta 1$-treated young mice showed patchy reduction in plaque count and size in the brainstem and some decrease in maturity (Figure 5B, S6E, S7E, S8E). However, these effects were marginal. The effects of $\beta 1$ in old mice were even less significant (Figure S6F, S7F, S8F). Therefore, $\beta 1$ was excluded from further analyses.

The inferred effects of NB360 and LIN5044 rely on complex computations on terabyte-sized datasets. To intuitively visualize these effects, we randomly selected single cortical mesoSPIM images of atlas-registered brains from each treatment and control groups. Upon segmentation, we color-coded plaques based on their size. Figure 5A and S15 confirm the reduced plaque density and plaque size in NB360 treated young mice and LIN5044 treated old mice, respectively.

Since LIN5044 and NB360 differ in their vehicle, route and schedule of administration, the different application modes may contribute to the patterns distinguishing LIN5044 and NB360. To test for this possibility, we repeated the computations by testing LIN5044-treated mice against the NB360 control group and vice versa. The patterns remained stable even under these conditions (Figure S16-S17). Conversely, testing the control groups against each other did not reveal any significant treatment patterns (Figure S18A). Male and female mice did not differ in plaque burden (Figure S18B). 


\section{Colocalization analysis reveals little overlap in the regiospecificity of therapies}

As a global measure of regiospecific similarity, we counted the overlapping SAVs in all treatment pairs and metrics (plaque density, mean plaque size and maturity) (Table S4). The maximal SAV overlap between pairs was $<1 \%$ or $<2.65 \%$ ( $p<0.05$ or $p<0.1$, respectively) indicating that each treatment had a unique regiospecific fingerprint (Figure 5D-E, Table S4). Hypergeometric tests confirmed that overlaps were not significant (p<0.03). The LIN5044 and NB360 SAVs appeared to cluster in distinct patterns (Figure 5D, Movie S1). To probe the randomness of such clusters, we measured the number of connected components (neighboring SAVs that are touching each other) in NB360 and LIN5044 treated brains (13'710 and 18'553, respectively).

We then generated 500 Monte Carlo simulations with the same number of SAVs than we measured experimentally, but without constraints on their spatial distribution. We found that the number of connected components in the experimental measurements was at least 5-fold lower than in the simulations, indicating that the SAVs are grouped into distinct, spatially confined clusters (Figure 5F).

\section{Regiospecificity is not due to pharmacokinetic differences}

To test if the regiospecificity was caused by differential penetration of therapeutic compounds, we determined the biodistribution of $\beta 1$, NB360 and LIN5044 by dissecting brains into 8 standard regions (Figure S19A). NB360 levels were measured 1 hour after oral administration (16). Since antibodies have long halflives (26) and limited blood-brain barrier penetration, brain levels were measured 6 and 24 hours after intraperitoneal injection. As the pharmacokinetic properties of LIN5044 are unknown, we measured brain levels 2 and 6 hours after intraperitoneal administration. There was no difference in regional NB360 levels. LIN5044-treated brains showed higher levels in the brainstem and cerebellum $(p<0.034$ and 0.024 , respectively) after 2 hours, but its distribution became homogeneous after 6 hours (Figure S19B-D). $\beta 1$ showed higher levels in the brainstem after 6, and in the brainstem and the cerebellum after 24 hours (Figure S19E, F). However, there was no difference in antibody levels between diencephalic and telencephalic regions. Pooled non-specific recombinant IgG was used for control and did not accumulate in any brain region at 24 hours (Figure S19G). Hence regional pharmacokinetic differences do not explain the region-specific drug effects. 
A
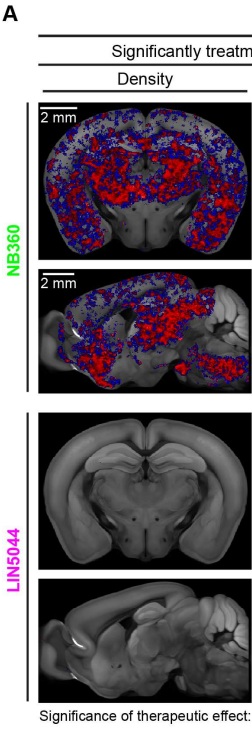

$B$
5 months

ment-affected voxels
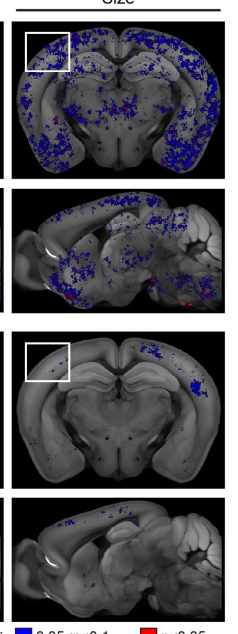

D<smiles>CC(C)(C)C1(c2ccccc2)CCCC1</smiles>
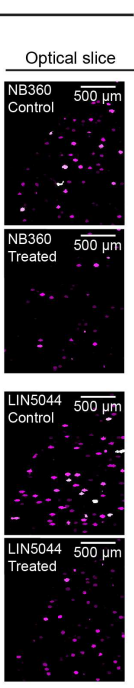

14 months
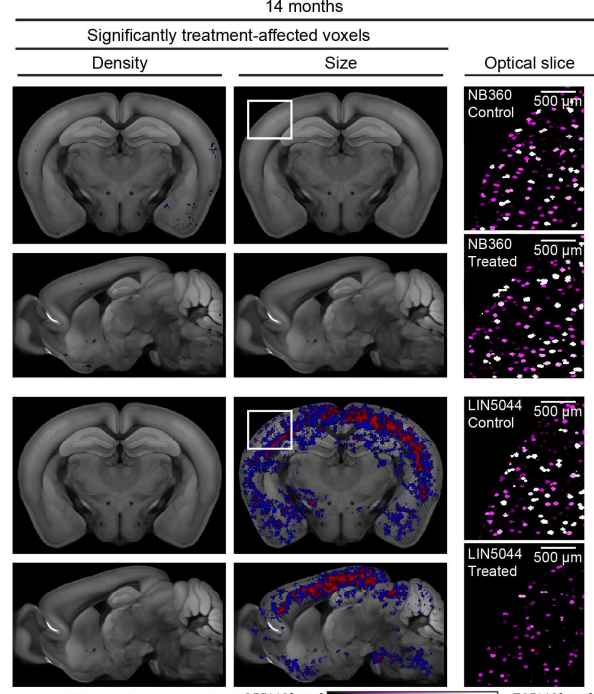

Plaque-size color scale: $<255^{*} 10^{3} \mu^{3}$

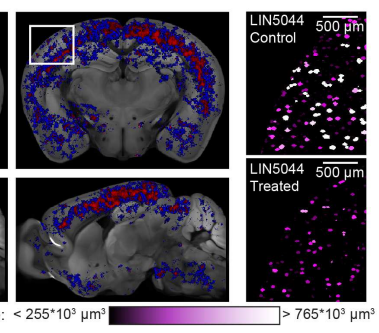

\section{(C)}

C
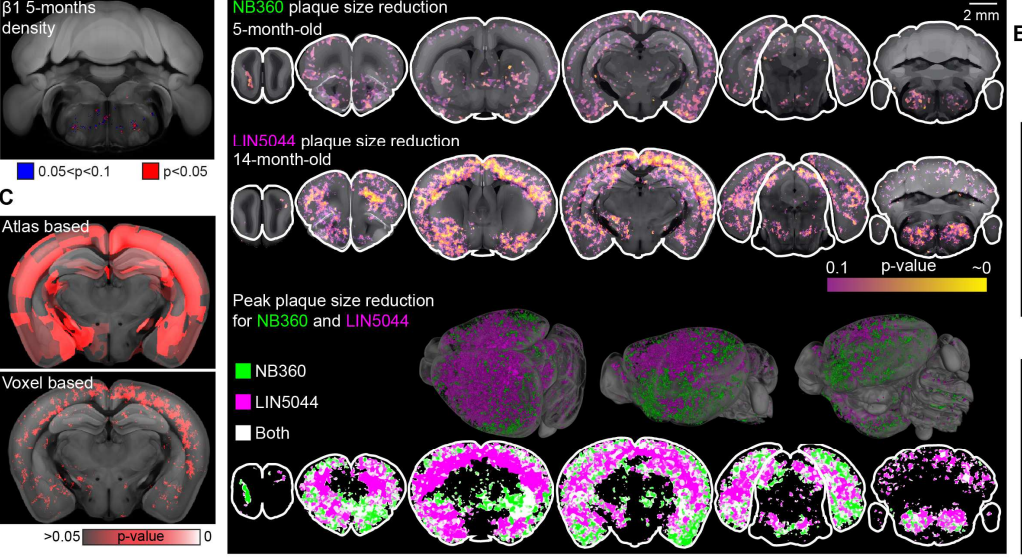

Number of voxels with plaque size reduction

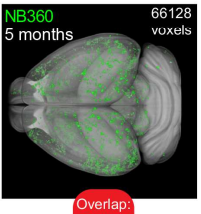
Overiap:

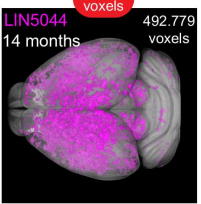

$\mathbf{F}$

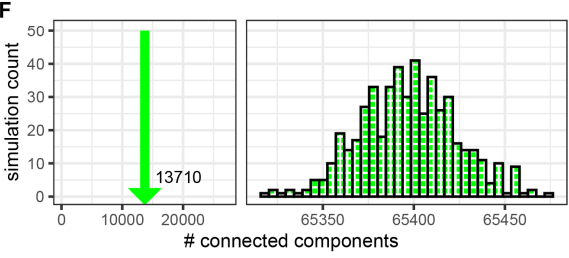

NB360 Experimental

(iii NB360 Simulated

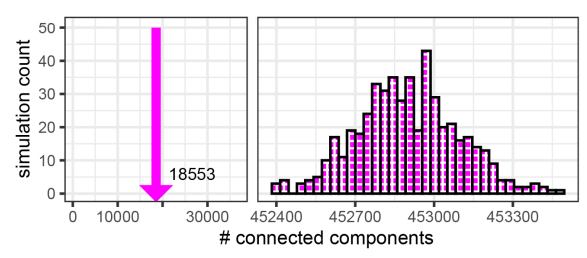

LIN5044 Experimental IIN5044 Simulated

Figure 5

Figure 5. Voxel-based brain analysis shows regional and temporally distinct anti-A $\beta$ treatment effects. (A) Each 3-dimensional map of SAVs (representative slices, $0.05<p<0.1$ blue, $p<0.05$ red, reference atlas grey) summarizes all the treated and control samples within a cohort (8-12 samples). These maps reveal regiospecific efficacy unique to each treatment modality. NB360 reduced plaque accumulation and growth in postero-ventral areas of young mice. LIN5044 showed profoundly divergent peaks targeting primarily plaque sizes in antero-dorsal areas of aged mice. The plaque burden reduction suggested by the voxel maps was confirmed by looking at randomly picked cortical (white inserts on heatmaps) optical slices, color-coded by plaque size. (B) $\beta 1$ treatment SAVs (plaque counts) in the brainstem. (C) Seeking an unbiased volume unit for spatial analysis we divided brain data into $(25 \mu \mathrm{m})^{3}$ voxels. Atlas-based anatomical normalization overestimates the volume of treatment-affected brain compared to voxel-level analysis. (D-E) The SAVs (plaque-size) of the strongest treatments (LIN5044 and NB360) cluster separately with limited overlap ( ${ }^{*} \mathrm{p}=0.03$, hypergeometric test). (F) To validate that these SAV-clusters are nonrandom Monte-Carlo simulations were run (randomly distributing the experimentally measured number of voxels), and the number of connected components was counted. LIN5044 and NB360 SAVs show at least 5 -fold higher clustering than random. 


\section{Genetic networks revealed by aligning the Q3D output to gene-expression atlases of the brain}

The findings above suggested that the local heterogeneity of drug efficacy may be controlled by intrinsic properties of the host brain. We therefore compared the plaque-size SAVs of NB360 and LIN5044 to a geneexpression atlas reporting whole-genome expression at $>30^{\prime} 000$ spots of the mouse brain (27). We calculated the mutual information (MI), a similarity metric describing the non-linear interdependence of random variables. As expected, most genes showed low MI scores with either treatment (Figure 6A). The MI of Thy1, whose promoter was used to drive APPPS1 expression, ranked at the $99^{\text {th }}$ percentile of 23371 genes for both

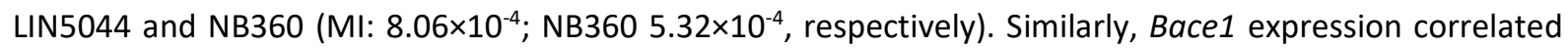
highly with the efficacy of its inhibitor NB360 (MI: $2.22 \times 10^{-4}, 96^{\text {th }}$ percentile), but not with LIN5044 $\left(1.37 \times 10^{-4}\right.$, $81^{\text {st }}$ percentile). This result confirm that the morphological-genetic analyses presented here identifies sensitively and reliably the genetic networks controlling the efficacy of amyloid removal therapies.

The effect of LIN5044 showed a high MI $\left(7.23 \times 10^{-4}, 98^{\text {th }}\right.$ percentile) with cx3cl1, a microglial chemoattractant mostly expressed by neurons (28) (NB360, cx3cl1 MI: $1.95 \times 10^{-4}, 95^{\text {th }}$ percentile) (Figure 6A), suggesting that the effect of LIN5044 are strongest in areas of high microglia recruitment. To test this, we quantified Iba1 ${ }^{+}$ microglia in cortical areas with strong or weak LIN5044 effects. Regions strongly affected by LIN5044 showed higher microglia counts (Figure 6C-E).

The five genes with the highest MI score showed remarkably asymmetric correlation to different anti-Abeta compounds. While neuronal markers (Nrgn, Snap25, Camk2n1) segregated with LIN5044 efficacy, oligodendrocyte-expressed genes ( $M b p$ and $P / p 1$ ) were associated with NB360 activity (Figure 6B). Next, we grouped the genes ranking above the $95^{\text {th }}$ percentile in $\mathrm{Ml}$ according to cell types based on a published database (29). Again, the genes with the highest MI for NB360 and LIN5044 were predominantly oligodendroglia and neuron-associated, respectively (Figure 6F-G). 
A
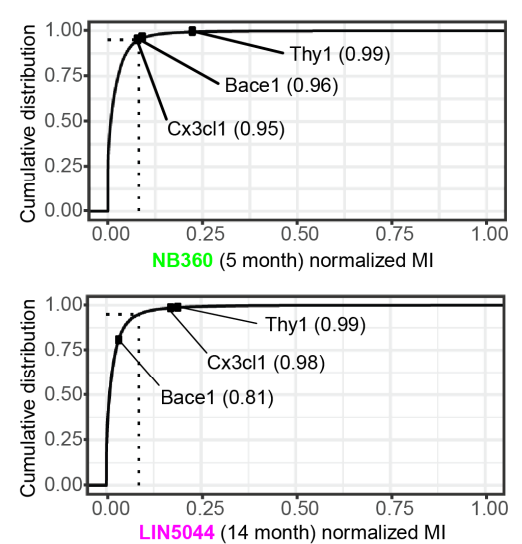

C

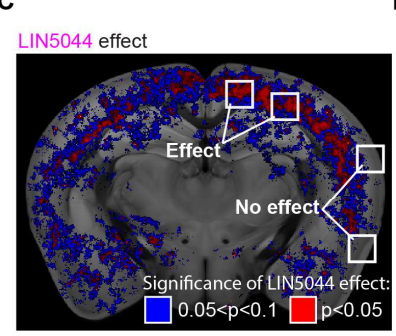

$\mathbf{F}$

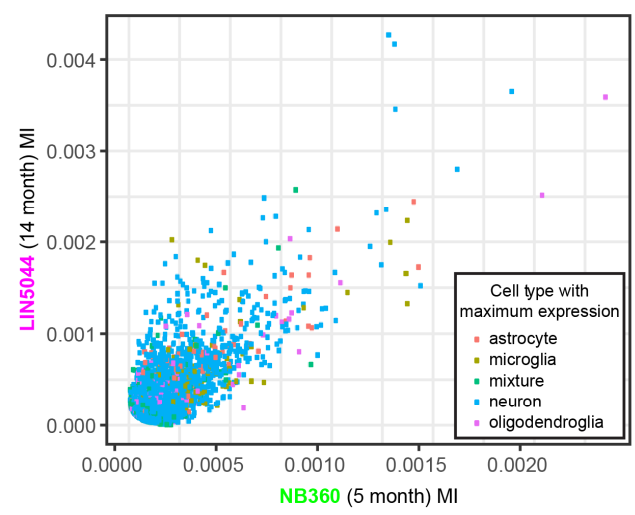

B

Iba1 stain

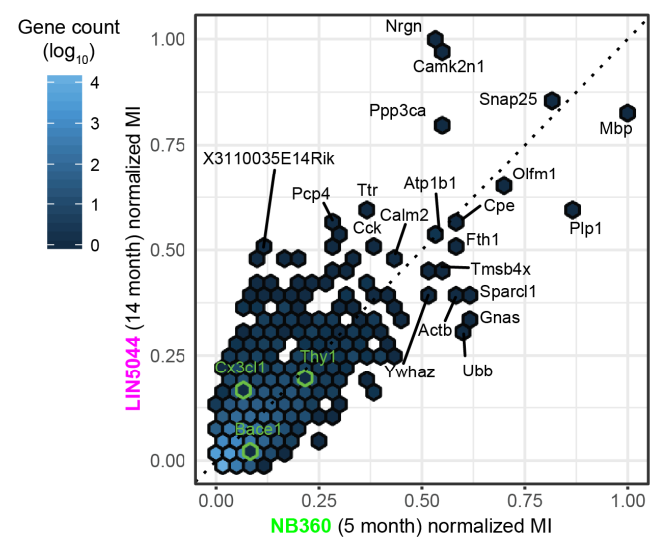

E

Area without LIN5044 effect Area with LIN5044 effect

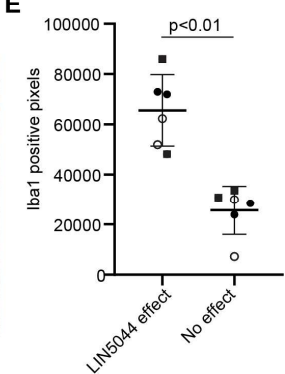

G
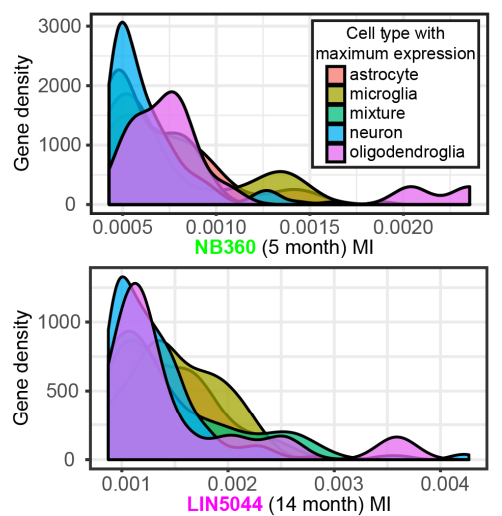

Figure 6

Figure 6. Genetic networks predict local drug responsiveness. (A) Mutual information (MI) between the spatial distributions of SAV and gene expression ranked cumulatively by MI (23371 genes). Dashed line: genes above the $95^{\text {th }}$ percentile of MI. (B) Normalized MI of genes above the $95^{\text {th }}$ percentile (ranked by $\mathrm{MI},[\mathrm{n}=1169]$ ) for either NB360 or LIN5044. Cx3cl1, a neuron-borne microglia chemoattractant mirrors the effect of LIN5044. (C) Microglia density was compared in regions displaying strong or absent LIN5044 efficacy of 3 three wild-type mice (3 slices/mouse). (D-E) Regions showing strong LIN5044 effects contained more microglia (each symbol represents one mouse). (F) Same raw data as in (B) but showing only the genes above the $95^{\text {th }}$ percentile. Genes were color-coded according to the cell types in which they are enriched. NB360 and LIN5044 treatments were associated with oligodendroglial and neuronal genetic networks, respectively. (G) After genes were associated to cell-types, we ranked the genes by MI. This shows that the genes with the highest MI are overtly oligodendrocyte-associated for BACE1 inhibition, while for LIN5044 neuron-associated genes are the most frequent with high MI. 


\section{Discussion}

Brain-wide analyses of $A \beta$ plaque load require brain clearing and reliable amyloid staining. However, current hydrogel-based methods of whole-brain clearing are slow and often inhomogeneous. We have solved these limitations by insulating the anodic from the cathodic detergent reservoir, thereby constraining the lipidclearing ion flow through the sample. This design enabled whole-brain clearing within $\leq 14$ hours $(20,21,30)$, and electrophoresis of qFTAA/hFTAA resulted in homogenous plaque staining within 2 hours. Comparison of the Q3D pipeline-including light-sheet acquisition $(3.26 \times 3.26 \times 6.5 \mu \mathrm{m}$ resolution) with conventional staining of histological sections showed that Q3D reliably visualizes $A \beta$ plaques within mouse brains. The precision of Q3D resulted in highly consistent plaque counts among age-matched APPPS1 mice (standard deviation: 2.5$3.3 \%)$.

The $\beta 1$ antibody showed only marginal effects in young APPPS1 mice and no effect in old mice, adding to the reports of its inconsistent efficacy in vivo $(31,32)$. Instead, LIN5044 cleared plaques as powerfully as NB360, providing the first evidence that polythiophenes can be efficacious against A $\beta$. Unexpectedly, Q3D revealed that the activities of LIN5044 and NB360 were highly divergent in many ways. The regiospecific effectiveness of LIN5044 and NB360 were almost mutually exclusive, being most active against rostro-dorsal and ventrocaudal amyloid deposits, respectively. Moreover, LIN5044 reduced the increase in the size of plaques rather than their number and was more active in aged mice than in young mice. In contrast, BACE1 inhibition was most effective against plaque numbers in young mice yet affected their size to a lesser extent.

Pharmacokinetic analyses did not support the notion that differential bioavailability may account for the regiospecific activities of NB360 and LIN5044. While primary nucleation is primarily dependent on A $\beta$ concentration $(33,34)$ and is highly sensitive to BACE1 inhibition $(35,36)$, secondary nucleation (37) may become more important in aged mice. In prion diseases, polythiophenes affect secondary nucleation by stabilizing amyloid fibrils and decreasing their templating potential $(14,15)$. The remarkable efficacy of LIN5044 in aged mice may relate to the dependency of secondary nucleation onto the concentration of seeds, which increases with age. Accordingly, LIN5044 reduced primarily plaque sizes increasing the number of smaller plaques and had no strong effect on the overall number of plaques (Figure 4C), providing further 
evidence that LIN5044 reduces additive plaque growth. The stronger effect of LIN5044 in old mice suggests that it preferentially targets tightly packed plaques which become highly overrepresented with time.

Because of its inherent fluorescence, LIN5044 might influence the spectral properties of plaques. We therefore compared plaque spectra in a mouse injected i.p. with LIN5044 (0.4 mg) and one injected with PBS. No differences were detected, suggesting that the effect of LIN5044 on plaque maturity is not artefactual. The reduction in plaque burden increase showed steep ventrocaudal (NB360) and dorsorostral (LIN5044) gradients whose boundaries did not correspond to defined neuroanatomical areas or vascular territories. By aligning SAV to a spatial transcriptomic atlas (27) we identified a strong correlation between Bace1 expression and the regiospecific efficacy of NB360, but not of LIN5044, whereas Thy1 expression correlated with both treatments. This finding validates the unsupervised mining approach chosen here.

This analysis revealed that the plaque clearing by LIN5044 vs. NB360 was predicted by local expression of distinct genetic ensembles. Specifically, the regional efficacy of LIN5044 was strongly correlated with CX3CL1, a neuron-borne microglial chemoattractant (38). The regional variation of CX3CL1 expression may result in differential recruitment of microglia, thereby contributing to the clearance of LIN5044-intercalated amyloid. Indeed, the areas where LIN5044 had a stronger effect also harbored more microglia in APPPS1 ${ }^{-}$mice. The cognate microglial receptor CX3CR1 is highly expressed at late AD stages (39), which may partly explain the potency of LIN5044 in old mice.

NB360 effectiveness was predicted by the expression of oligodendroglial genes, whereas LIN5044 correlated with neuron-enriched genes. This suggests that BACE1, in addition to modulating myelination by cleaving neuregulin $(40,41)$, influences $A \beta$ processing by processing oligodendrocyte-specific substrates. Intriguingly, oligodendrocyte-specific gene modules show brain-region-dependent alterations in early stages of cerebral amyloidosis (39).

The regiospecificity of anti-A $\beta$ therapies may be functionally relevant. The ventrocaudal effects of NB360 may modulate hippocampal and limbic functions, whereas the rostro-cortical clearance by LIN5044 might act on cognitive functions (42). Since LIN5044 and NB360 affect mostly non-overlapping areas of the brain, combination regimens may synergistically protect larger brain volumes from amyloid deposition. Notably, 
bioRxiv preprint doi: https://doi.org/10.1101/2021.01.15.426090; this version posted July 14, 2021. The copyright holder for this preprint (which was not certified by peer review) is the author/funder, who has granted bioRxiv a license to display the preprint in perpetuity. It is made available under aCC-BY-ND 4.0 International license.

the computational methods developed for $A \beta$ amyloid quantitation can enhance the statistical power of in vivo assessment of anti-A $\beta$ drugs and can be adapted to a broad range of protein aggregation diseases. 


\section{Materials and Methods}

\section{Animal treatments and tissue preparation}

All animal experiments were carried out in strict accordance with the Rules and Regulations for the Protection of Animal Rights (Tierschutzgesetz and Tierschutzverordnung) of the Swiss Bundesamt für Lebensmittelsicherheit und Veterinärwesen and were preemptively approved by the Animal Welfare Committee of the Canton of Zürich (permit 040/2015). APPPS1 male and female mice were either treated with NB-360 (16) BACE1-inhibitor (Novartis) orally $(0.5 \mathrm{~g}$ inhibitor $/ \mathrm{kg}$ chow, $6 \mathrm{~g} \mathrm{chow} / \mathrm{day} / \mathrm{mouse}=3 \mathrm{mg}$ inhibitor/day/mouse), with the $\beta 1$ monoclonal IgG2a antibody recognizing the human specific EFRH tetrapeptide of amino acids $3-6$ of $A \beta(18,31)$ (Novartis) $(0.5 \mathrm{mg} /$ week, once/week in $200 \mu \mathrm{l}$ phosphate buffered saline (PBS) intraperitoneally), or with the amyloid intercalator LIN5044 (14) (0.4 mg/week, once/week in $100 \mu \mathrm{PBS})$. Control mice were treated with control chow, pooled recombinant non-specific IgG, and PBS, respectively. The ages of NB-360, $\beta 1$ antibody, and LIN5044 treated mice were $353 \pm 21,313 \pm$ 9, and $308 \pm 7$ days, respectively (groups of old mice), as well as $61 \pm 3$ days, $59 \pm 2$ and $65 \pm 2$ days, respectively (groups of young mice) (Table S1). After treatments were completed, mice were deeply anaesthetized with ketamine and xylazine, then transcardially perfused with ice-cold phosphate-buffered saline (PBS) followed by a hydrogel monomer mixture of $4 \%$ acrylamide, $0.05 \%$ bisacrylamide and $1 \%$ paraformaldehyde (43). Brains were harvested and further incubated passively in the hydrogel mixture for 24 hours. The hydrogel was degassed and purged with nitrogen, followed by polymerization at $37^{\circ} \mathrm{C}$ for 2.5 hours. Samples were either stored in PBS or clearing solution until Q3D clearing.

For generating the whole-brain vascular images (Figure 1D), Claudin5-GFP (Gensat.org. Tg(Cldn5-GFP)) mice were processed as described above.

\section{Tissue clearing}

Brains were cleared with focused electrophoretic tissue clearing (FEC) in a custom-built chamber in $8 \%$ clearing solution ( $8 \% \mathrm{w} / \mathrm{w}$ sodium dodecyl sulphate in $200 \mathrm{mM}$ boric acid, $\mathrm{pH} 8.5$ ). Standard settings were $130 \mathrm{~mA}$ current-clamped at a voltage limit of $60 \mathrm{~V}$, at $39.5^{\circ} \mathrm{C}$. Clearing time varied between $6-14$ hours for a whole mouse brain. The polarity of the electrodes was switched after approximately $50 \%$ of the total clearing 
time. Transparency was assessed by visual inspection. The clearing solution was circulated from a buffer reservoir of $250 \mathrm{ml}$. After clearing a brain, $60 \mathrm{ml}$ of clearing buffer was exchanged with fresh buffer before starting to clear the next sample. Q3D-clearing chambers were 3D-printed, and clearing was done in an incubator at $39.5^{\circ} \mathrm{C}$. For details on the chamber design, see supplementary material and model repository (Figure S1) (44).

\section{Relative electrical resistivity measurement between brain tissue and buffer}

For electrical resistivity measurements comparisons, mouse brains were first fixed in $4 \%$ paraformaldehyde, then measured in PBS. Platinum electrodes $(1.5 \times 0.2 \mathrm{~mm})$ were mounted at a distance of $2 \mathrm{~mm}$, and a constant voltage of $30 \mathrm{~V}$ was applied. Current measurements were used to calculate the resistance between the electrodes. Brain tissue resistance was measured by sticking the electrode-pair into the brain at 3 different locations (frontal cortex, occipital cortex and brainstem). At each location, current values were measured three times. The resistivity in the buffer was measured nine times. These measurements resulted in a $\sim 1200-0 h m$ resistance in the brain and $\sim 300-0 h m$ resistance in the buffer. As the electrode setup and the voltages were constant for every measurement, the relative resistivity was calculated as the ratio of the two resistivity measurements, resulting in a resistivity ratio of 1:4 (buffer:brain).

\section{Comparison between Q3D and CLARITY}

Hydrogel-embedded brains from 3-month-old mice were either passively cleared with $8 \%$ clearing solution for 24 hours at $39^{\circ} \mathrm{C}(n=3)$ or for $4-6$ hours with either Q3D or CLARITY (20) clamped at $130 \mathrm{~mA}$ at $60 \mathrm{~V}$ at 39 ${ }^{\circ} \mathrm{C}$ (four active clearing groups, each $\mathrm{n}=3$ ). After clearing, brains were washed with PBS, followed by refractive index-matching and mounting in quartz cuvettes. Samples were illuminated with a $\sim 4-5 \mu \mathrm{m}$ wide 647-nm laser beam, calibrated to $0.35-\mathrm{mW}$ power. Each brain was illuminated stereotypically from the dorsal end at 10 aligned points with $0.5 \mathrm{~mm}$ spacing along the rostro-caudal axis, with the same incumbent laser power (as measured through the imaging medium and cuvette). This was done in 3 parallel lines (one in the midline, and a line $2 \mathrm{~mm}$ left and right from it), resulting in 3×10 measurement points per brain (Figure S1F). The point pattern was defined by starting from the lambdoid fossa. The transmitted light was measured at each point with a digital optical power meter (Thorlabs, PM100D, Compact Power and Energy Meter Console, 
Digital 4" LCD; Thorlabs S130C photodiode sensor). The mean and standard error of the mean for all points for each sample was plotted (Figure S1F-G). We also plotted the mean transmitted light on every rostrocaudal level, resulting in 10 datapoints summarizing the 3 parallel lines (two hemispheres and the midline) (0.35 mW input power, 647nm wavelength, 3 brains/group, 30 measurement points/brain, Figure 1C and S1). These 10 points per sample were submitted to a one-way ANOVA $(\alpha=0.05)$, which was corrected with Tukey's test for multiple comparisons.

\section{Electrophoretic staining with Q3D}

Histochemistry by iontophoretic tissue staining was initially done by layering paraffin and agarose around the sample in order to limit current flow to the tissue. Later, Q3D staining chambers were 3D-printed (Figure S2A-B).0 $50 \mathrm{mM}$ tris and $50 \mathrm{mM}$ tricine at a $\mathrm{pH}$ of 8.5 was used as the electrophoresis buffer.obi: Tests in native polyacrylamide gel electrophoresis were followed by silver staining (Thermo Scientific Pierce Silver Stain Kit, \#24612) that showed, as expected, that electrophoretic mobility is highly dependent on the pH and buffer (Figure S2D-G). Amyloid plaques were stained with a combination of luminescent conjugated polythiophenes (LCP), heptamer-formyl thiophene acetic acid (hFTAA), and quadro-formyl thiophene acetic acid (qFTAA). The combination of these dyes was used for the discrimination of neuritic plaques (22) at different maturation states (23).

\section{Refractive index matching}

Brains that were cleared and stained with Q3D were refractive index (RI) -matched to 1.46 with a modified version of the refractive index matching solution (43) by including triethanolamine (tRIMS). tRIMS was made by mixing Histodenz (Sigma \#D2158) (100 mg), phosphate buffered saline (75 ml), sodium azide (10\% w/v, $500 \mu \mathrm{l})$, tween-20 (75 $\mu \mathrm{l})$ and triethanolamine $(42 \mathrm{ml})$. tRIMS maintained the RI while reducing the amount of Histodenz required and improving transparency. After prolonged air and light exposure, tRIMS tends to undergo browning; however, in air-tight tubes at $4{ }^{\circ} \mathrm{C}$ samples remain stable for at least two years.

\section{Antibody and polythiophene staining}

Slices from formalin fixed and paraffin embedded brain tissue from a 13-month-old APPPS1 mouse were stained for $A \beta$ plaques. Slices were stained with mouse anti-human $A \beta_{17-24}$ antibody (4G8, Biolegend SIG- 
39220) after antigen retrieval with $10 \%$ formic acid. Slices were blocked with M.O.M. Kit (BMK-2202) and the primary antibody was detected with Alexa-594 conjugated goat anti-mouse IgG (Invitrogen A-11005, 1:1000 dilution). Alternatively, slices were stained with $A \beta N 3 p E$ rabbit anti-human antibody (IBL 1A-018, 1:50 dilution) after $10 \%$ formic acid antigen retrieval, followed by blocking with $10 \%$ goat serum, detected with Alexa-594 conjugated goat anti-rabbit IgG (Invitrogen A-11037, 1:500 dilution). Both antibody stainings were followed by staining with qFTAA ( $0.75 \mu \mathrm{M}$ in PBS) and hFTAA ( $3 \mu \mathrm{M}$ in PBS) for 30 minutes, followed by diamidino-phenylindole (DAPI) staining. Slices were imaged with a Leica SP5 confocal microscope with a 10x air objective (numerical aperture 0.4). The qFTAA and hFTAA stainings were imaged by exciting both at 488 $\mathrm{nm}$ and collecting emission between $493-510 \mathrm{~nm}$ and $530-579 \mathrm{~nm}$, respectively. The dynamic range of images was adjusted consistently across stainings and images $(3.57 \mu \mathrm{m} /$ pixel) were median filtered with ImageJ (pixel radius 0.5).

To test the effect of the LIN5044 treatment on the qFTAA+hFTAA plaque maturity analysis, 12-month-old

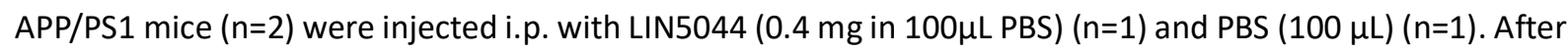
3 days mice were deeply anaesthetized with ketamine and xylazine and transcardially perfused first with ice cold PBS, followed by $4 \%$ paraformaldehyde. Brains were harvested and were further incubated in the paraformaldehyde solution for 24 hours. Brains were then incubated in $30 \%$ sucrose in PBS for two days at $4{ }^{\circ} \mathrm{C}$. Next, brains were snap-frozen and stored at $-80^{\circ} \mathrm{C}$ overnight. Brains were embedded in tissue freezing medium (Leica biosystems), and $20 \mu \mathrm{m}$ coronal slices were cut with a cryostat and mounted on Super-frost micro-slides. Tissue slices were fixed in $10 \%$ formalin overnight and rehydrated by dipping them in consecutive baths of $99 \%$ ethanol, $70 \%$ ethanol, $\mathrm{dH} 2 \mathrm{O}$, and PBS, 10 min in each. The tissue sections were allowed to dry under ambient conditions. For polythiophene staining $200 \mu \mathrm{L}$ of hFTAA and qFTAA solution (20 $\mu \mathrm{M})$ were added onto the tissue sections to cover them and slices were incubated for $30 \mathrm{~min}$ at room temperature. Sections were rinsed in a PBS bath for $10 \mathrm{~min}$, followed by nuclear staining with DAPI. Tissue sections were dried under ambient conditions, followed by mounting with fluorescence mounting medium (DAKO). Slides were imaged with a Leica SP5 Confocal microscope. Nuclei and plaques were imaged with a 10X/0.25 NA dry objective, using the following settings: 405/30 nm excitation/emission filters for DAPI (nuclei) and 498-520nm (compact amyloid) and 565-605nm (looser amyloid) for LCPs. Laser power was set 24 
on $10 \%$ for all the conditions and a line average of 96 was used for acquisition. Three 8 -bit images were recorded from each sample. Ten plaques per image were measured for their fluorescent intensity by quantifying the maximum intensity of a line drawn through each individual plaque with Fiji. The mean intensity of ten plaques per image was compared with a 2-tailed T-test between the two conditions (LIN5044 or PBS treated).

For microglia immunohistochemistry, fixed brains of LIN5044 treated transgene-negative littermates from APPPS1 nests $(n=3)$ were embedded in paraffin. 4- $\mu$ m-thick paraffin sections ( 3 sections per mouse) were deparaffinized through a decreasing alcohol series. Slices were stained with Iba-1 antibody (1:1000; Wako Chemicals GmbH, Germany) and detected using an IVIEW DAB Detection Kit (Ventana). Sections were imaged using a Zeiss Axiophot light microscope. For the quantification of the lba-1 staining, in every slice two regions of interest were selected in the cortex. The four regions of interest were selected representing 2-2 cortical areas with either high or no LIN5044 therapeutic effect (Figure 5A, 6C-E). Pixels in the regions of interest were classified and counted as microglia (Iba-1 positive) or background (Iba-1 negative) with a manually trained (trained on three images) pixel classifier in ILASTIK (https://www.ilastik.org/), and ImageJ. Hypothesis testing was done with a 2-tailed T-test.

\section{Drug distribution measurements}

NB360 was administered orally in three male C57BL/6 black mice at $5 \mathrm{mg} / \mathrm{kg}$ body-weight dose-level at 0.5 $\mathrm{mg} / \mathrm{ml}$ in water with $0.5 \%$ methylcellulose and $0.1 \%$ Tween-80. Based on preceding pharmacokinetic studies (16), brains were harvested one hour later, followed by homogenization in water and acetonitrile precipitation. NB360 levels were measured with tandem mass spectrometry with electrospray ionisation. LIN5044 was administered intraperitoneally into male C57BL/6 black mice at $16 \mathrm{mg} / \mathrm{kg}$ body-weight doselevel at $4 \mathrm{mg} / \mathrm{ml}$ in PBS. As preceding pharmacokinetic studies were not available, two- and six-hour incubation timepoints were chosen, each with three mice. Brains were homogenized in water and precipitated with methanol. LIN5044 levels were measured with high pressure liquid chromatography tandem fluorescence detection. Brain regions' drug levels were compared with one-way ANOVA $(\alpha=0.05)$ for each compound and timepoint separately (NB360, LIN5044 2 hour, LIN5044 6 hour); multiple comparisons were corrected for with Tukey's test. 


\section{Antibody brain-distribution measurements}

C57BL/6 mice were injected one-time with either $\beta 1$ antibody $(n=6)$, as a control with pooled recombinant non-specific IgG ( $n=2)$ (0.5 mg in $200 \mu$ intraperitoneally), or with no injection ( $n=1)$. $\beta 1$ injected mice were sacrificed after $6(n=3)$ or 24 hours $(n=3)$, while control mice were sacrificed 24 hours after injection. Amyloid $\beta$ Protein Fragment 1-42 (A9810, Sigma) was diluted at $1 \mu \mathrm{g} / \mathrm{mL}$ in PBS and passively absorbed on multiwell plates (SpectraPlate-384 HB, Perkin Elmer) overnight at $4{ }^{\circ} \mathrm{C}$. Plates were washed three times in $0.1 \%$ PBSTween 20 (PBS-T) and blocked with $80 \mu \mathrm{l}$ per well of 5\% skim milk (Migros) in $0.1 \%$ PBS-T, for $2 \mathrm{~h}$ at room temperature. $\beta 1$-antibody and pooled recombinant IgG were used as positive and negative controls, respectively. Blocking buffer was discarded, and both samples and controls were dissolved in $1 \%$ skim milk in $0.1 \%$ PBS-T for $1 \mathrm{~h}$ at $37^{\circ} \mathrm{C}$. 2-fold dilutions of $\beta 1$-antibody, starting at a dilution of $1000 \mathrm{ng} / \mathrm{ml}$ in $1 \%$ skim milk and in $0.1 \%$ PBS-T were used for a calibration curve. Goat polyclonal anti-mouse antibody $\left(1: 1^{\prime} 000,115-\right.$ 035-062, Jackson ImmunoResearch) was used to detect murine antibodies. Chromogenic reaction was induced by addition of TMB Stabilized Chromogen (SB02, Thermo Fisher Scientific) and stopped by addition of $0.5 \mathrm{M} \mathrm{H}_{2} \mathrm{SO}_{4}$. Absorbance was read at $\lambda=450 \mathrm{~nm}$. Unknown $\beta 1$-antibody concentrations were interpolated from the linear range of the calibration curve using linear regression (GraphPad Prism, GraphPad Software).

\section{Whole-brain imaging}

Whole brain images were recorded with a custom-made selective plane illumination microscope (mesoSPIM) (13). SPIM imaging was done after clearing and refractive index matching. The laser/filter combinations for mesoSPIM imaging were as follows: for qFTAA at $488 \mathrm{~nm}$ excitation, a $498-520 \mathrm{~nm}$ bandpass filter (BrightLine 509/22 HC, Semrock / AHF) was used as the emission filter; for hFTAA at $488 \mathrm{~nm}$ excitation, a 565 - $605 \mathrm{~nm}$ bandpass filter (585/40 BrightLine HC, Semrock / AHF) was used. Transparent whole-brains were imaged at a voxel size of $3.26 \times 3.26 \times 3 \mu \mathrm{m}^{3}(\mathrm{X} \times \mathrm{Y} \times \mathrm{Z})$. For scanning a whole brain, 16 tiles per channel were imaged ( 8 tiles per brain hemisphere). After the acquisition of one hemisphere, the sample was rotated and the other hemisphere was then acquired. The entire process resulted in typical acquisition times of 2-3 hours, followed by stitching (45). Data accumulated from one brain ranged around $600 \mathrm{~GB}$ in size. Further technical details of the mesoSPIM have been previously reported (13). 


\section{Computational and statistical analysis}

The following computations were performed using custom scripts written in Python and R (46) as well as existing third-party libraries (Table 2). The 2-channel (498-520 nm and 565-605 nm) substacks for each brain hemisphere were first stitched together with Terastitcher (45). The result was downsampled from the acquired resolution ( $3.26 \mu \mathrm{m}$ lateral, $3 \mu \mathrm{m}$ depth) to an isotropic $25 \mu \mathrm{m}$ resolution and then registered to the Allen Institute $25 \mu \mathrm{m}$ average anatomical template atlas (25). This was performed automatically using a combination of affine and b-spline transformation registrations with a mutual information similarity metric, using parameters influenced from a previous study performing mouse whole-brain fluorescence quantification (47). The resulting pairs of transformations were used in subsequent steps to transform coordinates in the raw data space to the template atlas space (Figure S3).

The 565-605 $\mathrm{nm}$ channel at its original resolution was used to determine the locations of aggregates of amyloid- $\beta$ stained with qFTAA and hFTAA. A random forest classifier was used to classify each voxel as either "belonging to a plaque" or "background". This classifier was generated using the open-source llastik framework (48), and trained on a random subset of data (random stacks, 3 stacks [187x176x1242 pixels] picked from every experimental group) that was separately annotated by two neuropathologists. Amyloid- $\beta$ aggregates were considered to be the individually connected components from this binarized volume. The three-dimensional center of mass and total volume was then calculated for each component. Connected components with a volume below a global threshold were considered noise and ignored. The centers of mass were used to look up the peak fluorescent intensity of each plaque in the 498-520 nm (qFTAA) channel. Plaque maturity was calculated for each plaque as its peak intensity in the 498-520 nm (qFTAA) channel divided by its peak intensity in the 565-605 nm (hFTAA) channel(22) (Figure S3).

After downsampling each aggregate center to $25-\mu \mathrm{m}$ resolution and applying the optimized registration transformation, the number of aggregates were counted at each voxel in this atlas space (Figure S4). Smoothed heatmaps were generated by placing a spherical ROI with 15 -voxel diameter $(=375 \mu \mathrm{m})$ at each voxel and summing the plaque counts within the ROI. This ROI diameter was set to match the mean spatial jacobian-matrix determinant of the previously-registered b-spline transformation across all samples. This 
method for smoothing and accounting for variable registration quality has also been described in a previous whole-brain study (47). Voxel-level statistics across treated and control brains involved running a two-sided t-test at each heatmap voxel across the two groups. Each voxel p-value was adjusted using the BenjaminiHochberg method (49). These adjusted $p$-value maps were then binarized with a threshold of 0.05 or 0.10 for subsequent analysis or visualization.

The transformed locations of each plaque were also further grouped into 134 different anatomically segmented regions in the Allen Reference Atlas (25) for further statistical analysis between longitudinal groups. Similar heatmap generation, voxel statistics, and regional statistics were performed for two other metrics: the mean plaque volume and the mean plaque maturity.

The voxel-level statistical map for each treatment group was also compared against a spatially-resolved transcriptomics database consisting of 23371 genes across 34103 locations throughout the brain (27). Since the data from this study and the spatial transcriptomic database were both in the ARA coordinate space, it was possible to spatially compare each gene's expression map with each treatment group's binarized p-value map using a similarity metric. In this case, mutual information was used as the similarity metric since it will detect any sort of linear or non-linear relationship between these two discrete datasets. In order to rank the relevancy of genes in contributing to the spatial map of plaque removal efficacy for a particular compound, we generated a ranked list of genes for each treatment group, sorted by their corresponding mutual information score. We additionally used the Allen Cell Types Database to assign each gene to its most likely cell type (astrocyte, microglia, neuron, oligodendroglia, mixture) (29).

Key Resources are summarized in supplemental table 2 (Table S5). See also References (50-53) 


\section{Supplementary Materials}

Figure S1. Focused electrophoretic tissue clearing (FEC) chambers allow for improved tissue clearing efficiency.

Figure S2. Digitally designed and 3D printed setups allow for convenient electrophoretic staining of tissues.

Figure S3. Digital atlas registration and machine learning-based plaque segmentation results in precise plaque-load heatmaps.

Figure S4. Custom-made data analysis pipeline handles raw image data automatically and results in intuitive heatmaps of treatment effect.

Figure S5. The $\beta 1$ antibody treatment shows a limited effect across all analyzed metrics.

Figure S6. Plaque count reduction by $\beta 1$ antibody is minimal in 5 -month-old mice and absent in old mice.

Figure S7. The plaque-size change induced by $\beta 1$ antibody treatment in 5-month-old mice is very limited and absent in 14-month-old mice.

Figure $\mathrm{S8}$. The plaque-maturity change induced by $\beta 1$ antibody treatment in 5 - and 14 -month-old mice is very limited.

Figure S9. BACE1-inhibition induced conspicuous plaque count reduction in 5-month-old mice, but not in 14month-old mice.

Figure S10. BACE1-inhibition induces considerable plaque size reduction in 5-month-old mice, but not in 14month-old mice.

Figure S11. Plaque maturity change by BACE1-inhibition in 5-month-old mice shows region-dependent maturity increase and decrease while there is no effect at 14-months.

Figure S12. Trend in plaque-count reduction in few anatomical regions after LIN5044 treatment in 5- and 14month-old mice.

Figure S13. Mean plaque-sizes are significantly reduced in some anatomical regions after LIN5044 treatment in 5- and 14-month-old mice.

Figure S14. Anti-amyloid $\beta$ treatments reduce plaque counts and sizes. 
Figure S15. The pattern of plaque density reduction upon different treatments is unaltered by permuting the control groups.

Figure S16. The pattern of mean plaque size reduction upon different treatments is unaltered by permuting the control groups.

Figure S17. There is no significant difference in plaque burden between the control cohorts of the LIN5044 and BACE1 - inhibitor groups, or control female and male mice.

Figure S18. Regional variations of bioavailability do not explain the spatial patterns of drug effectiveness.

Table S1. Number of mice in treatment cohorts.

Table S2. Neuroanatomical areas used for Allen Reference Atlas registration.

Table S3. Plaque loads in control mice of each treatment cohort show low variability.

Table S4. Significantly affected voxels (SAV) after NB360, $\beta 1$-antibody or LIN5044 treatment.

Table S5. Third-party libraries used for the computational pipeline.

Movie S1. A $\beta$-therapies target distinct areas of the brain. 


\section{References}

1. A. Lau, R. W. L. So, H. H. C. Lau, J. C. Sang, A. Ruiz-Riquelme, S. C. Fleck, E. Stuart, S. Menon, N. P. Visanji, G. Meisl, R. Faidi, M. M. Marano, C. Schmitt-Ulms, Z. Wang, P. E. Fraser, A. Tandon, B. T. Hyman, H. Wille, M. Ingelsson, D. Klenerman, J. C. Watts, alpha-Synuclein strains target distinct brain regions and cell types. Nat Neurosci 23, 21-31 (2020).

2. M. Shahnawaz, A. Mukherjee, S. Pritzkow, N. Mendez, P. Rabadia, X. Liu, B. Hu, A. Schmeichel, W. Singer, G. Wu, A. L. Tsai, H. Shirani, K. P. R. Nilsson, P. A. Low, C. Soto, Discriminating alpha-synuclein strains in Parkinson's disease and multiple system atrophy. Nature 578, 273-277 (2020).

3. K. M. Fiest, J. I. Roberts, C. J. Maxwell, D. B. Hogan, E. E. Smith, A. Frolkis, A. Cohen, A. Kirk, D. Pearson, T. Pringsheim, A. Venegas-Torres, N. Jette, The Prevalence and Incidence of Dementia Due to Alzheimer's Disease: a Systematic Review and Meta-Analysis. The Canadian journal of neurological sciences. Le journal canadien des sciences neurologiques 43 Suppl 1, S51-82 (2016).

4. J. Hardy, D. J. Selkoe, The amyloid hypothesis of Alzheimer's disease: progress and problems on the road to therapeutics. Science 297, 353-356 (2002).

5. D. R. Thal, U. Rub, M. Orantes, H. Braak, Phases of A beta-deposition in the human brain and its relevance for the development of AD. Neurology 58, 1791-1800 (2002).

6. H. Braak, E. Braak, J. Bohl, Staging of Alzheimer-related cortical destruction. Eur Neurol 33, 403-408 (1993).

7. B. De Strooper, R. Vassar, T. Golde, The secretases: enzymes with therapeutic potential in Alzheimer disease. Nat Rev Neurol 6, 99-107 (2010).

8. L. Jiang, C. Liu, D. Leibly, M. Landau, M. Zhao, M. P. Hughes, D. S. Eisenberg, Structure-based discovery of fiber-binding compounds that reduce the cytotoxicity of amyloid beta. Elife 2, e00857 (2013).

9. J. Sevigny, P. Chiao, T. Bussiere, P. H. Weinreb, L. Williams, M. Maier, R. Dunstan, S. Salloway, T. Chen, Y. Ling, J. O'Gorman, F. Qian, M. Arastu, M. Li, S. Chollate, M. S. Brennan, O. Quintero-Monzon, R. H. Scannevin, H. M. Arnold, T. Engber, K. Rhodes, J. Ferrero, Y. Hang, A. Mikulskis, J. Grimm, C. Hock, R. M. Nitsch, A. Sandrock, The antibody aducanumab reduces Abeta plaques in Alzheimer's disease. Nature 537, 50-56 (2016).

10. R. Howard, K. Y. Liu, Questions EMERGE as Biogen claims aducanumab turnaround. Nat Rev Neurol 16, 63-64 (2020).

11. G. P. Morris, I. A. Clark, B. Vissel, Questions concerning the role of amyloid-beta in the definition, aetiology and diagnosis of Alzheimer's disease. Acta Neuropathol 136, 663-689 (2018).

12. R. A. Sperling, J. Karlawish, K. A. Johnson, Preclinical Alzheimer disease-the challenges ahead. Nat Rev Neurol 9, 54-58 (2013).

13. F. F. Voigt, D. Kirschenbaum, E. Platonova, S. Pages, R. A. A. Campbell, R. Kastli, M. Schaettin, L. Egolf, A. van der Bourg, P. Bethge, K. Haenraets, N. Frezel, T. Topilko, P. Perin, D. Hillier, S. Hildebrand, A. Schueth, A. Roebroeck, B. Roska, E. T. Stoeckli, R. Pizzala, N. Renier, H. U. Zeilhofer, T. Karayannis, U. Ziegler, L. Batti, A. Holtmaat, C. Luscher, A. Aguzzi, F. Helmchen, The mesoSPIM initiative: opensource light-sheet microscopes for imaging cleared tissue. Nat Methods, (2019).

14. U. S. Herrmann, A. K. Schutz, H. Shirani, D. Huang, D. Saban, M. Nuvolone, B. Li, B. Ballmer, A. K. Aslund, J. J. Mason, E. Rushing, H. Budka, S. Nystrom, P. Hammarstrom, A. Bockmann, A. Caflisch, B. H. Meier, K. P. Nilsson, S. Hornemann, A. Aguzzi, Structure-based drug design identifies polythiophenes as antiprion compounds. Sci Transl Med 7, 299ra123 (2015).

15. I. Margalith, C. Suter, B. Ballmer, P. Schwarz, C. Tiberi, T. Sonati, J. Falsig, S. Nystrom, P. Hammarstrom, A. Aslund, K. P. Nilsson, A. Yam, E. Whitters, S. Hornemann, A. Aguzzi, Polythiophenes inhibit prion propagation by stabilizing prion protein (PrP) aggregates. J Biol Chem 287, 18872-18887 (2012).

16. U. Neumann, H. Rueeger, R. Machauer, S. J. Veenstra, R. M. Lueoend, M. Tintelnot-Blomley, G. Laue, K. Beltz, B. Vogg, P. Schmid, W. Frieauff, D. R. Shimshek, M. Staufenbiel, L. H. Jacobson, A novel BACE inhibitor NB-360 shows a superior pharmacological profile and robust reduction of amyloid-beta and neuroinflammation in APP transgenic mice. Molecular neurodegeneration 10, 44 (2015). 
17. U. Neumann, R. Machauer, D. R. Shimshek, The beta-secretase (BACE) inhibitor NB-360 in preclinical models: From amyloid-beta reduction to downstream disease-relevant effects. Br J Pharmacol, (2019).

18. P. A. Paganetti, M. Lis, H. W. Klafki, M. Staufenbiel, Amyloid precursor protein truncated at any of the gamma-secretase sites is not cleaved to beta-amyloid. J Neurosci Res 46, 283-293 (1996).

19. R. Radde, T. Bolmont, S. A. Kaeser, J. Coomaraswamy, D. Lindau, L. Stoltze, M. E. Calhoun, F. Jaggi, H. Wolburg, S. Gengler, C. Haass, B. Ghetti, C. Czech, C. Holscher, P. M. Mathews, M. Jucker, Abeta42driven cerebral amyloidosis in transgenic mice reveals early and robust pathology. EMBO Rep 7, 940946 (2006).

20. K. Chung, J. Wallace, S. Y. Kim, S. Kalyanasundaram, A. S. Andalman, T. J. Davidson, J. J. Mirzabekov, K. A. Zalocusky, J. Mattis, A. K. Denisin, S. Pak, H. Bernstein, C. Ramakrishnan, L. Grosenick, V. Gradinaru, K. Deisseroth, Structural and molecular interrogation of intact biological systems. Nature 497, 332-337 (2013).

21. R. Tomer, L. Ye, B. Hsueh, K. Deisseroth, Advanced CLARITY for rapid and high-resolution imaging of intact tissues. Nat Protoc 9, 1682-1697 (2014).

22. S. Nystrom, K. M. Psonka-Antonczyk, P. G. Ellingsen, L. B. Johansson, N. Reitan, S. Handrick, S. Prokop, F. L. Heppner, B. M. Wegenast-Braun, M. Jucker, M. Lindgren, B. T. Stokke, P. Hammarstrom, K. P. Nilsson, Evidence for age-dependent in vivo conformational rearrangement within Abeta amyloid deposits. ACS chemical biology 8, 1128-1133 (2013).

23. J. Rasmussen, J. Mahler, N. Beschorner, S. A. Kaeser, L. M. Hasler, F. Baumann, S. Nystrom, E. Portelius, K. Blennow, T. Lashley, N. C. Fox, D. Sepulveda-Falla, M. Glatzel, A. L. Oblak, B. Ghetti, K. P. R. Nilsson, P. Hammarstrom, M. Staufenbiel, L. C. Walker, M. Jucker, Amyloid polymorphisms constitute distinct clouds of conformational variants in different etiological subtypes of Alzheimer's disease. Proc Natl Acad Sci U S A 114, 13018-13023 (2017).

24. A. Rijal Upadhaya, I. Kosterin, S. Kumar, C. A. von Arnim, H. Yamaguchi, M. Fandrich, J. Walter, D. R. Thal, Biochemical stages of amyloid-beta peptide aggregation and accumulation in the human brain and their association with symptomatic and pathologically preclinical Alzheimer's disease. Brain 137, 887-903 (2014).

25. Q. Wang, S. L. Ding, Y. Li, J. Royall, D. Feng, P. Lesnar, N. Graddis, M. Naeemi, B. Facer, A. Ho, T. Dolbeare, B. Blanchard, N. Dee, W. Wakeman, K. E. Hirokawa, A. Szafer, S. M. Sunkin, S. W. Oh, A. Bernard, J. W. Phillips, M. Hawrylycz, C. Koch, H. Zeng, J. A. Harris, L. Ng, The Allen Mouse Brain Common Coordinate Framework: A 3D Reference Atlas. Cell 181, 936-953 e920 (2020).

26. P. Vieira, K. Rajewsky, The half-lives of serum immunoglobulins in adult mice. Eur J Immunol 18, 313316 (1988).

27. C. Ortiz, J. F. Navarro, A. Jurek, A. Martin, J. Lundeberg, K. Meletis, Molecular atlas of the adult mouse brain. Sci Adv 6, eabb3446 (2020).

28. G. Tarozzo, S. Bortolazzi, C. Crochemore, S. C. Chen, A. S. Lira, J. S. Abrams, M. Beltramo, Fractalkine protein localization and gene expression in mouse brain. J Neurosci Res 73, 81-88 (2003).

29. A. Institute. (Allen Institute for Brain Science, Allen Institute, 2015), vol. 2020.

30. D. S. Richardson, J. W. Lichtman, Clarifying Tissue Clearing. Cell 162, 246-257 (2015).

31. M. Pfeifer, S. Boncristiano, L. Bondolfi, A. Stalder, T. Deller, M. Staufenbiel, P. M. Mathews, M. Jucker, Cerebral hemorrhage after passive anti-Abeta immunotherapy. Science 298, 1379 (2002).

32. K. Balakrishnan, A. Rijal Upadhaya, J. Steinmetz, J. Reichwald, D. Abramowski, M. Fandrich, S. Kumar, H. Yamaguchi, J. Walter, M. Staufenbiel, D. R. Thal, Impact of amyloid beta aggregate maturation on antibody treatment in APP23 mice. Acta Neuropathol Commun 3, 41 (2015).

33. S. Burgold, S. Filser, M. M. Dorostkar, B. Schmidt, J. Herms, In vivo imaging reveals sigmoidal growth kinetic of beta-amyloid plaques. Acta Neuropathol Commun 2, 30 (2014).

34. E. Hellstrand, B. Boland, D. M. Walsh, S. Linse, Amyloid beta-protein aggregation produces highly reproducible kinetic data and occurs by a two-phase process. ACS Chem Neurosci 1, 13-18 (2010).

35. F. Peters, H. Salihoglu, E. Rodrigues, E. Herzog, T. Blume, S. Filser, M. Dorostkar, D. R. Shimshek, N. Brose, U. Neumann, J. Herms, BACE1 inhibition more effectively suppresses initiation than progression of beta-amyloid pathology. Acta Neuropathol 135, 695-710 (2018). 
36. M. Brendel, A. Jaworska, F. Overhoff, T. Blume, F. Probst, F. J. Gildehaus, P. Bartenstein, C. Haass, B. Bohrmann, J. Herms, M. Willem, A. Rominger, Efficacy of chronic BACE1 inhibition in PS2APP mice depends on the regional $A$ beta deposition rate and plaque burden at treatment initiation. Theranostics 8, 4957-4968 (2018).

37. S. I. Cohen, S. Linse, L. M. Luheshi, E. Hellstrand, D. A. White, L. Rajah, D. E. Otzen, M. Vendruscolo, C. M. Dobson, T. P. Knowles, Proliferation of amyloid-beta42 aggregates occurs through a secondary nucleation mechanism. Proc Natl Acad Sci U S A 110, 9758-9763 (2013).

38. Z. Szepesi, O. Manouchehrian, S. Bachiller, T. Deierborg, Bidirectional Microglia-Neuron Communication in Health and Disease. Front Cell Neurosci 12, 323 (2018).

39. W. T. Chen, A. Lu, K. Craessaerts, B. Pavie, C. Sala Frigerio, N. Corthout, X. Qian, J. Lalakova, M. Kuhnemund, I. Voytyuk, L. Wolfs, R. Mancuso, E. Salta, S. Balusu, A. Snellinx, S. Munck, A. Jurek, J. Fernandez Navarro, T. C. Saido, I. Huitinga, J. Lundeberg, M. Fiers, B. De Strooper, Spatial Transcriptomics and In Situ Sequencing to Study Alzheimer's Disease. Cell, (2020).

40. X. Hu, C. W. Hicks, W. He, P. Wong, W. B. Macklin, B. D. Trapp, R. Yan, Bace1 modulates myelination in the central and peripheral nervous system. Nat Neurosci 9, 1520-1525 (2006).

41. M. Willem, A. N. Garratt, B. Novak, M. Citron, S. Kaufmann, A. Rittger, B. DeStrooper, P. Saftig, C. Birchmeier, $\mathrm{C}$. Haass, Control of peripheral nerve myelination by the beta-secretase BACE1. Science 314, 664-666 (2006).

42. J. Duncan, A. M. Owen, Common regions of the human frontal lobe recruited by diverse cognitive demands. Trends in neurosciences 23, 475-483 (2000).

43. B. Yang, J. B. Treweek, R. P. Kulkarni, B. E. Deverman, C. K. Chen, E. Lubeck, S. Shah, L. Cai, V. Gradinaru, Single-Cell Phenotyping within Transparent Intact Tissue through Whole-Body Clearing. Cell 158, 945-958 (2014).

44. D. Kirschenbaum. (GRABCAD, 2020).

45. A. Bria, G. Iannello, TeraStitcher - a tool for fast automatic 3D-stitching of teravoxel-sized microscopy images. BMC Bioinformatics 13, 316 (2012).

46. E. Dadgar-Kiani. (Github, 2020).

47. N. Renier, E. L. Adams, C. Kirst, Z. Wu, R. Azevedo, J. Kohl, A. E. Autry, L. Kadiri, K. Umadevi Venkataraju, Y. Zhou, V. X. Wang, C. Y. Tang, O. Olsen, C. Dulac, P. Osten, M. Tessier-Lavigne, Mapping of Brain Activity by Automated Volume Analysis of Immediate Early Genes. Cell 165, 1789-1802 (2016).

48. S. Berg, D. Kutra, T. Kroeger, C. N. Straehle, B. X. Kausler, C. Haubold, M. Schiegg, J. Ales, T. Beier, M. Rudy, K. Eren, J. I. Cervantes, B. Xu, F. Beuttenmueller, A. Wolny, C. Zhang, U. Koethe, F. A. Hamprecht, A. Kreshuk, ilastik: interactive machine learning for (bio)image analysis. Nat Methods 16, 1226-1232 (2019).

49. Y. Benjamini, D. Drai, G. Elmer, N. Kafkafi, I. Golani, Controlling the false discovery rate in behavior genetics research. Behav Brain Res 125, 279-284 (2001).

50. G. Bradski, The OpenCV library. Dr Dobbs J 25, 120-+ (2000).

51. D. Furth, T. Vaissiere, O. Tzortzi, Y. Xuan, A. Martin, I. Lazaridis, G. Spigolon, G. Fisone, R. Tomer, K. Deisseroth, M. Carlen, C. A. Miller, G. Rumbaugh, K. Meletis, An interactive framework for wholebrain maps at cellular resolution. Nat Neurosci 21, 139-149 (2018).

52. S. Klein, M. Staring, K. Murphy, M. A. Viergever, J. P. W. Pluim, elastix: A Toolbox for Intensity-Based Medical Image Registration. IEEE transactions on medical imaging 29, 196-205 (2010).

53. K. J. Millman, M. Aivazis, Python for Scientists and Engineers. Comput Sci Eng 13, 9-12 (2011). 
Acknowledgements: We thank Dr. Giulia Miracca, Dr. Todd E Golde and Dr. Soyon Hong for critical reading of the manuscript, Dr. Ulf Neumann for providing NB360 and $\beta 1$, and Dr. Michael B. Smith for help with designing 3D-printed parts. Scientific sketches were used from SciDraw.io doi.org/10.5281/zenodo.3925971, doi.org/10.5281/zenodo.3925911, doi.org/10.5281/zenodo.3926119. Funding: AA is the recipient of an Advanced Grant of the European Research Council and grants from the Swiss National Research Foundation, the Gelu Foundation, the Nomis Foundation, the Swiss Personalized Health Network (SPHN, 2017DRI17), the USZ Foundation and a donation from the estate of Dr. Hans Salvisberg. KPRN is the recipient of a Consolidator Grant from the Swedish Research Council (Grant 2016-00748). FH is a recipient of an Advanced Grant of the European Research Council (BRAINCOMPATH, project no. 670757). Authors contributions: D.K., J.H.L. and A.A. designed the study. D.K. conducted the experiments, acquired and analyzed the data. D.K. and A.A. prepared the figures and wrote the paper. F.F.V. designed and built the imaging platform. E.D.K. developed the computational analysis pipeline, analyzed data, and created figures. F.C. conducted animal experiments and imaging. O.B. worked on tissue clearing. P.N. and H.S. developed polythiophenes. K.J.F. measured antibody concentrations with ELISA. P.P. developed anti-amyloid $\beta$ antibodies. F.H. helped develop the imaging platform. J.H.L. and A.A. supervised personnel and wrote the paper. Competing Interests: J.H.L. is a founder, consultant, and shareholder of LVIS. The University of Zurich has filed a patent protecting certain aspects of the rapid-clarification technology described here. 


\section{Supplementary Material}

\section{Supplementary figures}

A

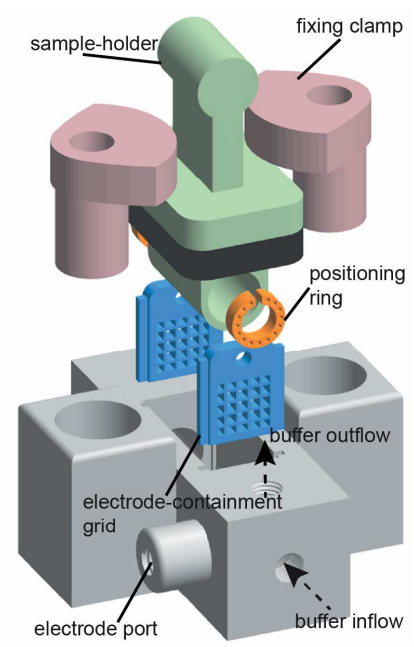

B

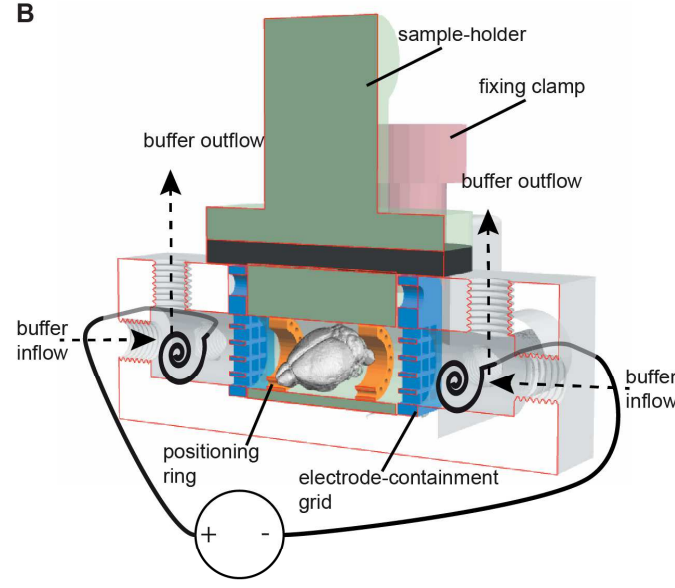

D
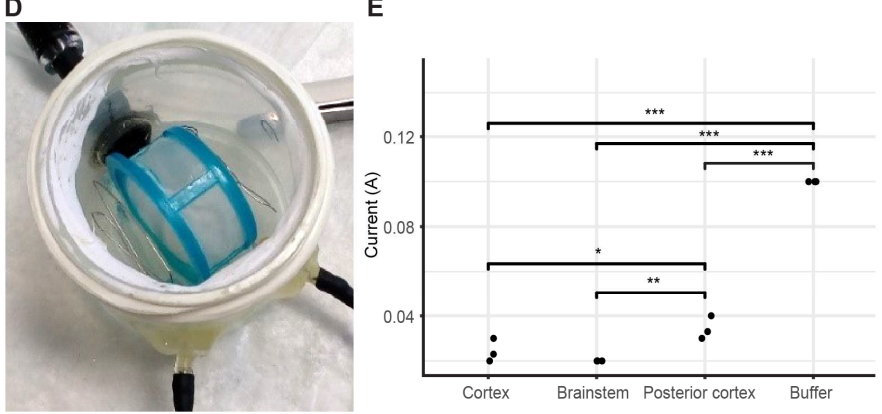

C
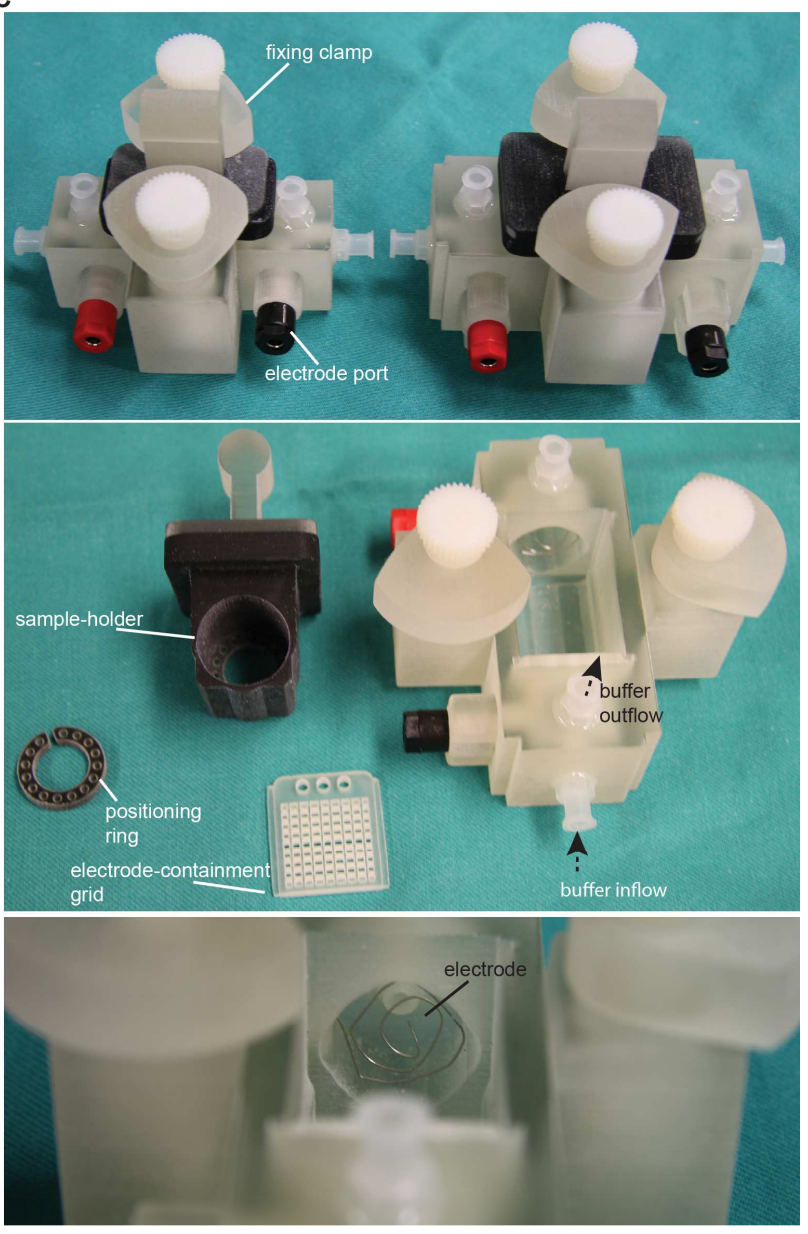

$\mathbf{F}$

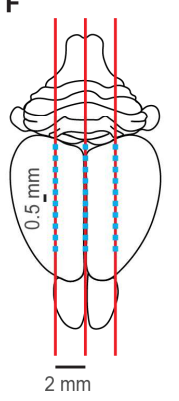

G

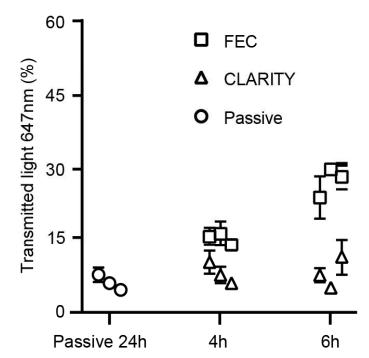

\section{Supplementary figure 1}

Supplementary figure 1. Focused electrophoretic tissue clearing (FEC) chambers allow for improved tissue

clearing efficiency. (A-C) Computer designed and 3D-printed Q3D-clearing chambers. (A) Rendering and (B) cross-section of a chamber. The clearing solution is circulated using two independent, electrically isolated 
circuits around each electrode. The tissue is contained in a sample-holding plunger (green), and is separated from the electrodes by small nets (blue). The plunger is sealed by a rubber ring (black). Samples are positioned within the tube with rings (orange). (C) 3D printed FEC clearing chambers in different sizes. (D) Reproduction of a CLARITY chamber for comparison. (E) Electric current measurements in different parts of 4\% paraformaldehyde fixed brain in PBS and in PBS buffer $\left({ }^{*} p<0.05,{ }^{* *} p<0.01,{ }^{* * *} p<0.001\right)$. (F-G) CLARITY and FEC were compared by measuring the light transmitted through the brain in 30 points (f, blue dots). Measurement points were defined along 3 parallel lines $2 \mathrm{~mm}$ apart, one in the midline (red lines). Then, for every measurement the laser beam was moved in $0.5 \mathrm{~mm}$ steps rostrally starting from the lambdoid fossa. (G) Higher transparency in FEC-cleared samples after 4 and 6 hours. Each datapoint represents the mean of all 30 measurements in one mouse brain ( $n=3$ per group). 
bioRxiv preprint doi: https://doi.org/10.1101/2021.01.15.426090; this version posted July 14, 2021. The copyright holder for this preprint (which was not certified by peer review) is the author/funder, who has granted bioRxiv a license to display the preprint in perpetuity. It is made available under aCC-BY-ND 4.0 International license.

A

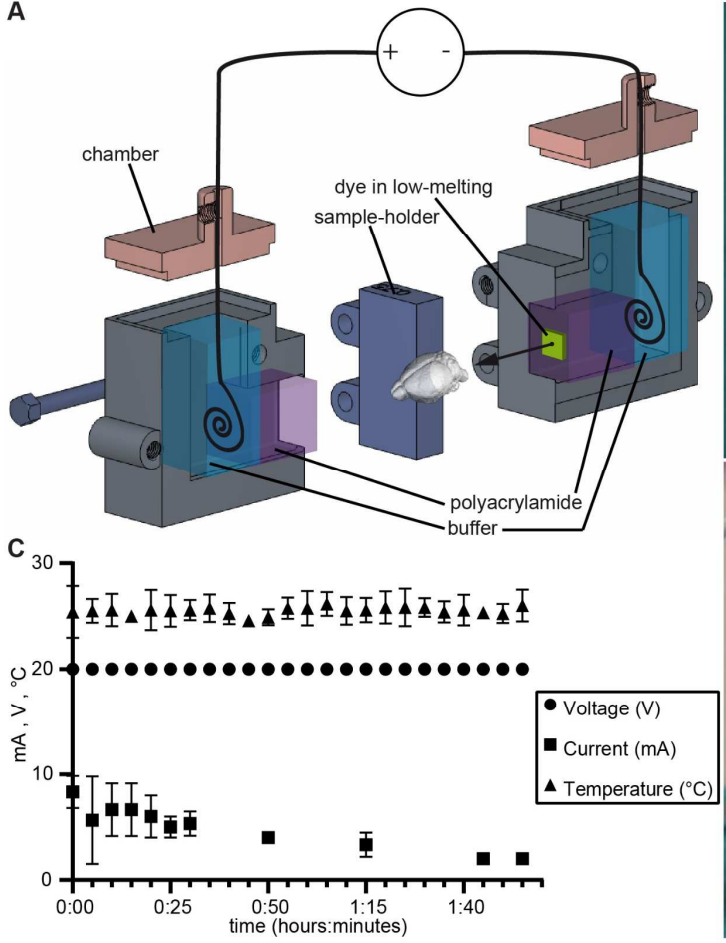

D $\quad$ BSA-647BSA-647 BSA-647 BSA-647 $\quad \beta 1-594 \quad \beta 1-677 \quad \beta 1-678$ aGFP-594 $\quad \beta 1$ $+6250 \quad 7 \mathrm{~h} \quad 5 \mathrm{~h} \quad 3 \mathrm{~h}$

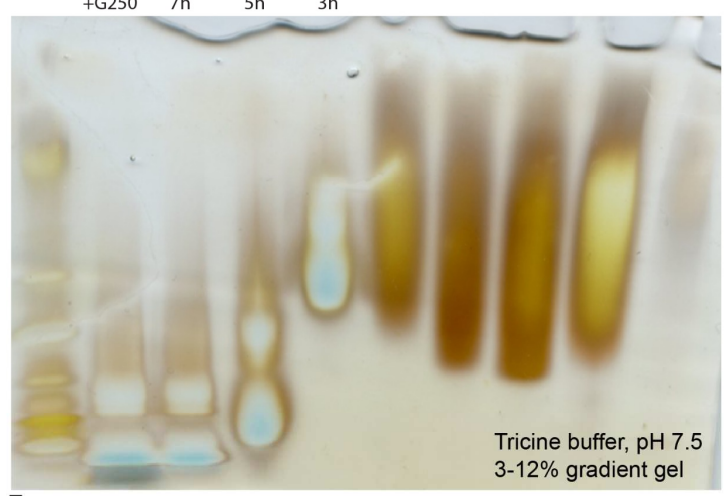

F $\quad$ BSA-647 BSA-647 BSA-647 BSA-647 $\beta 1-594 \quad \beta 1-677 \quad \beta 1-678$ Fab-lgG- $\beta 1$ $+\mathrm{G} 250 \quad 7 \mathrm{~h} \quad 5 \mathrm{~h} \quad 3 \mathrm{~h}$

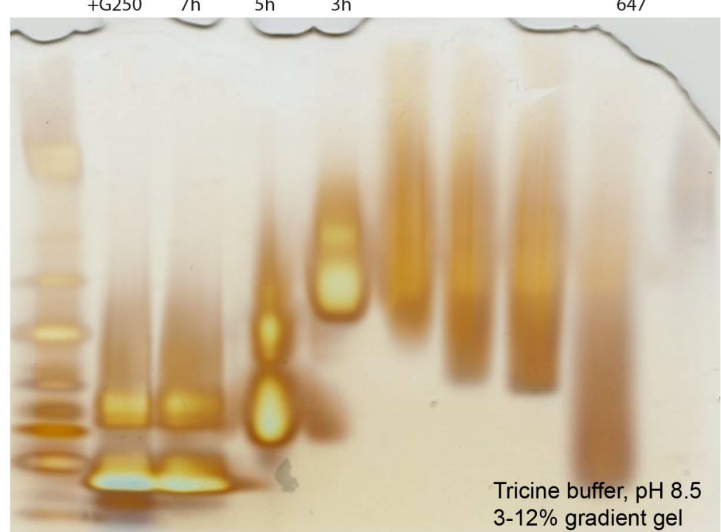

Supplementary figure 2

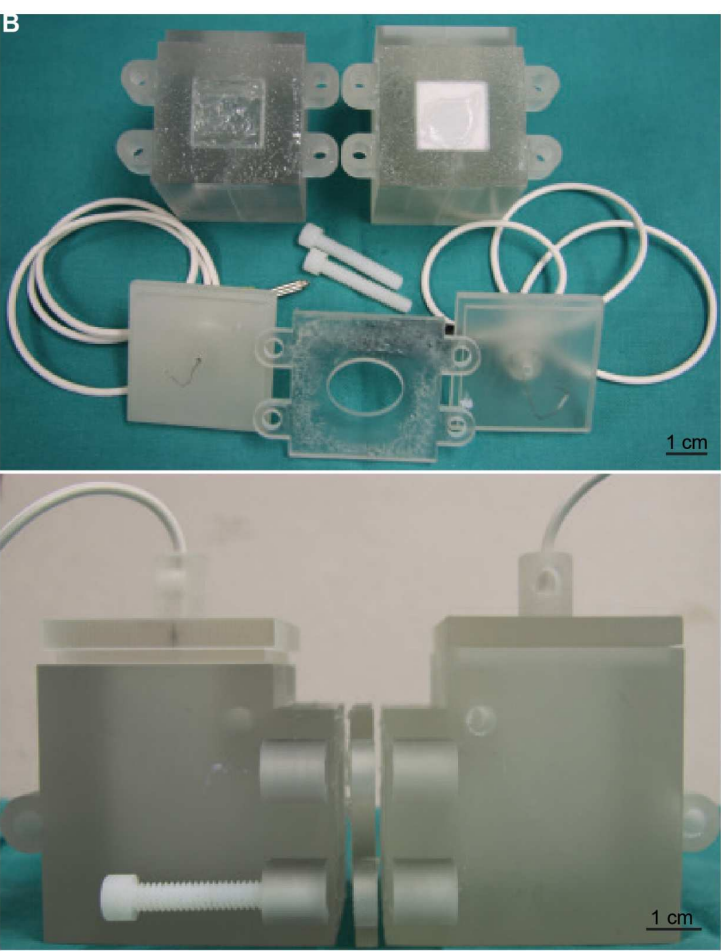

E $\quad$ BSA-647BSA-647 BSA-647 BSA-647 $\quad \beta 1-594 \quad \beta 1-677 \quad \beta 1-678$ aGFP-594 $\quad \beta 1$ $+\mathrm{G} 250 \quad 7 \mathrm{~h} \quad 5 \mathrm{~h} \quad 3 \mathrm{~h}$

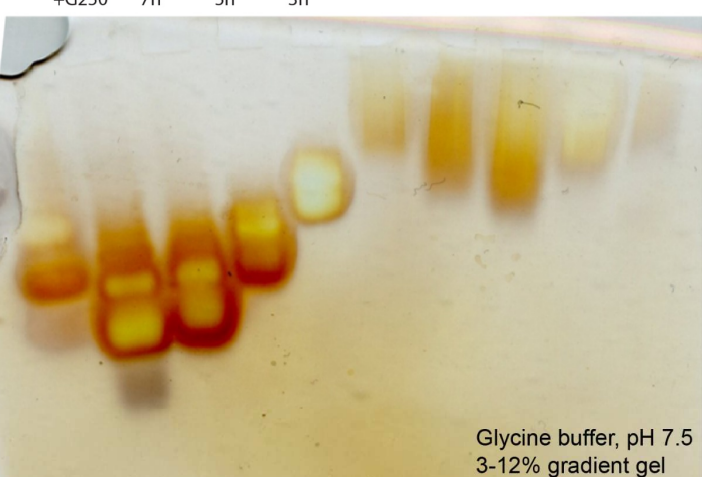

$3-12 \%$ gradient gel

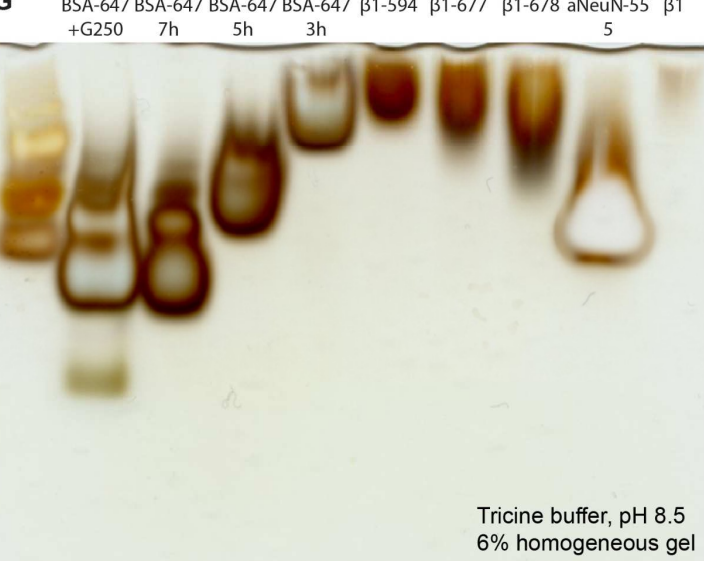




\section{Supplementary figure 2. Digitally designed and 3D printed setups for convenient electrophoretic staining}

of tissues. (A-B) Rendering and 3D prints of electrophoretic tissue staining Q3D chambers. Electrophoresis buffer (light blue) chambers (gray) are separated by two blocks containing polyacrylamide plugs (purple). The sample is placed in a spacer (dark blue) between the plugs. One of the plugs contains the dye solution immobilized in low-melting agarose (green). Each chamber contains a platinum electrode (black). (C) Electrophoretic staining was performed at constant voltage and tissue temperature. The electrical current decreased after some minutes. (D-G) Non-denaturing polyacrylamide gel electrophoresis of various proteins at a range of $\mathrm{pH}$ and buffer compositions. (D-F) Tricine buffer provided better electrophoretic mobility than (E) glycine buffer, as did higher pH (D: $\mathrm{pH} 7.5, \mathrm{~F}: \mathrm{pH}$ 8.5). (D-G) Increasing the electric charge of the $\beta 1$ antibody by covalently coupling three valent anionic fluorophores ( $\beta 1-594, \beta 1-677, \beta 1-768)$ increased electrophoretic mobility. BSA-647 was loaded in 2-hour intervals. In a $6 \%$ polyacrylamide native gel (G, while D - F are 3-12 \% gradient gels) this resulted in running distances proportional to the run-time. (BSA-bovine serum albumin, $\beta 1$ - $\beta 1$ antibody, aNeuN-555-Alexa555 conjugated anti-NeuN antibody, aGFP-594-Alexa594 conjugated anti-GFP antibody). 
bioRxiv preprint doi: https://doi.org/10.1101/2021.01.15.426090; this version posted July 14, 2021. The copyright holder for this preprint (which was not certified by peer review) is the author/funder, who has granted bioRxiv a license to display the preprint in perpetuity. It is made available under aCC-BY-ND 4.0 International license.

A

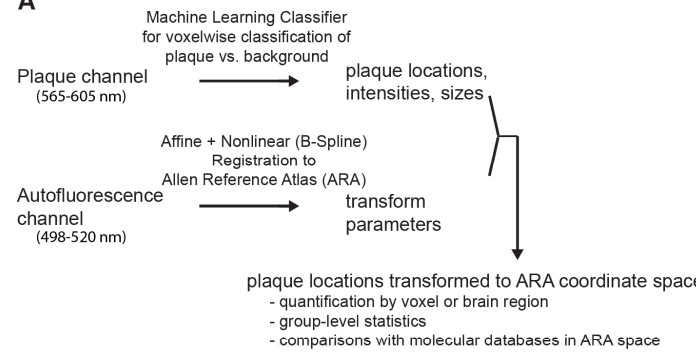

B

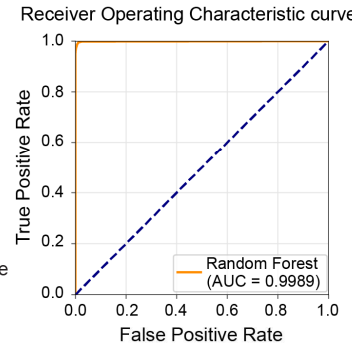

2-class Precision Recall curve

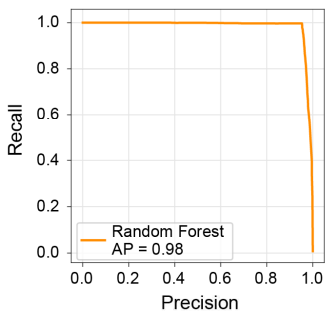

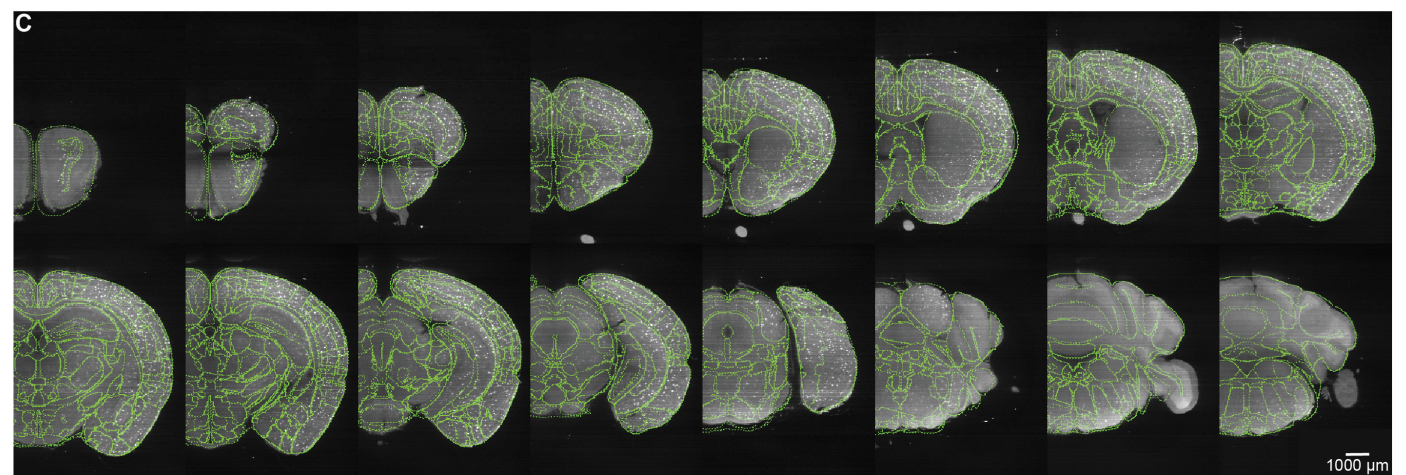
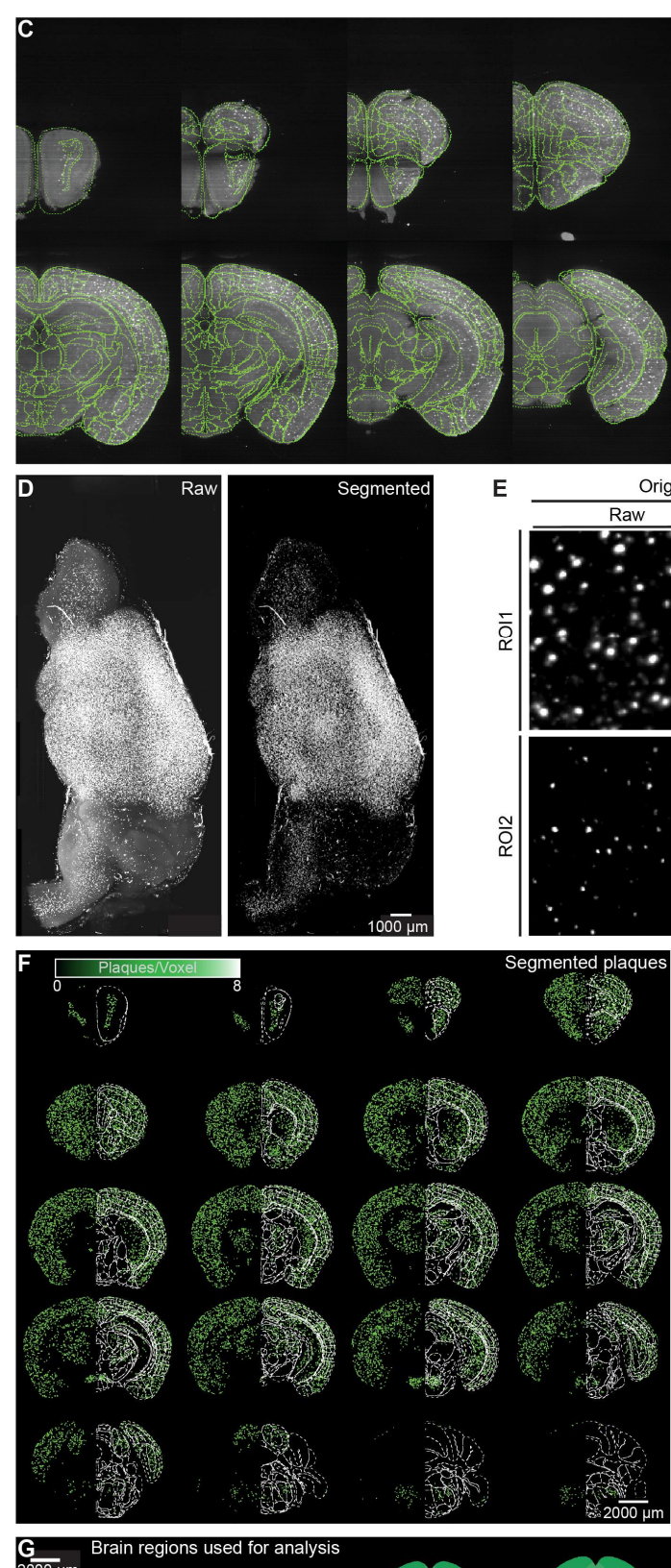

G Brain regions used for analysis

Orthogonal reslice

$10 \bar{\mu} \mu \mathrm{m}$
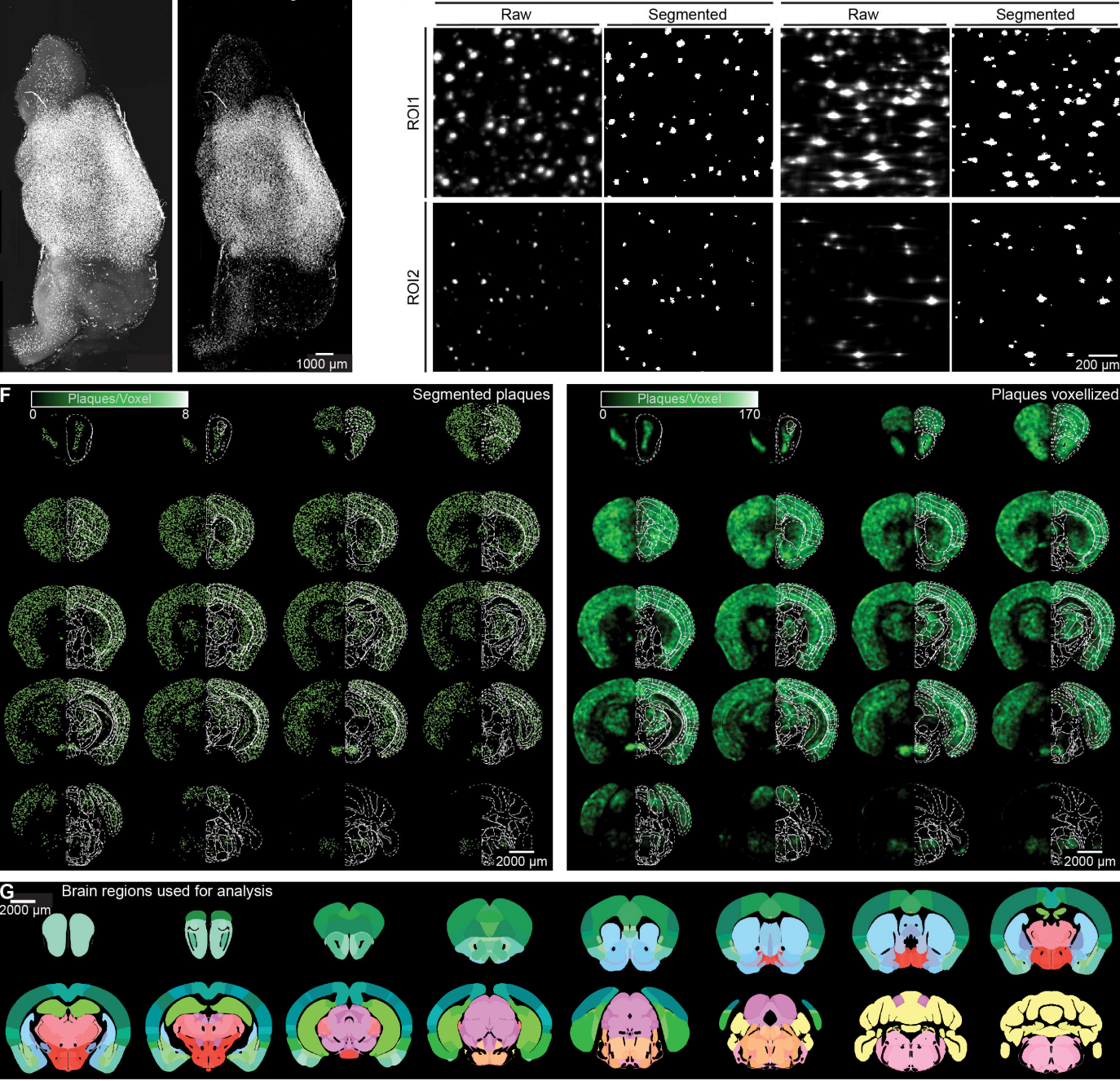

Supplementary figure 3 


\section{Supplementary figure 3. Digital atlas registration and machine learning-based plaque segmentation results}

in precise plaque-load heatmaps. (A) Schematic of sample quantification pipeline describes the segmentation of plaques, registration of autofluorescence channel to an atlas, and finally application of the registration transformation to plaque information to an atlas space where group-level analysis can be performed. (B) The Receiver Operating Characteristic and Precision Recall curves quantify the accuracy of plaque detection on an expert-annotated test dataset. (C) Steps in the data analysis pipeline include accurate registration of brains to an atlas and plaque segmentation with expert-trained machine learning. Whole mouse brain data were first registered to the Allen Brain Atlas through non-linear transformations. Brain regions (green outlines) match with the autofluorescence of the brain data. (D) Plaque segmentation allows for automated segmentation of entire brains. (E) Machine learning based segmentation fits with raw data. Spherical plaques (C, Orthogonal imaging plane) show spindle artefacts when digitally resliced orthogonally (C, Orthogonal reslice - Raw). Segmentation decreased artefacts (C, Orthogonal reslice - Raw and Segmented). (F) Segmented plaques (left) are voxelized resulting in heatmaps of either plaque density, mean size or maturity (right). (G) Statistics on segmented plaques can be done by grouping them into brain regions. 
bioRxiv preprint doi: https://doi.org/10.1101/2021.01.15.426090; this version posted July 14, 2021. The copyright holder for this preprint (which was not certified by peer review) is the author/funder, who has granted bioRxiv a license to display the preprint in perpetuity. It is made available under aCC-BY-ND 4.0 International license.

A

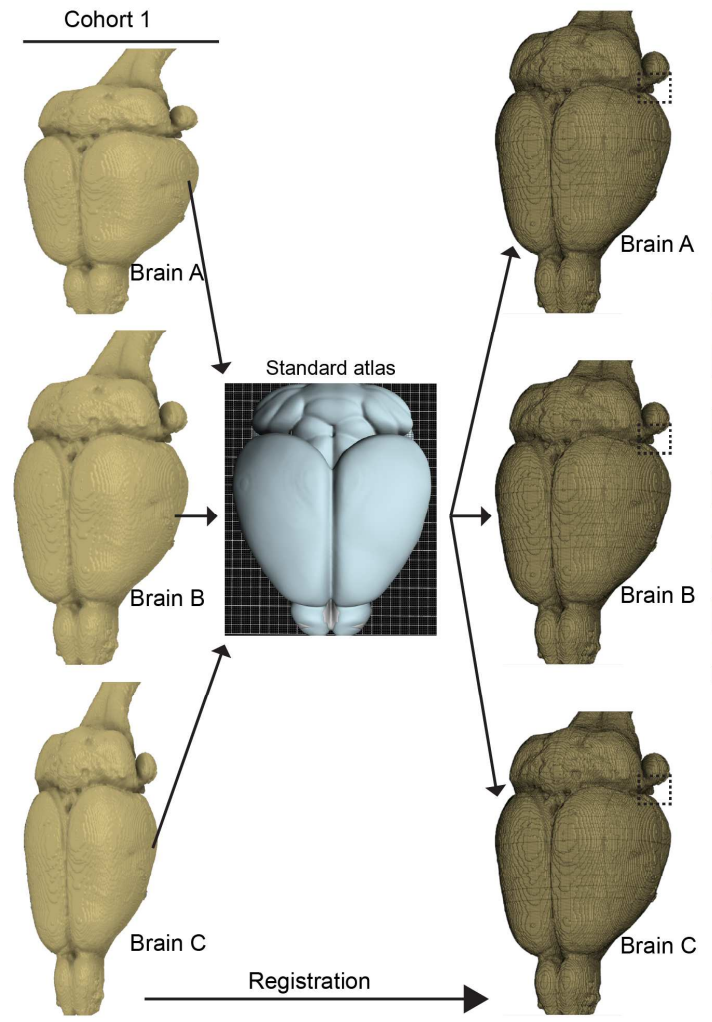

B

Descriptive statistics of a voxel.

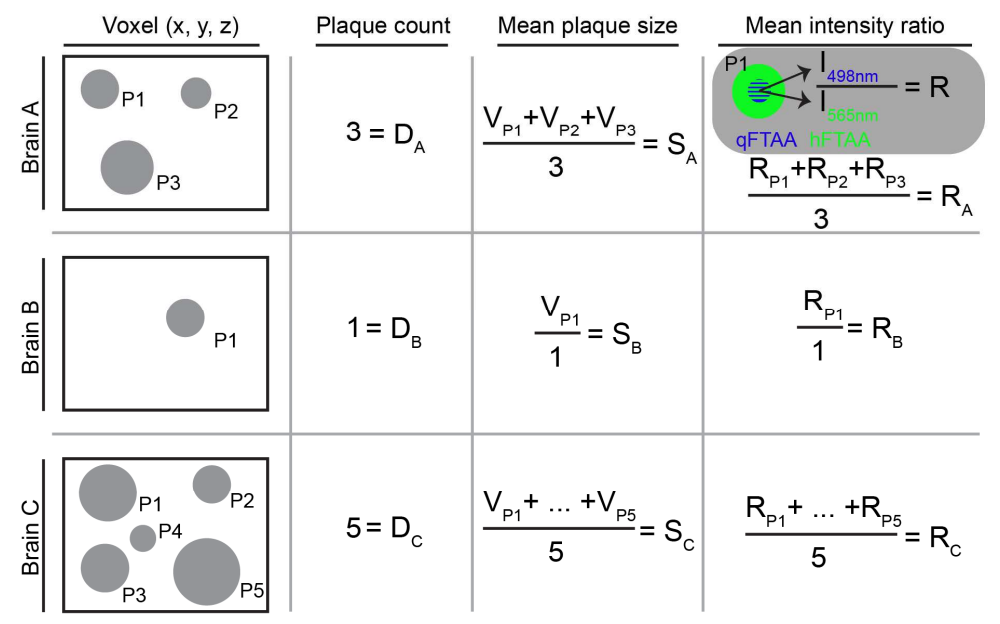

$\operatorname{Voxel}(x, y, z)$
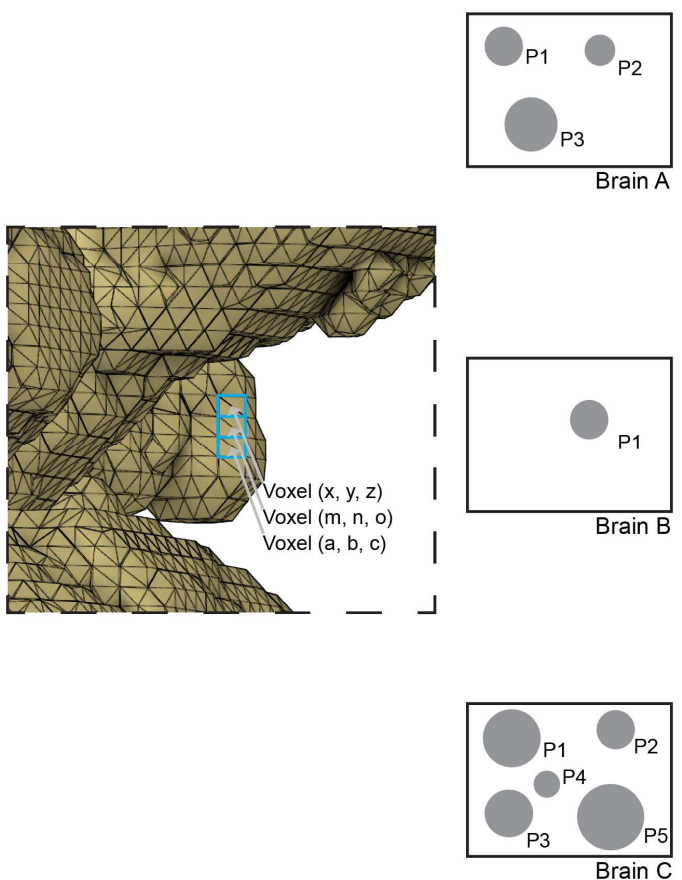

Voxellation $(25 \times 25 \times 25 \mu \mathrm{m})$

c

Descriptive statistics of a voxel in a cohort of samples.

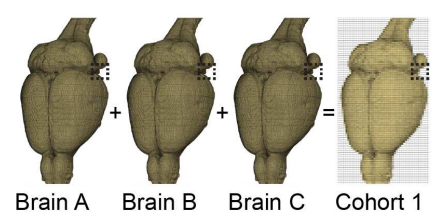

D

Comparison of two sample cohorts based on inferential statistics of all voxels across all samples.

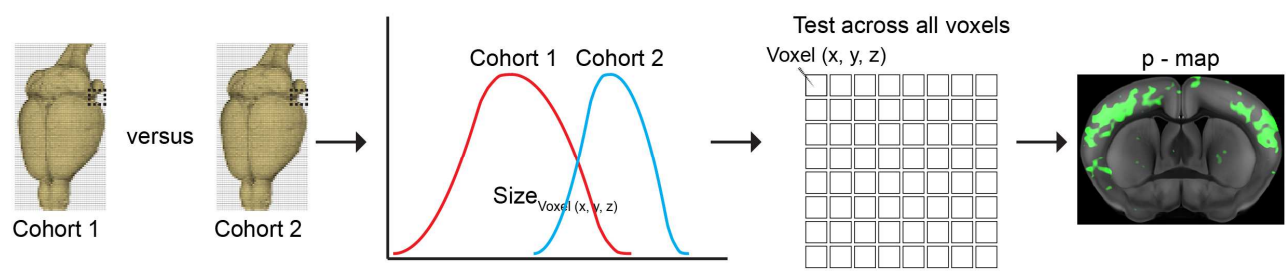

\section{Supplementary figure 4}




\section{Supplementary figure 4. Custom-made data analysis pipeline handles raw image data automatically and}

results in intuitive heatmaps of treatment effect. (A) Statistical pipeline of whole-brain analysis starting from stitched whole-brain mesoSPIM images and resulting in maps of significantly affected voxels (SAVs) in the end. Stitched whole-brain images were transformed and registered to a standard brain atlas, followed by voxellation of the registered volumes. (B) Descriptive statistics were calculated for every voxel of individual brains resulting in plaque counts, mean plaque size and mean intensity ratio for each voxel (plaques: P1, P2 ... Pn). Intensity ratios were calculated by dividing the peak fluorescent emission in the qFTAA channel with the peak emission of the hFTAA channel in the center of each plaque. (C) Descriptive statistics for each treatment and control cohort were calculated by calculating mean values of corresponding voxels across individual brains within a cohort. (D) Inferential statistical tests to compare treated and control cohorts were applied on cohort-level statistics across each voxel. Significantly affected voxels were mapped on digitally resliced coronal brain sections ( $p$-map). 

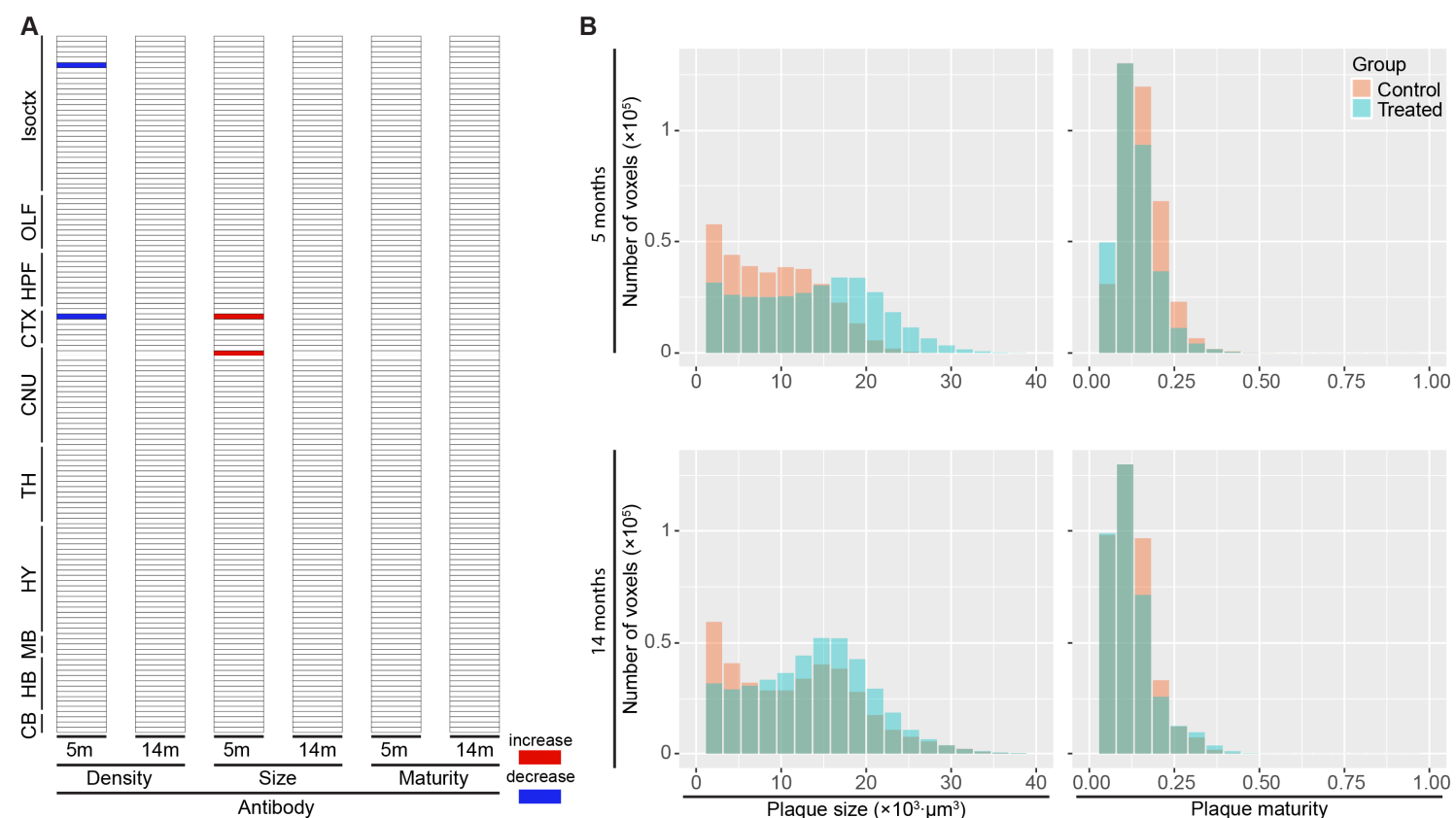

\section{Supplementary figure 5}

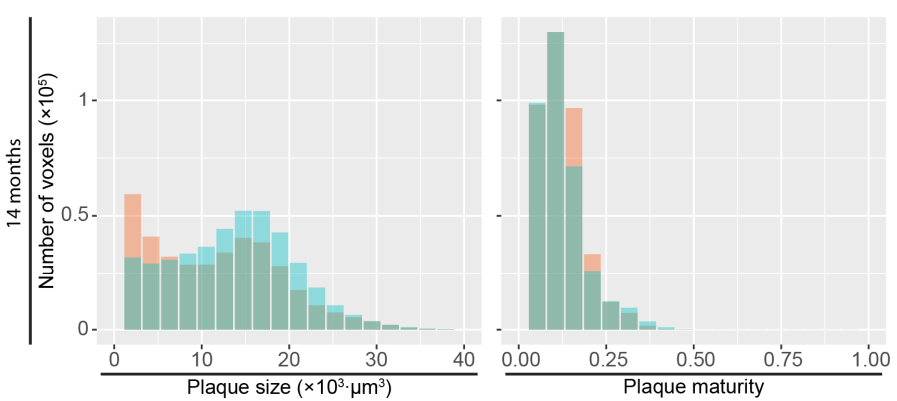

Supplementary figure 5 . The $\beta 1$ antibody treatment shows a limited effect across all analyzed metrics. (A)

The $\beta 1$ antibody treatment showed very limited effects in all analyzed brain regions across all analyzed metrics (B) There was a trend of reduction in the mean frequency of small plaques, but there was no change in plaque maturity. 

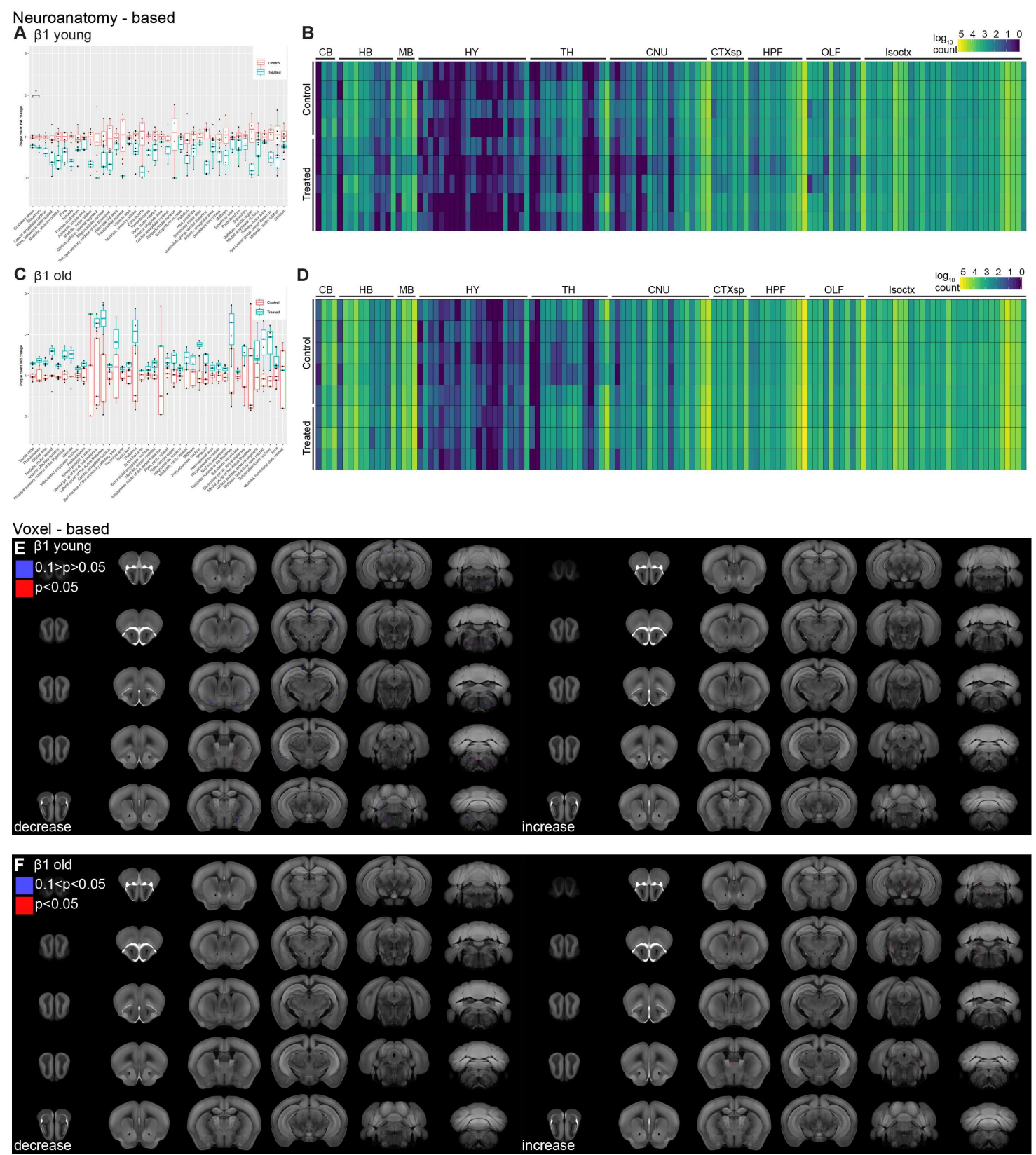

Supplementary figure 6

\section{Supplementary figure 6 . The $\beta 1$ antibody has a minimal effect on plaque-count increase in 5 -month-old}

mice and has no effect in old mice. (A-D) Neuroanatomy-based statistics. (A) Fold-change reduction in plaque count in the 40 brain regions with the most significant therapy-induced changes $(0.0139<p<0.4658)$ in the left hemisphere of 5-month-old mice. (B) Heatmaps of regional plaque burden in individual mice in 5-montold mice. (C) Fold-change reduction of plaque count of the 40 brain regions with the most significant therapyinduced changes $(0.3284<p<0.4835)$ in the left hemisphere at 14 -months. (D) Heatmaps of regional plaque 
bioRxiv preprint doi: https://doi.org/10.1101/2021.01.15.426090; this version posted July 14, 2021. The copyright holder for this preprint (which

was not certified by peer review) is the author/funder, who has granted bioRxiv a license to display the preprint in perpetuity. It is made available under ACC-BY-ND 4.0 International license.

burden in individual mice in 5-month-old mice. (E-F) Voxel-based analysis. (E) SAV upon $\beta 1$ antibody treatment. Significant effects occurred mostly in the brainstem. (F) The plaque-count change induced by $\beta 1$ antibody treatment in 14-month-old mice is negligible on the voxel level. Isoctx - isocortex, OLF - olfactory areas, HPF - hippocampal formation, CTX sp - cortical subplate, CNU - caudate nucleus, TH - thalamus, HY - hypothalamus, $\mathrm{MB}$ - midbrain, $\mathrm{HB}$ - hindbrain, $\mathrm{CB}$ - cerebellum. 
bioRxiv preprint doi: https://doi.org/10.1101/2021.01.15.426090; this version posted July 14, 2021. The copyright holder for this preprint (which was not certified by peer review) is the author/funder, who has granted bioRxiv a license to display the preprint in perpetuity. It is made available under aCC-BY-ND 4.0 International license.
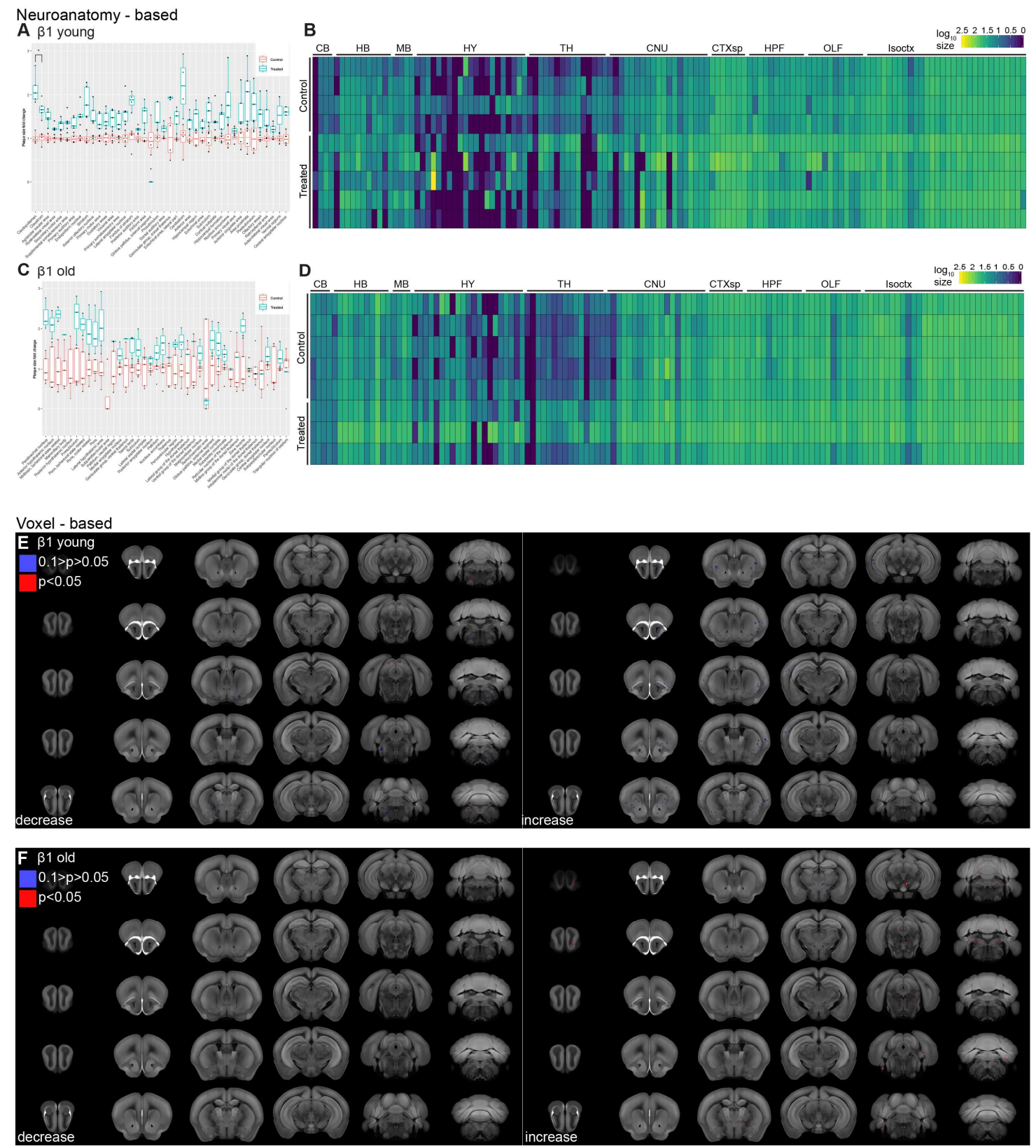

Supplementary figure 7 
Supplementary figure 7. The plaque-size change induced by $\beta 1$ antibody treatment in 5-month-old mice is very limited and absent in 14-month-old mice. (A-D) Neuroanatomy-based statistics. (A) Fold-change reduction of mean plaque size of the 40 brain regions with the most significant therapy-induced changes $(0.0437<p<0.01702)$ in the left hemisphere of 5 -month-old mice. (B) Heatmap of regional plaque size in individual 5-month-old mice. (C) Fold-change reduction of mean plaque size of the 40 brain regions with the most significant therapy-induced changes $(0.6861<p<0.6861)$ in the left hemisphere at 14 -months. (D) Heatmap of regional plaque size in individual 14-month-old mice. (E-F) Voxel-based analysis. (E) Heatmap of voxels with significant mean plaque size reduction upon $\beta 1$ antibody treatment in 5-month-old mice, compared to control. (F) Heatmap of voxels with significant mean plaque size reduction upon $\beta 1$ antibody treatment in 14-month-old mice, compared to control. Isoctx - isocortex, OLF - olfactory areas, HPF hippocampal formation, CTX sp - cortical subplate, CNU - caudate nucleus, TH - thalamus, HY hypothalamus, $\mathrm{MB}$ - midbrain, $\mathrm{HB}$ - hindbrain, $\mathrm{CB}$ - cerebellum 
bioRxiv preprint doi: https://doi.org/10.1101/2021.01.15.426090; this version posted July 14, 2021. The copyright holder for this preprint (which was not certified by peer review) is the author/funder, who has granted bioRxiv a license to display the preprint in perpetuity. It is made available under aCC-BY-ND 4.0 International license.
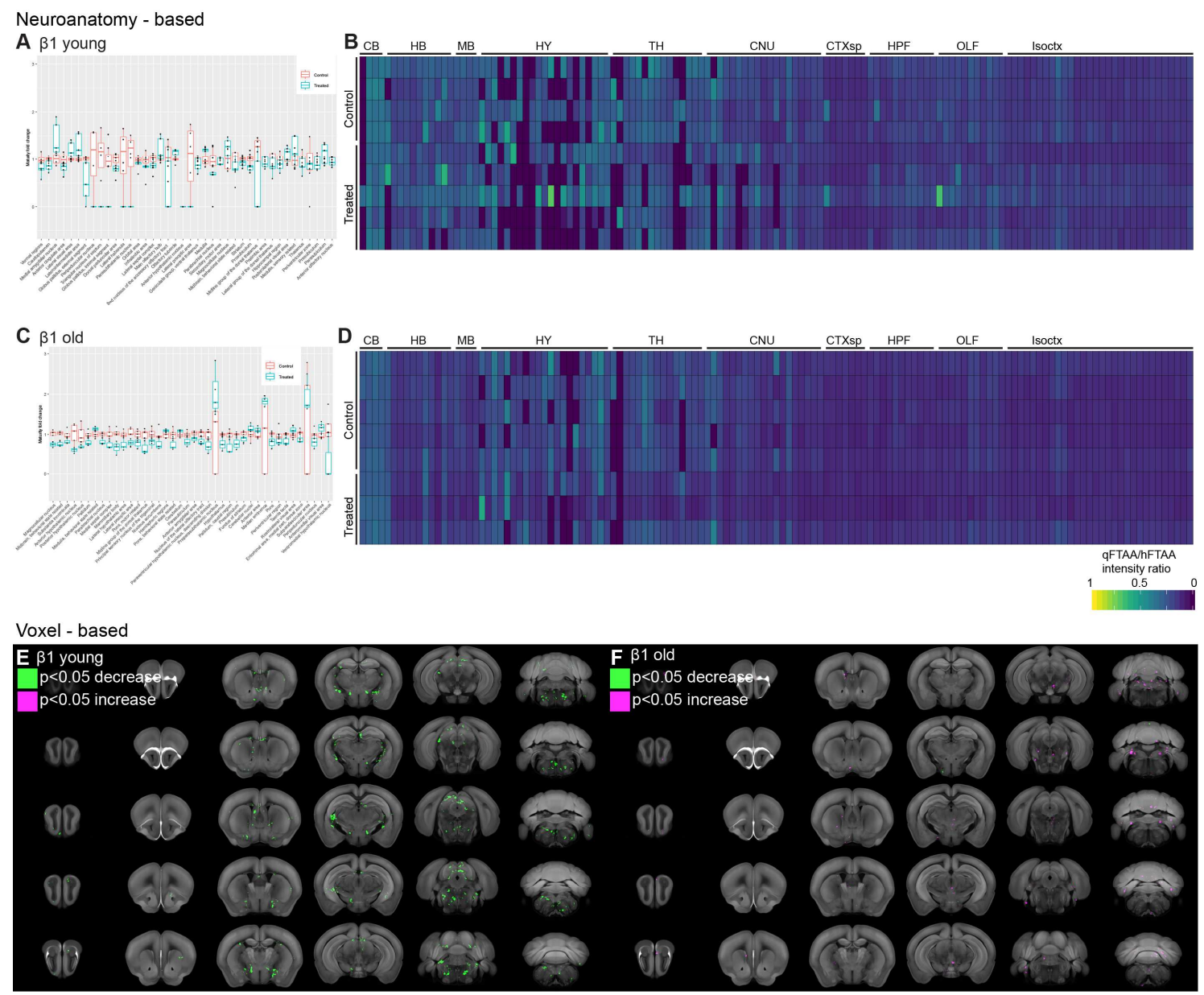

\section{Supplementary figure 8}




\section{Supplementary figure 8 . The plaque-maturity change induced by $\beta 1$ antibody treatment in 5- and 14-}

month-old mice is very limited. (A-D) Neuroanatomy-based statistics. (A) Fold-change in mean plaque maturity of the 40 brain regions with the most significant therapy-induced changes $(0.8293<p<0.8293)$ in the left hemisphere of 5-month-old mice. (B) Heatmap of regional plaque maturity in individual 5-month-old mice. (C) Fold-change in mean plaque maturity of the 40 brain regions with the most significant therapyinduced changes $(0.6787<p<0.7330)$ in the left hemisphere of old mice. (D) Heatmap of regional plaque maturity in individual 14-month-old mice. (E-F) Voxel-based analysis. (E) Heatmap of voxels with significant mean plaque maturity change upon $\beta 1$ antibody treatment, compared to control in 5-month-old mice. (F) Heatmap of voxels with significant mean plaque maturity change upon $\beta 1$ antibody treatment in 14-monthold mice. Isoctx - isocortex, OLF - olfactory areas, HPF - hippocampal formation, CTX sp - cortical subplate, $\mathrm{CNU}$ - caudate nucleus, $\mathrm{TH}$ - thalamus, $\mathrm{HY}$ - hypothalamus, $\mathrm{MB}$ - midbrain, $\mathrm{HB}$ - hindbrain, $\mathrm{CB}$ - cerebellum 

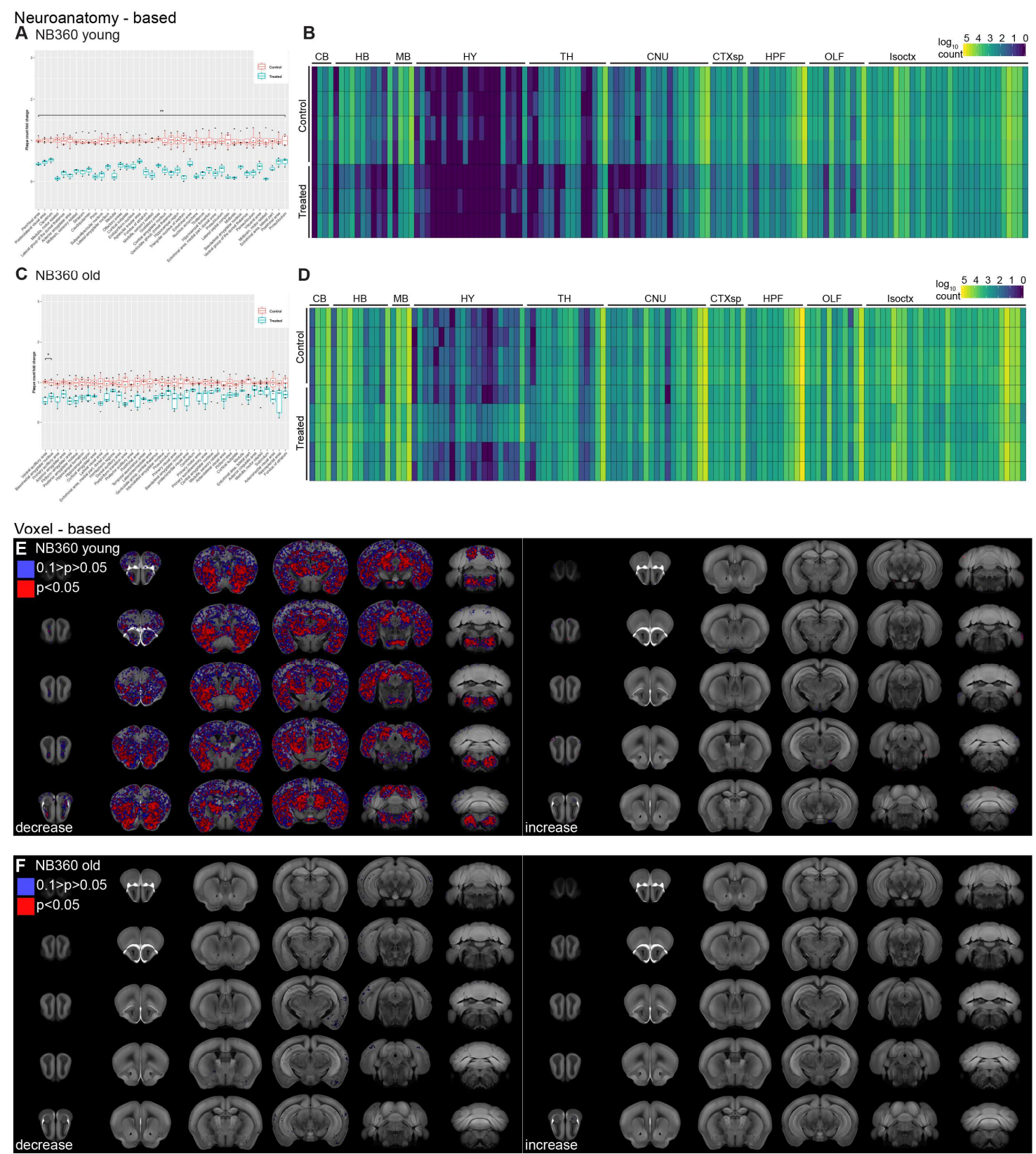

Supplementary figure 9

\section{Supplementary figure 9. BACE1-inhibition induced conspicuous plaque count reduction in 5-month-old}

mice, but not in 14-month-old mice. (A-D) Neuroanatomy-based statistics. (A) Fold-change reduction of plaque count of the 40 brain regions with the most significant therapy-induced changes $(0.0043<p<0.0091)$ in the left hemisphere of 5-month-old mice. (B) Heatmap of regional plaque burden in individual mice at 5 months. The strong effect of BACE1 inhibition is conspicuous on the single-sample level. (C) Fold-change reduction of plaque count of the 40 brain regions with the most significant therapy-induced changes $(0.0159<p<0.1338)$ in the left hemisphere at 14 -months. (D) Heat map of regional plaque burden in individual 
bioRxiv preprint doi: https://doi.org/10.1101/2021.01.15.426090; this version posted July 14, 2021. The copyright holder for this preprint (which

was not certified by peer review) is the author/funder, who has granted bioRxiv a license to display the preprint in perpetuity. It is made available under ACC-BY-ND 4.0 International license.

mice at 14-months of age. (E-F) Voxel-based analysis (E) Heatmap of voxels with significant plaque count reduction upon NB360 treatment in young mice, compared to control. (F) Upon BACE1 inhibition in 14month-old mice only very few voxels show significant plaque-count reduction.Isoctx - isocortex, OLF olfactory areas, HPF - hippocampal formation, CTX sp - cortical subplate, CNU - caudate nucleus, TH thalamus, $\mathrm{HY}$ - hypothalamus, $\mathrm{MB}$ - midbrain, $\mathrm{HB}$ - hindbrain, $\mathrm{CB}$ - cerebellum 

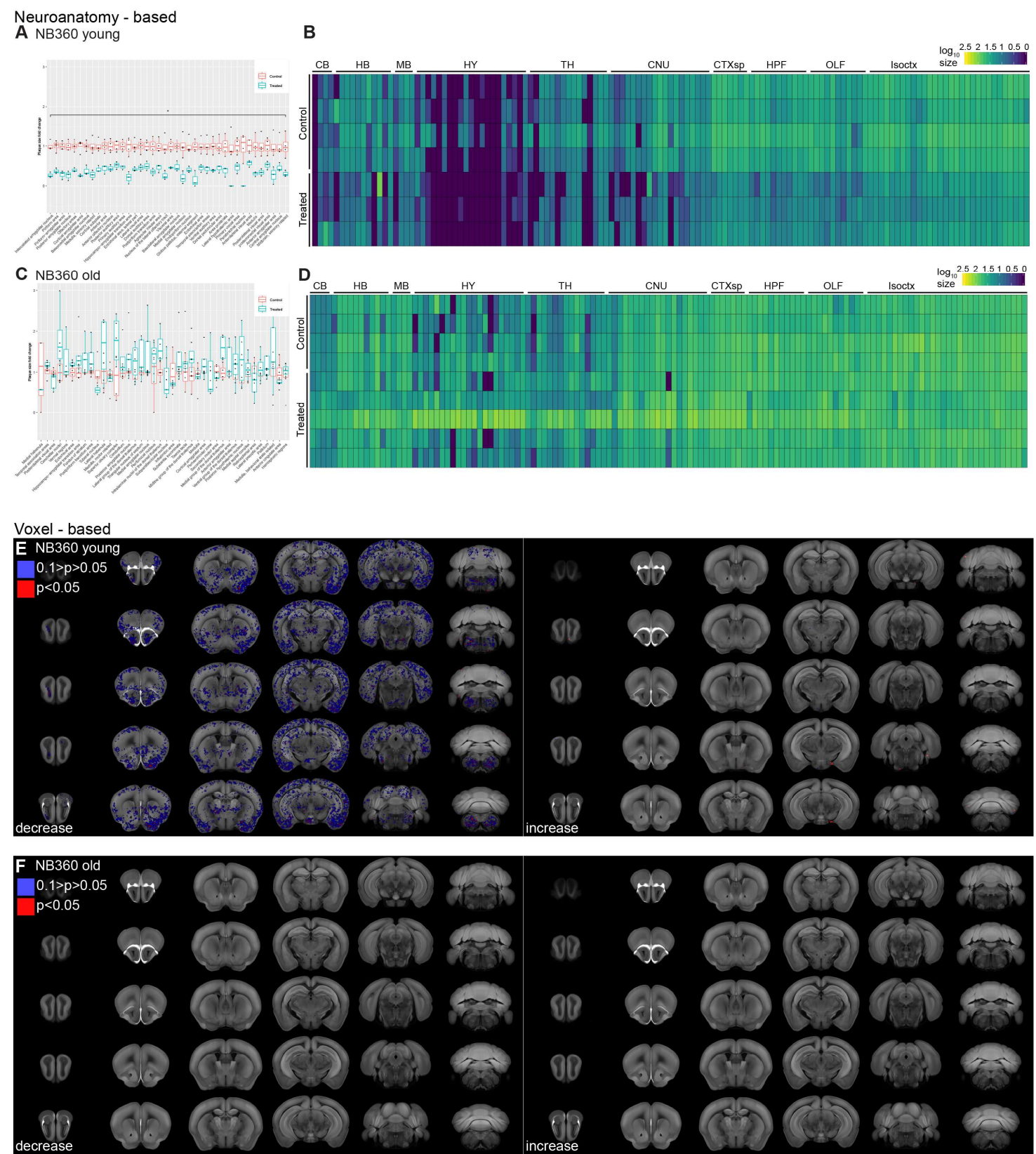

Supplementary figure 10

Supplemental figure 10. BACE1-inhibition induces considerable plaque size reduction in 5-month-old mice,

but not in 14-month-old mice. (A-D) Neuroanatomy-based statistics. (A) Fold-change reduction of mean plaque size of the 40 brain regions with the most significant therapy-induced changes $(0.0236<p<0.0425)$ in the left hemisphere in 5-month-old mice. (B) Heatmap of regional mean plaque sizes in individual mice at 5 months. (C) Fold-change reduction of mean plaque size of the 40 brain regions with the most significant therapy-induced changes $(0.7641<p<0.7641)$ in the left hemisphere at 14-months. (D) Heatmap of regional 
bioRxiv preprint doi: https://doi.org/10.1101/2021.01.15.426090; this version posted July 14, 2021. The copyright holder for this preprint (which

was not certified by peer review) is the author/funder, who has granted bioRxiv a license to display the preprint in perpetuity. It is made available under ACC-BY-ND 4.0 International license.

mean plaque sizes in individual mice at 14-months of age. (E-F) Voxel-based analysis. (E) Heatmap of voxels with significant mean plaque size reduction upon NB360 treatment in young mice, compared to control. (F) Heatmaps of significantly affected voxels show very limited plaque size change by BACE1-inhibition in 14month-old mice. Isoctx - isocortex, OLF - olfactory areas, HPF - hippocampal formation, CTX sp - cortical subplate, $\mathrm{CNU}$ - caudate nucleus, $\mathrm{TH}$ - thalamus, $\mathrm{HY}$ - hypothalamus, $\mathrm{MB}$ - midbrain, $\mathrm{HB}$ - hindbrain, $\mathrm{CB}$ cerebellum 
bioRxiv preprint doi: https://doi.org/10.1101/2021.01.15.426090; this version posted July 14, 2021. The copyright holder for this preprint (which was not certified by peer review) is the author/funder, who has granted bioRxiv a license to display the preprint in perpetuity. It is made available under aCC-BY-ND 4.0 International license.

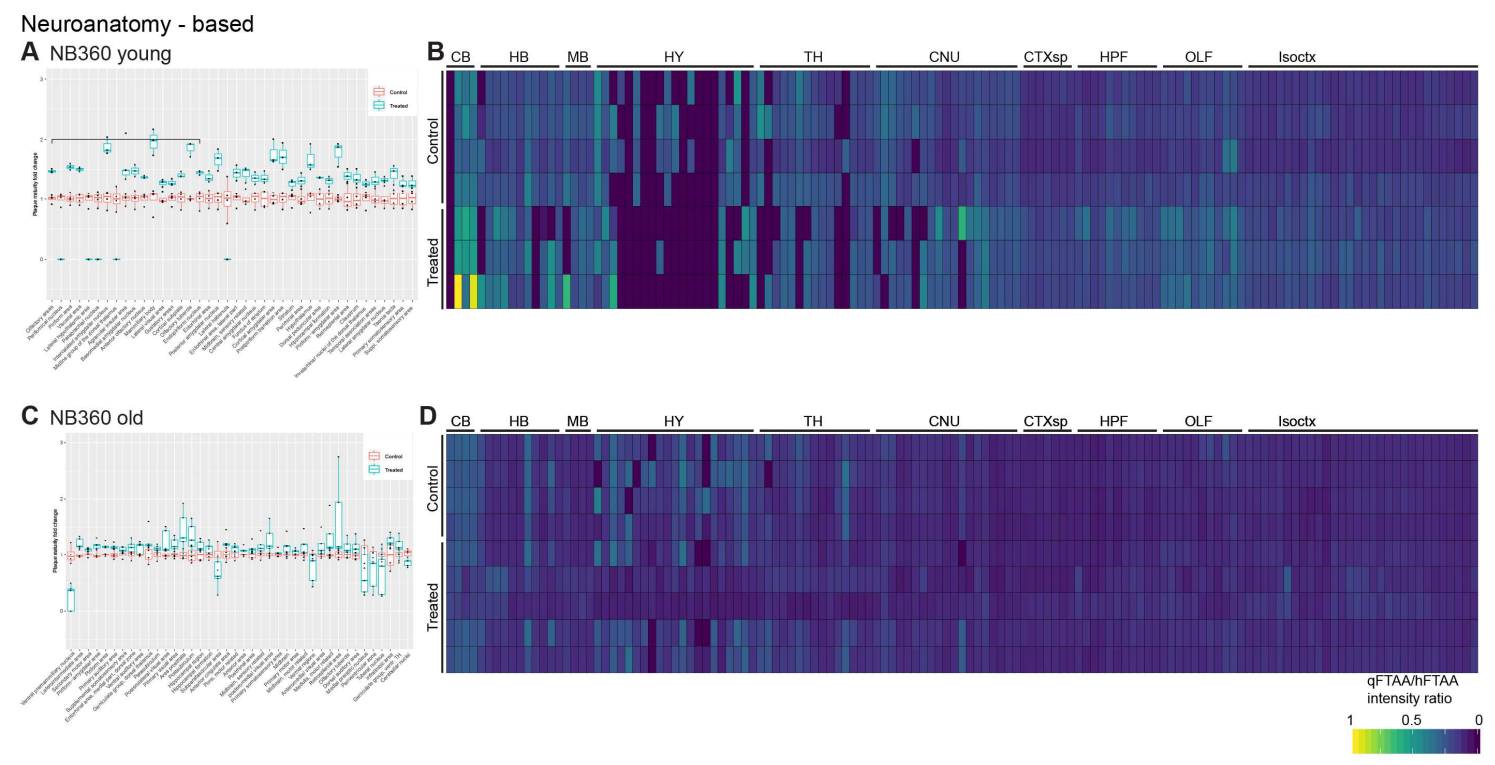

Voxel - based

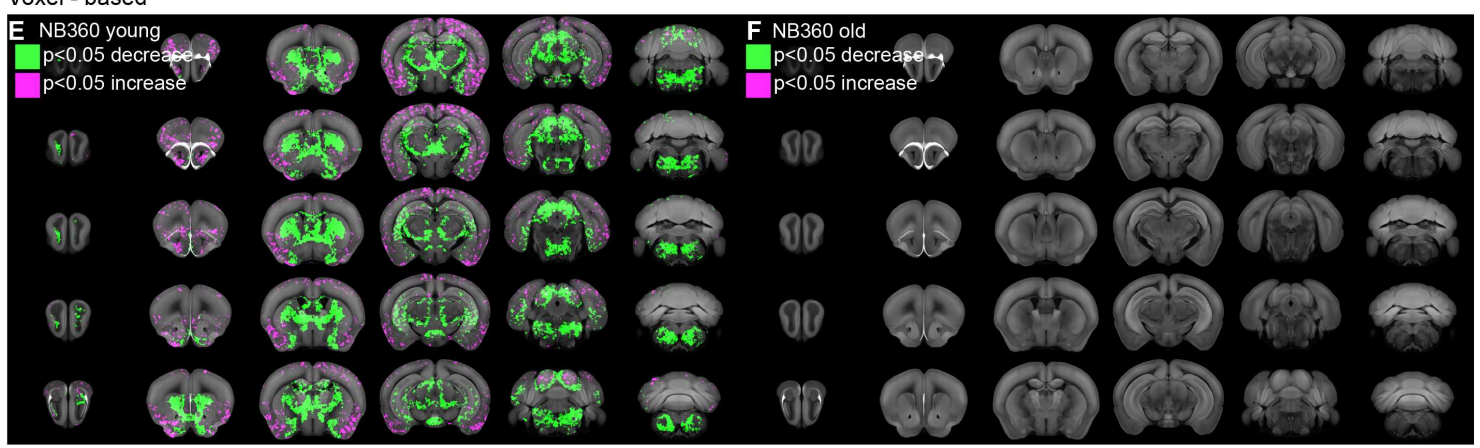

Supplementary figure 11 


\section{Supplementary figure 11. Plaque maturity change by BACE1-inhibition in 5-month-old mice shows region-} dependent maturity increase and decrease while there is no effect at 14-months. (A-D) Neuroanatomybased statistics. (A) Fold-change in mean plaque maturity of the 40 brain regions with the most significant therapy-induced changes $(0.0107<p<0.1036$, both maturity increase and decrease) in the left hemisphere in 5-month-old mice. (B) Heatmap of regional plaque maturity in individual 5-month-old mice. (C) Fold-change in mean plaque maturity of the 40 brain regions with the most significant therapy-induced changes $(0.1047<p<0.5783$, both maturity increase and decrease) in the left hemisphere at 14-months. (D) Heatmap of regional plaque maturity in individual 14-month-old mice. (E-F) Voxel-level analysis. (E) Heatmap of voxels with significant mean plaque maturity change upon NB360 treatment, compared to control in 5-month-old mice. (F) Heatmap of voxels with significant mean plaque maturity change upon NB360 treatment, compared to control at 14-months. Isoctx - isocortex, OLF - olfactory areas, HPF - hippocampal formation, CTX sp cortical subplate, $\mathrm{CNU}$ - caudate nucleus, $\mathrm{TH}$ - thalamus, $\mathrm{HY}$ - hypothalamus, MB - midbrain, HB - hindbrain, $\mathrm{CB}$ - cerebellum 

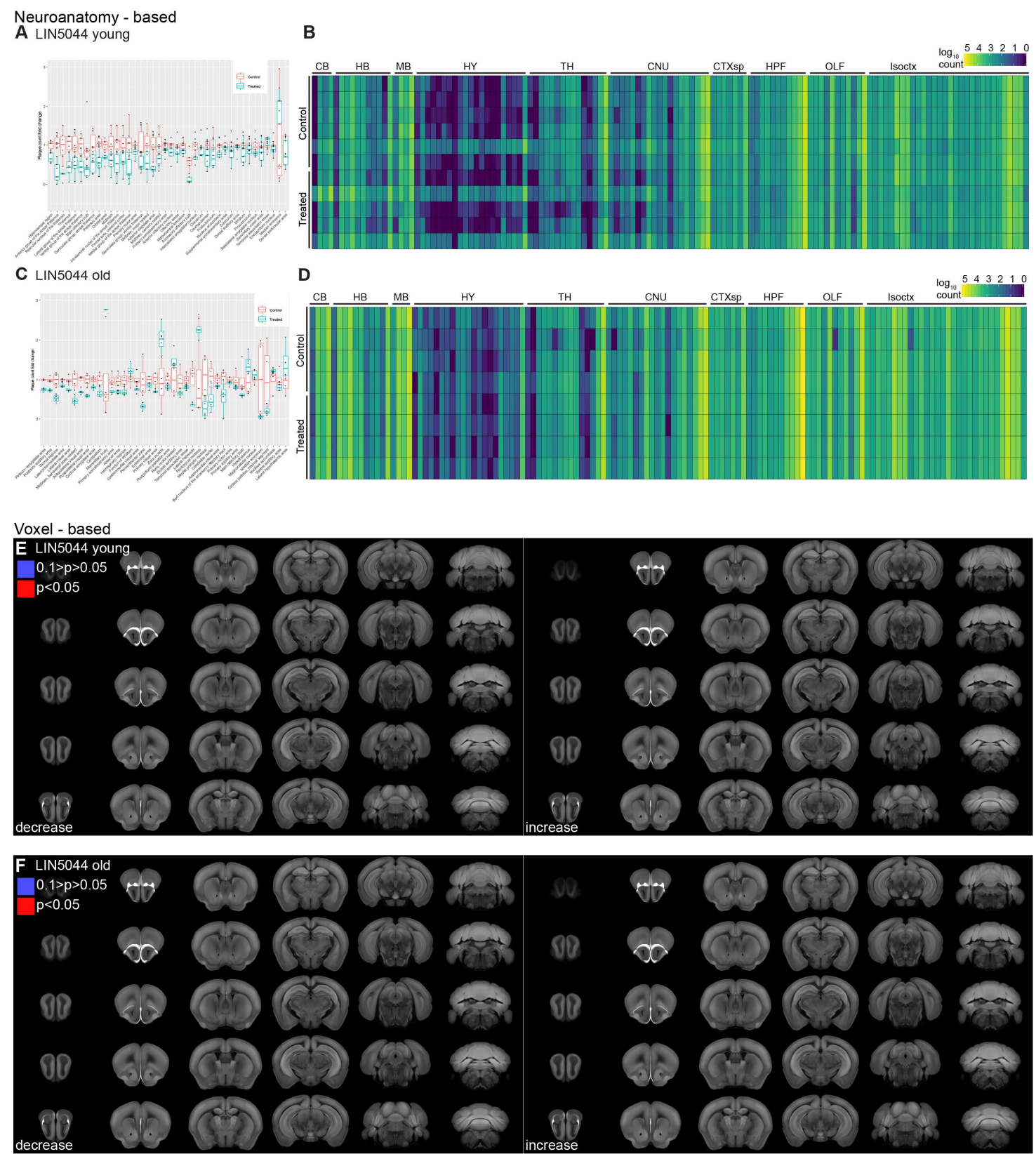

Supplementary figure 12

Supplementary figure 12. Trend in plaque-count reduction in few anatomical regions after LIN5044 treatment in 5- and 14-month-old mice. (A-D) Neuroanatomy-based statistics. (A) Fold-change reduction of plaque count of the 40 brain regions with the most significant therapy-induced changes $(0.3022<p<0.8724)$ in the left hemisphere in 5-month-old mice. (B) Heatmap of regional plaque burden in individual mice at 5 months. (C) Fold-change reduction of plaque count of the 40 brain regions with the most significant therapyinduced changes $(0.0913<p<0.6366)$ in the left hemisphere in 14-months-old mice. Plaque-count reduction 
bioRxiv preprint doi: https://doi.org/10.1101/2021.01.15.426090; this version posted July 14, 2021. The copyright holder for this preprint (which

was not certified by peer review) is the author/funder, who has granted bioRxiv a license to display the preprint in perpetuity. It is made available under aCC-BY-ND 4.0 International license.

is not significant but shows a trend in 14-month-old mice. (D) Heatmap of regional plaque burden in individual mice at 14-months of age. (E-F) Voxel-based analysis. (E) Heatmap of voxels with significant plaque count reduction upon LIN5044 treatment, compared to control at 5-months of age. (F) Heatmap of voxels with significant plaque count reduction upon LIN5044 treatment, compared to control in 14-month-old mice. Isoctx - isocortex, OLF - olfactory areas, HPF - hippocampal formation, CTX sp - cortical subplate, CNU caudate nucleus, $\mathrm{TH}$ - thalamus, $\mathrm{HY}$ - hypothalamus, $\mathrm{MB}$ - midbrain, $\mathrm{HB}$ - hindbrain, $\mathrm{CB}$ - cerebellum 

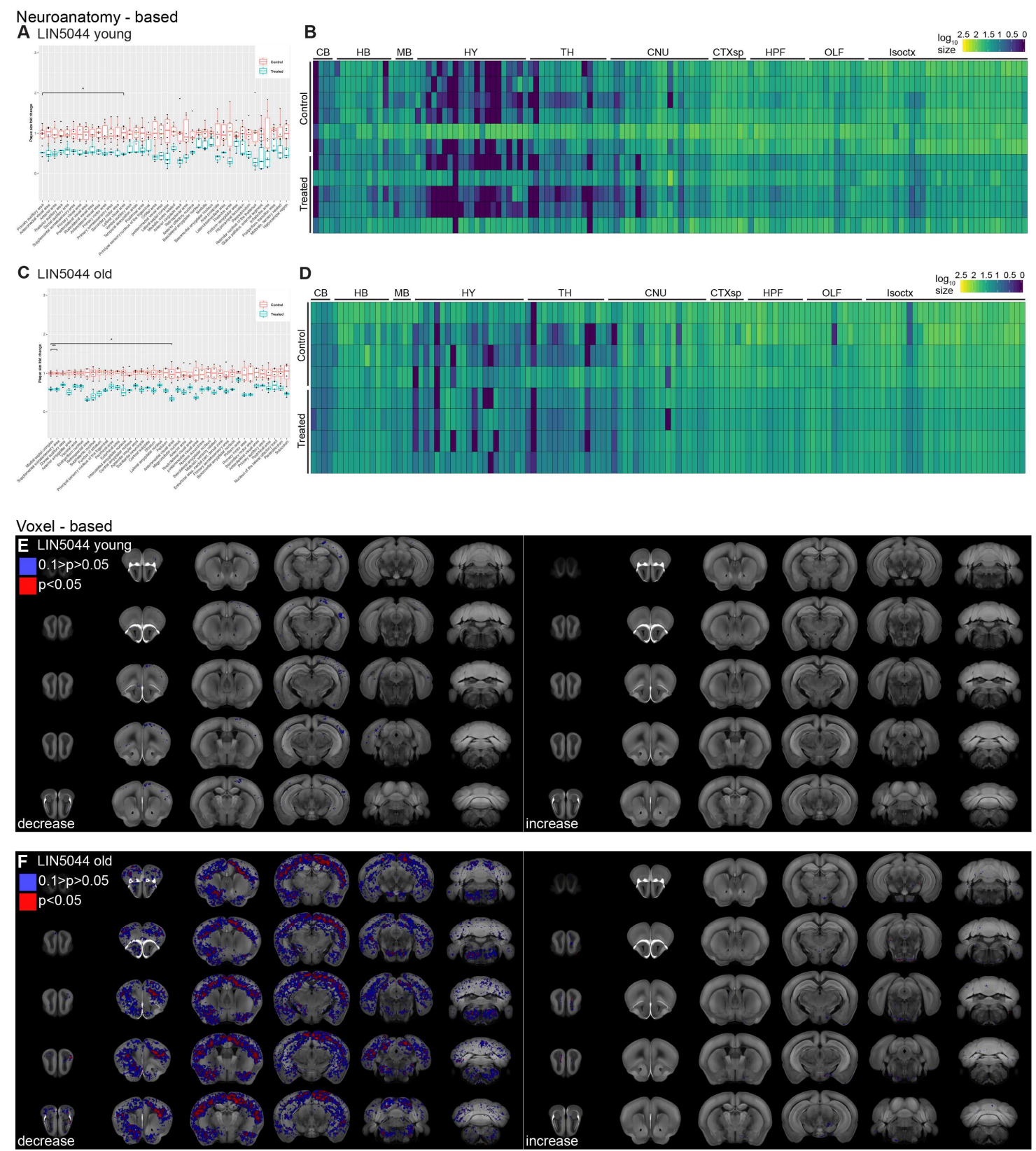

Supplementary figure 13

\section{Supplementary figure 13. Mean plaque-sizes are significantly reduced in some anatomical regions after}

LIN5044 treatment in 5- and 14-month-old mice. (A-D) Neuroanatomy-based statistics. (A) Fold-change reduction of mean plaque size of the 40 brain regions with the most significant therapy-induced changes $(0.0197<p<0.1333)$ shows some areas with significant $(p<0.05)$ effect in the left hemisphere in 5 -month-old mice. (B) Heatmap of regional mean plaque sizes in individual mice at 5-months. (C) Fold-change reduction of mean plaque size of the 40 brain regions with the most significant therapy-induced changes 
$(0.0048<p<0.0865)$ in the left hemisphere of 14 -month-old mice show significant size reduction in cortical areas. (D) Heatmap of regional mean plaque sizes in individual mice at 14-months. The strong effect of LIN5044 is conspicuous on the single-sample level. (E-F) Voxel-based analysis. (E) Heatmap of voxels with significant mean plaque size reduction upon LIN5044 treatment in 5-month-old mice. Some cortical areas show patches with significant treatment effect. (F) Heatmap of voxels with significant mean plaque size reduction upon LIN5044 treatment shows a strong effect with rostro-dorsal emphasis at 14-months. Isoctxisocortex, OLF - olfactory areas, HPF - hippocampal formation, CTX sp - cortical subplate, CNU - caudate nucleus, $\mathrm{TH}$ - thalamus, $\mathrm{HY}$ - hypothalamus, $\mathrm{MB}$ - midbrain, $\mathrm{HB}$ - hindbrain, $\mathrm{CB}$ - cerebellum 
A
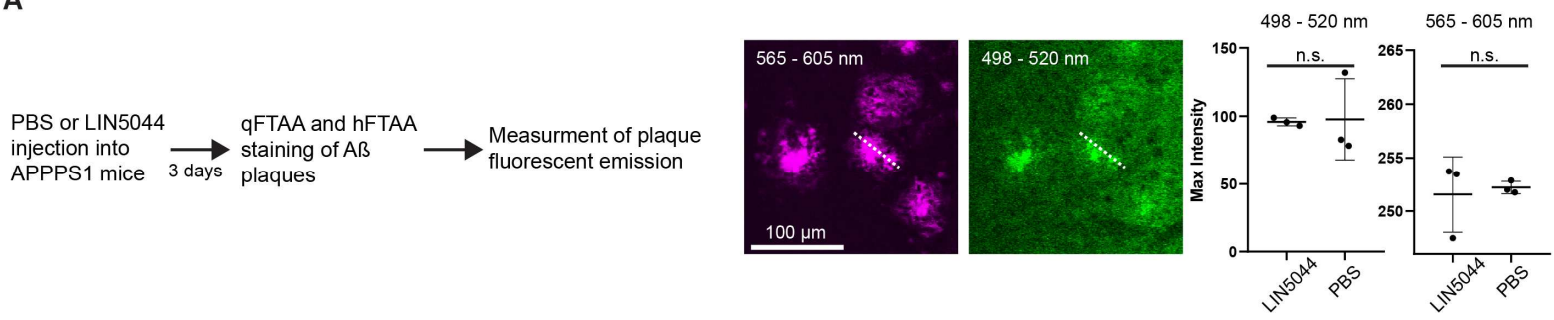

Neuroanatomy - based

B LIN5044 young
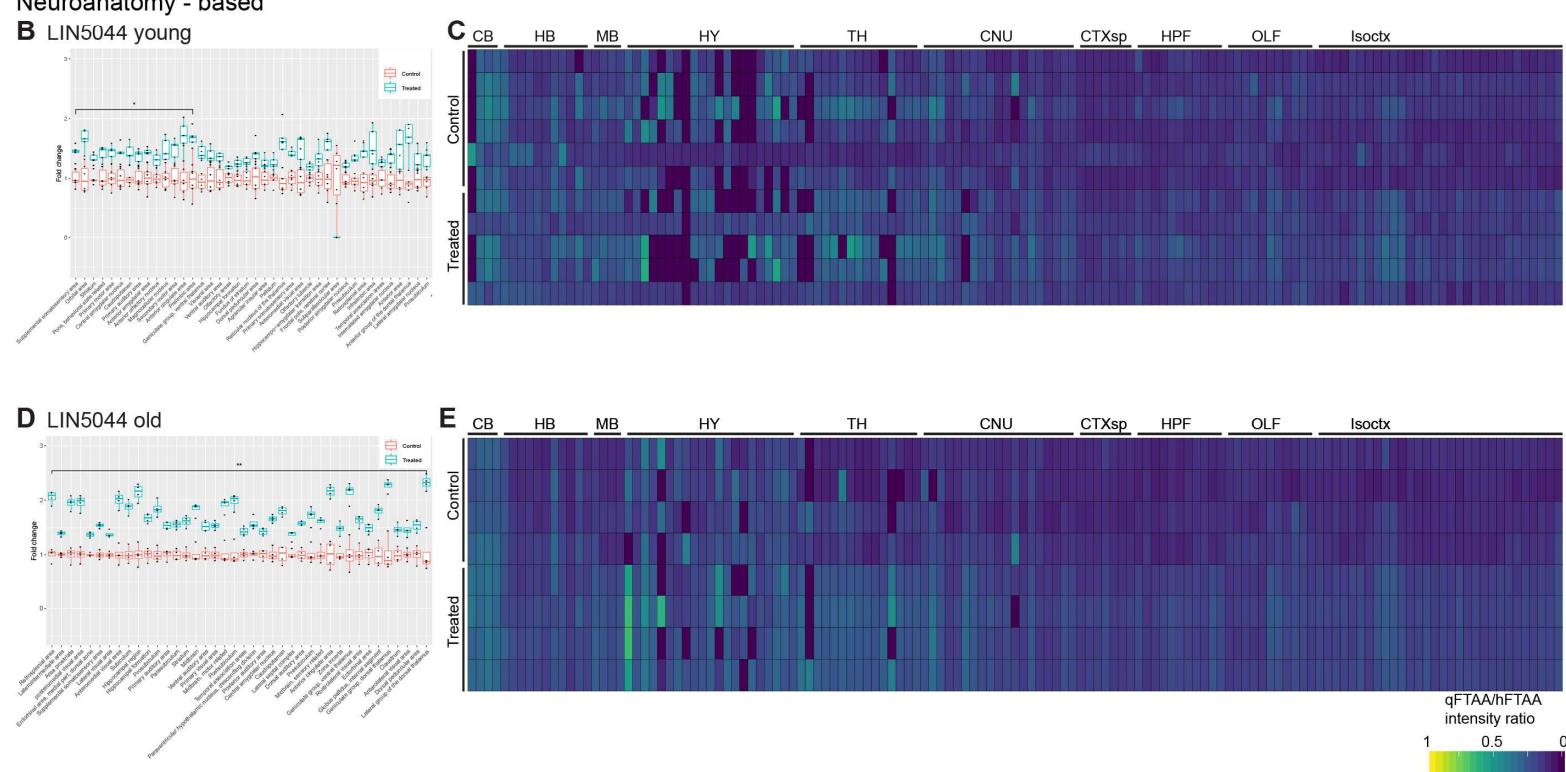

Voxel - based

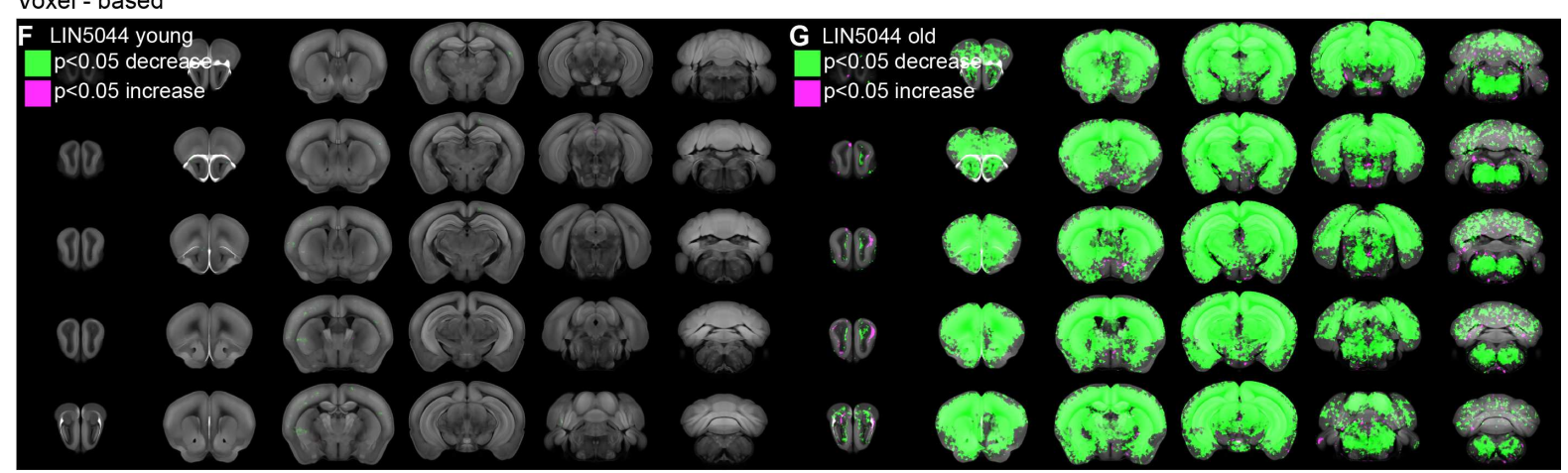

Supplementary figure 14

Supplementary figure 14. Plaque maturity change by LIN5044 in 5-month-old mice shows regiondependent maturity increase and a widespread increase at 14-months. (A) To see whether LIN5044 induces artefacts into the plaque-maturity analysis APPPS1 mice were injected with a single-dose PBS $(n=1)$ or

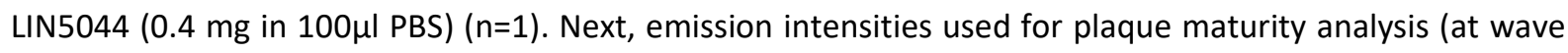
lengths $498-520$ and $565-605 \mathrm{~nm}$ ) were measured in 10 plaques in 3 slices per animal with a confocal microscope. Plaques of LIN5044 and PBS injected mice showed no difference in fluorescent emissions. (B-E) Neuroanatomy-based statistics of LIN5044 treatment cohorts. (B) Fold-change in mean plaque maturity of 
the 40 brain regions with the most significant therapy-induced changes $(0.026<p<0.107)$ shows some areas with significant $(p<0.05)$ maturity increase in the left hemisphere in 5 -month-old mice. (C) Heatmap of regional mean plaque maturity in individual mice at 5-months. (D) Fold-change reduction of mean plaque maturity of the 40 brain regions with the most significant therapy-induced changes $(0.001<p<0.006)$ in the left hemisphere of 14-month-old mice show significant maturity increase in cortical areas. (E) Heatmap of regional mean plaque maturity in individual mice at 14-months. (G-H) Voxel-based analysis. (G) Heatmap of voxels with significant mean plaque maturity change upon LIN5044 treatment in 5-month-old mice. Some cortical areas show patches with significant treatment effect. $(\mathbf{H})$ Heatmap of voxels with significant mean plaque maturity increase upon LIN5044 treatment shows a widespread strong effect at 14-months. Isoctxisocortex, OLF - olfactory areas, HPF - hippocampal formation, CTX sp - cortical subplate, CNU - caudate nucleus, $\mathrm{TH}$ - thalamus, $\mathrm{HY}$ - hypothalamus, $\mathrm{MB}$ - midbrain, $\mathrm{HB}$ - hindbrain, $\mathrm{CB}$ - cerebellum 

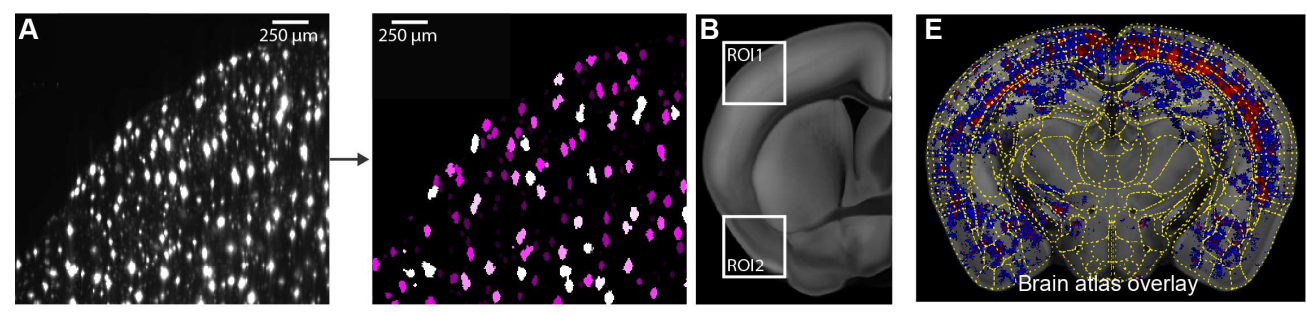

C

ROI1

5 month
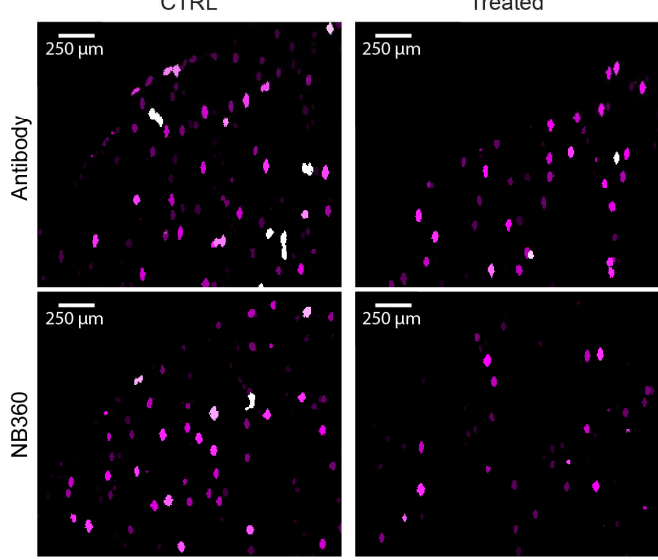

$2 \overline{0 \mu \mathrm{m}}$
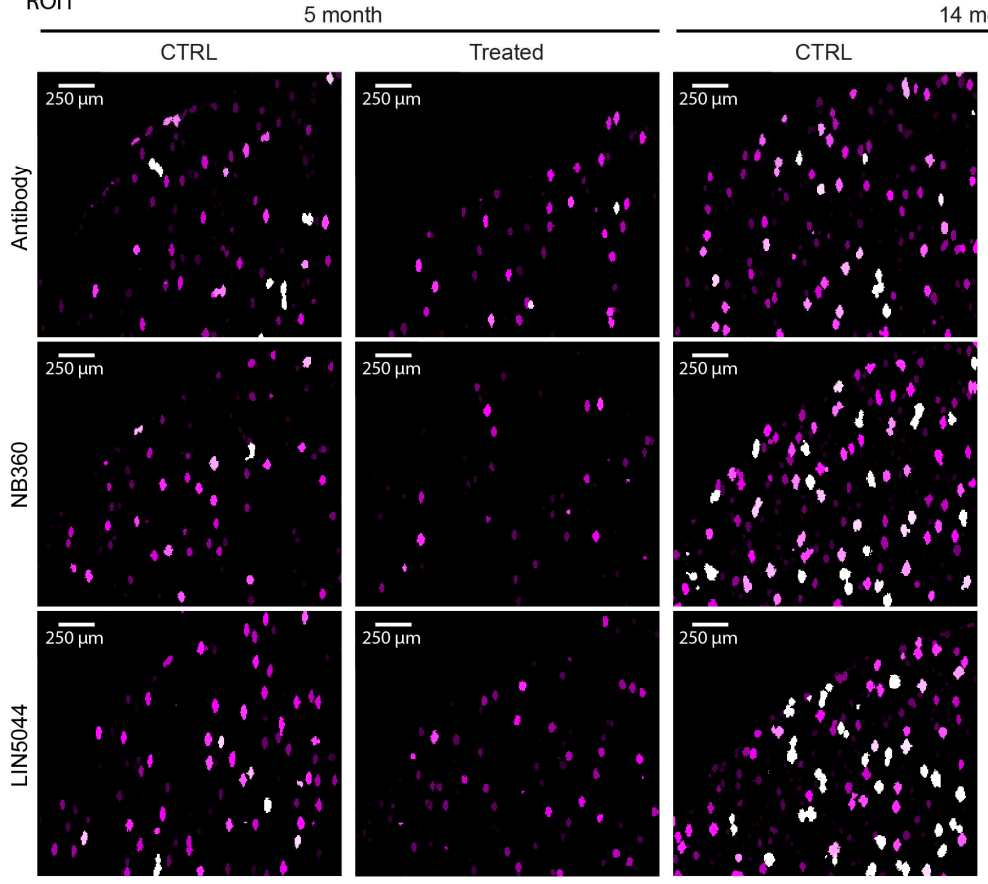

4 month

ROI2

5 month
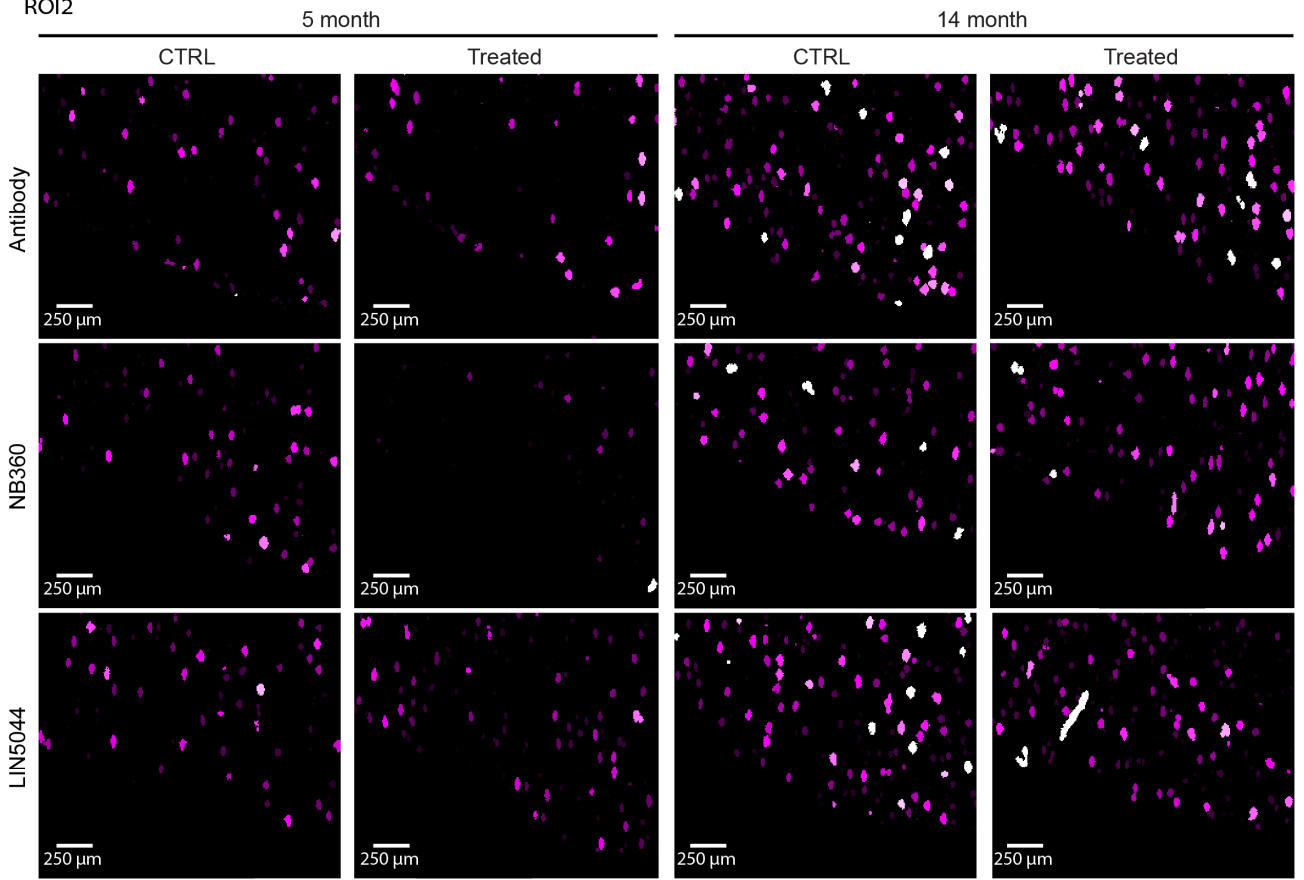

Plaque-size color scale
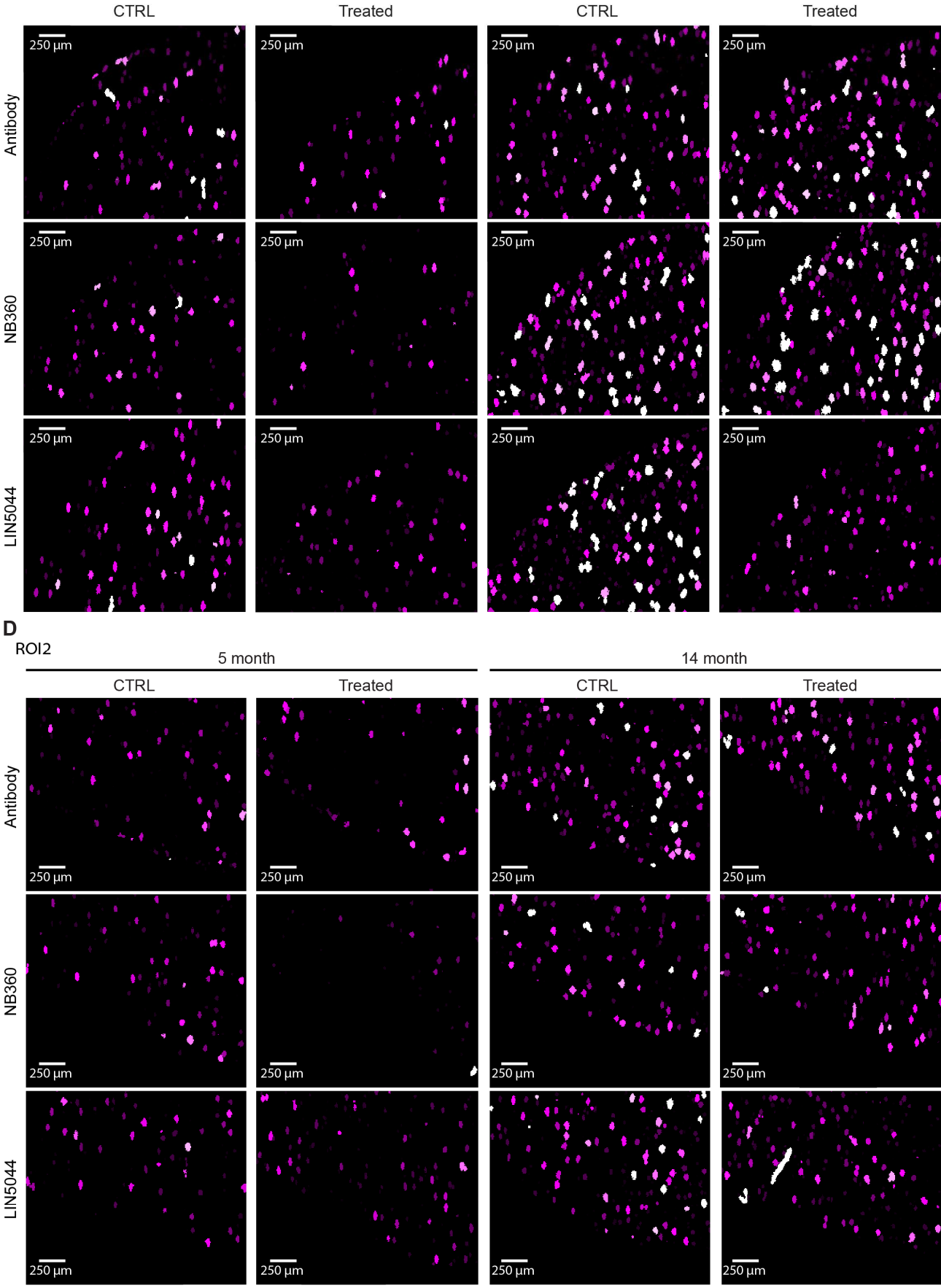

Supplementary figure 15

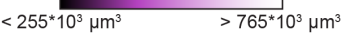


Supplementary figure 15. Anti-amyloid $\beta$ treatments reduce plaque counts and sizes. (A) We randomly picked an optical slice from the cortex (B, ROI1, ROI2 white inserts) of a control and a treated brain in each treatment cohort. Next, we segmented the plaques and color-coded them such that colors represent 4 equal portions of the total range of plaque sizes. (C) NB360 conspicuously reduced numbers and sizes of plaques in young mice, while (D) LIN5044 the number of large plaques in aged mice. The effect in the other treatment cohorts is less obvious. (E) Voxel-based and anatomy-based plaque burden analysis differ in how the brain is spatially sampled for statistics. Voxel level statistics is more granular and highlights how treatment effects distribute in space in an unbiased way. We overlaid the outlines of anatomical brain regions on the voxelbased significance maps of therapy-affected voxels. Voxel-based statistics shows clusters of therapy-affected voxels occupying spaces which do not follow the boundaries of anatomical regions. 

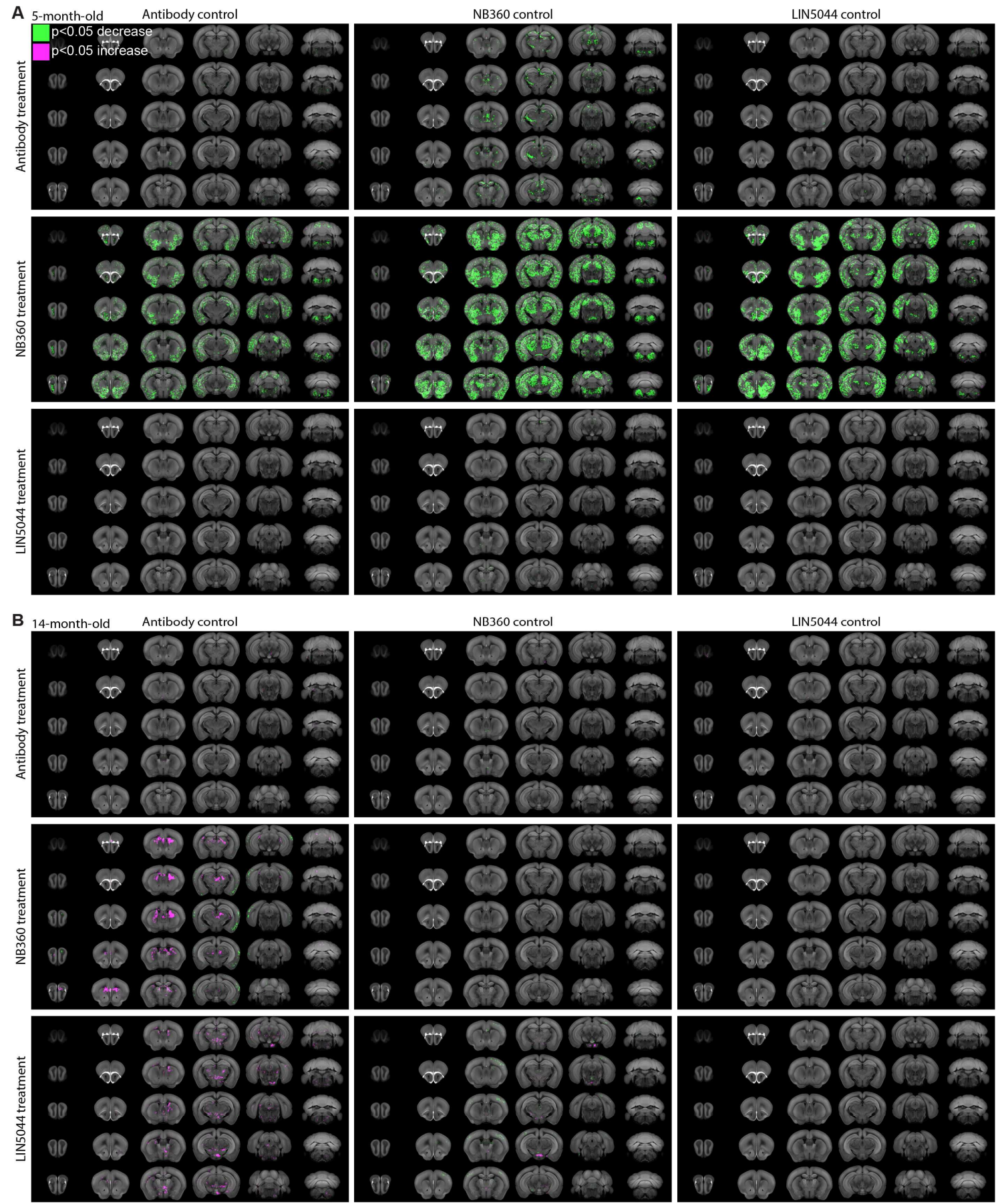

Supplementary figure 16

\section{Supplementary figure 16 . The pattern of plaque density reduction upon different treatments is unaltered}

by permuting the control groups. Testing the effect of the controls PBS (LIN5044), recombinant IgG in PBS

( $\beta 1$ antibody), and food chow on plaque load. For this, control groups were switched between the treatment cohorts when performing voxel-based statistical analysis. This did not change the spatial distribution of 
bioRxiv preprint doi: https://doi.org/10.1101/2021.01.15.426090; this version posted July 14, 2021. The copyright holder for this preprint (which was not certified by peer review) is the author/funder, who has granted bioRxiv a license to display the preprint in perpetuity. It is made available under aCC-BY-ND 4.0 International license.

significantly affected voxels in (A) 5-months-old or (B) 14-months-old mice. Pooled IgG controls reduce the significance of every treatment hinting that the IgG control cohorts have lower plaque density values. 

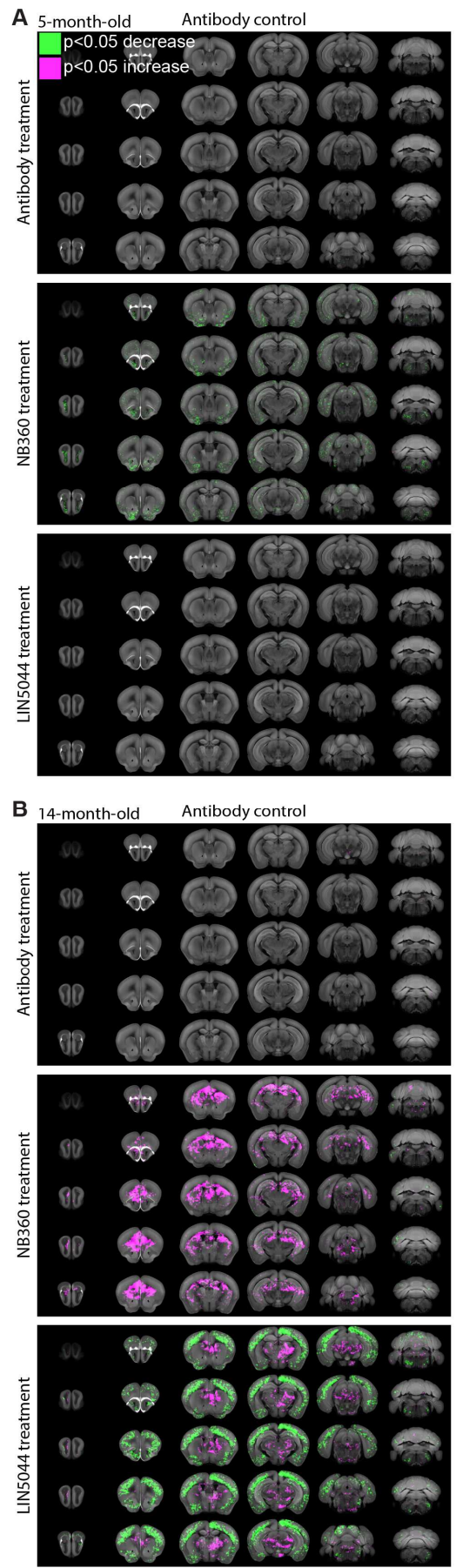

Supplementary figure 17
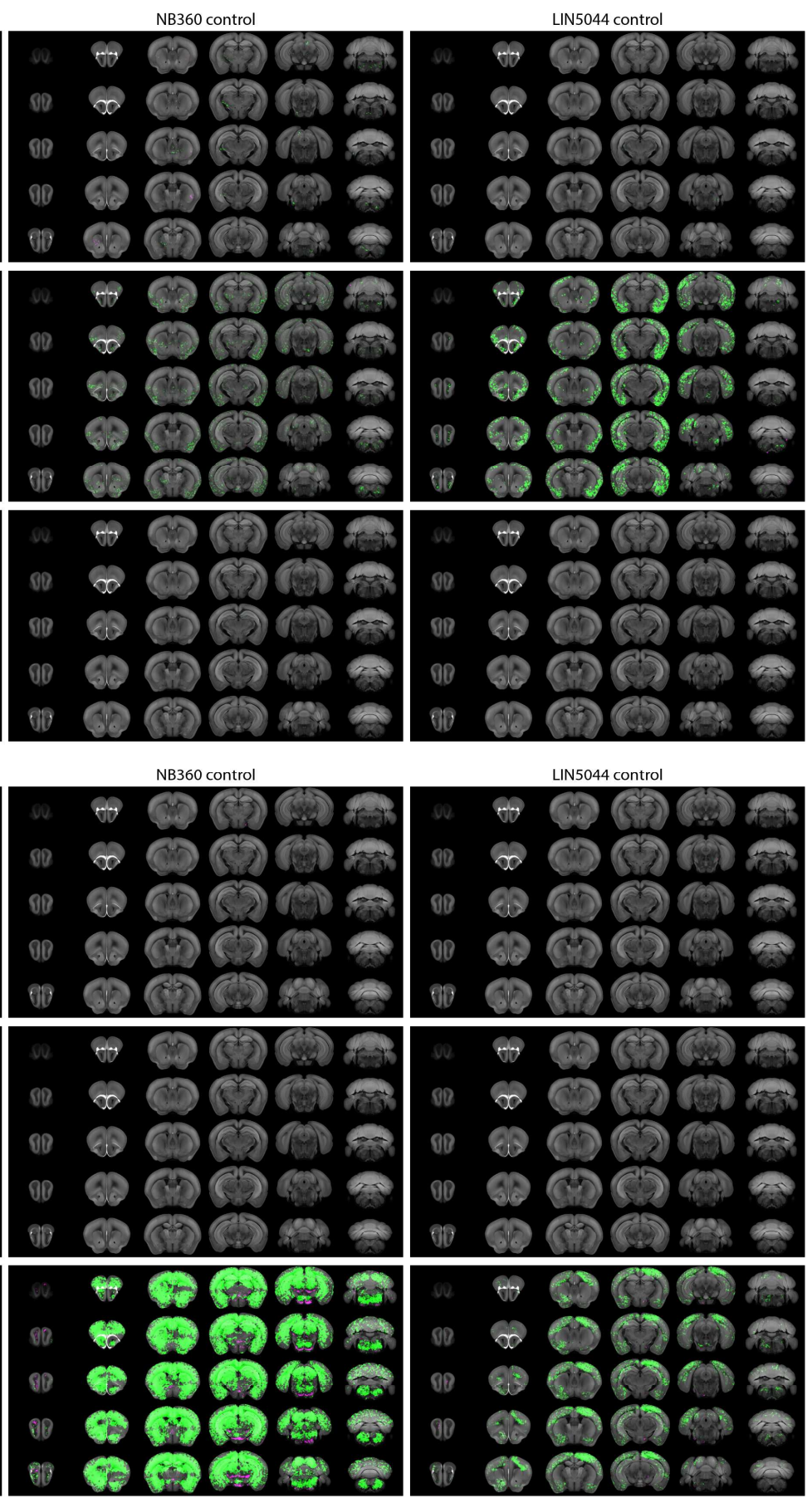

\section{Supplementary figure 17. The pattern of mean plaque size reduction upon different treatments is}

unaltered by permuting the control groups. Testing the effect of the controls PBS (LIN5044), recombinant IgG in PBS ( $\beta 1$ antibody), and food chow on mean plaque size. For this, control groups were switched between the treatment cohorts when performing voxel-based statistical analysis. This did not change the overall spatial distribution of significantly affected voxels in (A) 5-months-old or (B) 14-months-old mice. In some 
bioRxiv preprint doi: https://doi.org/10.1101/2021.01.15.426090; this version posted July 14, 2021. The copyright holder for this preprint (which was not certified by peer review) is the author/funder, who has granted bioRxiv a license to display the preprint in perpetuity. It is made available under aCC-BY-ND 4.0 International license.

cases, the level of significance changed. Pooled IgG controls reduce the significance of every treatment hinting that the IgG control cohorts have lower plaque size values. 
A

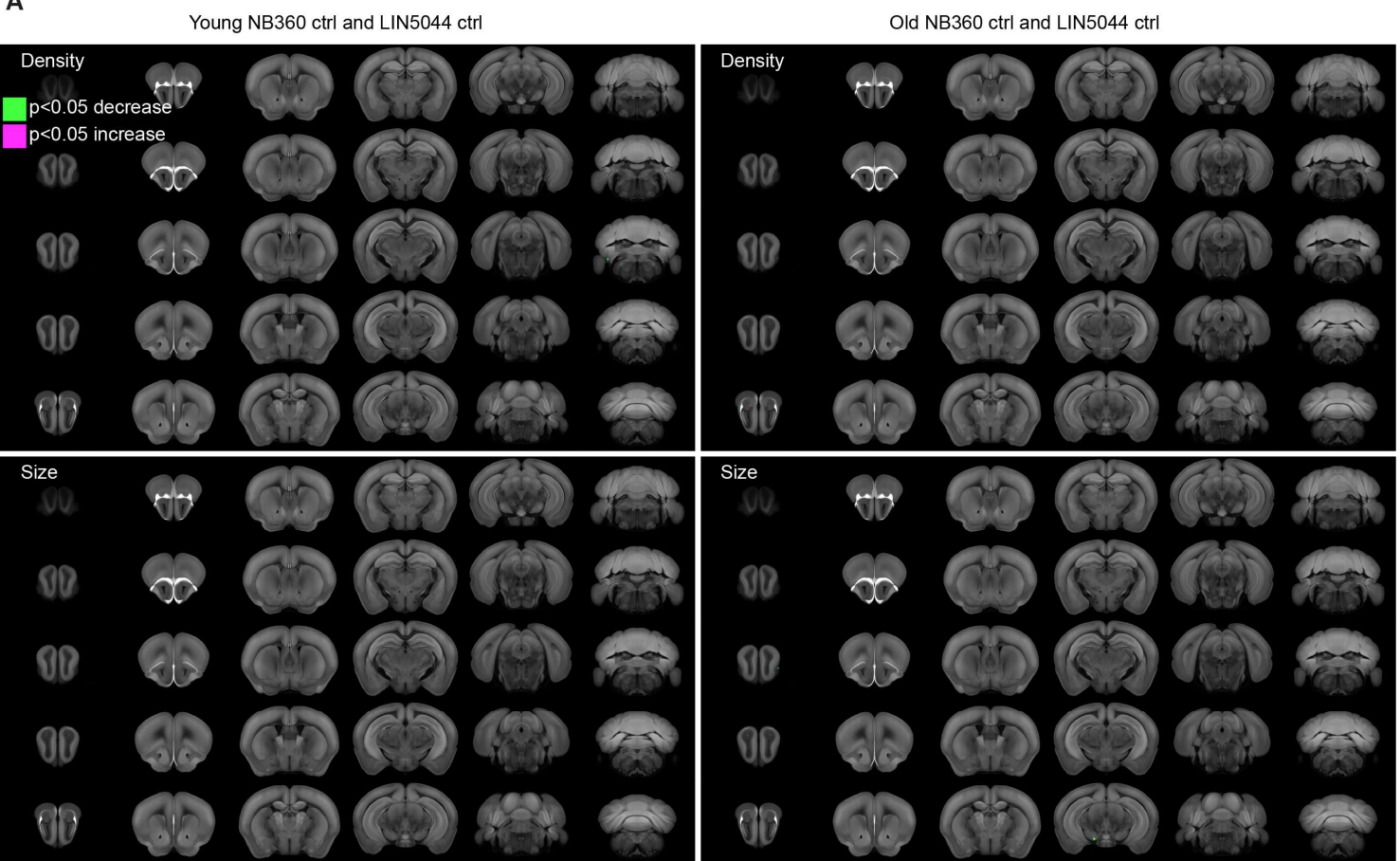

B
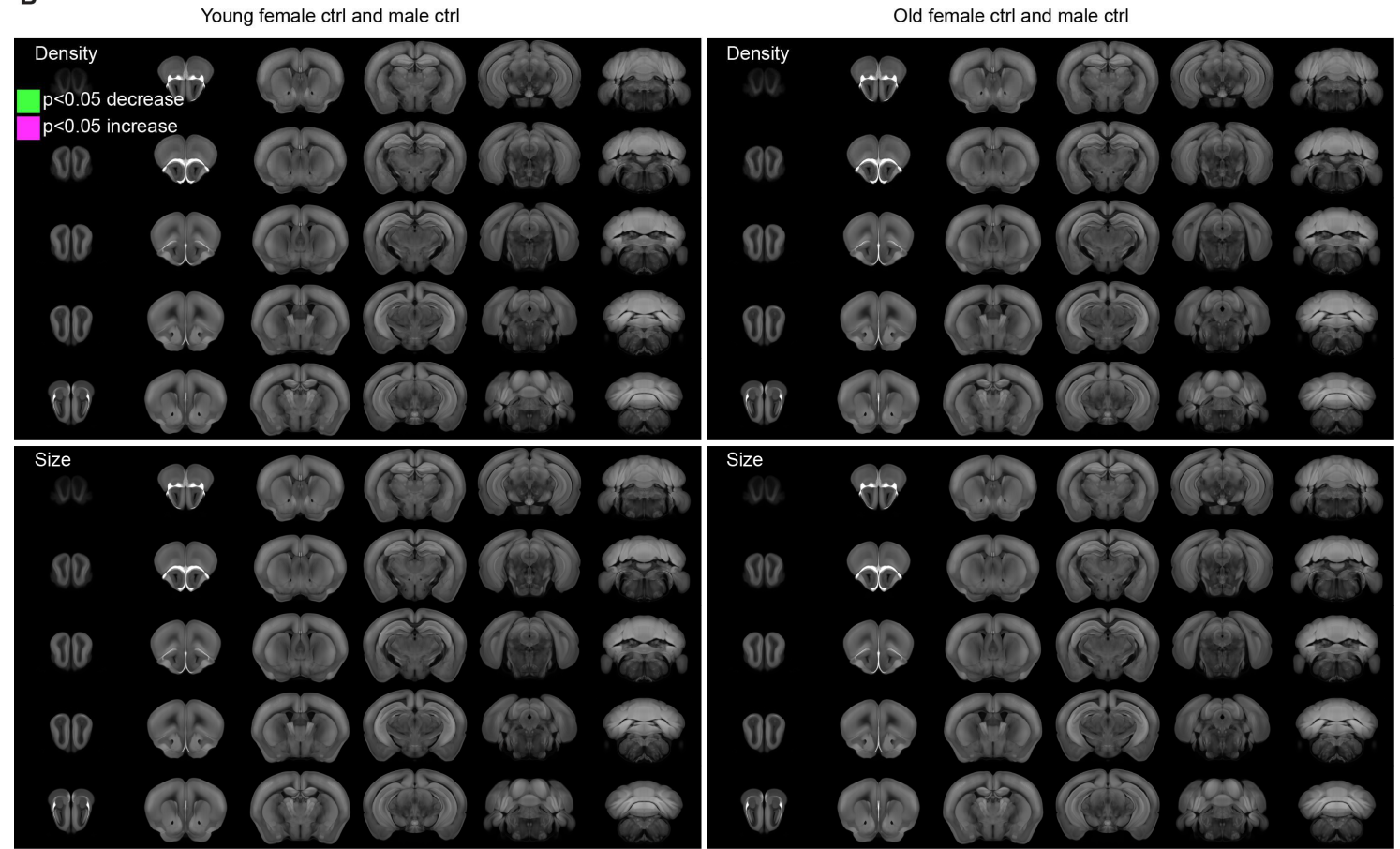

Supplementary figure 18

Supplementary figure 18. There is no significant difference in plaque burden between the control cohorts of the LIN5044 and BACE1 - inhibitor groups, or control female and male mice. (A) Voxel-level statistical comparison between control animals in the NB360 and LIN5044 cohorts show no significantly altered voxels 
bioRxiv preprint doi: https://doi.org/10.1101/2021.01.15.426090; this version posted July 14, 2021. The copyright holder for this preprint (which was not certified by peer review) is the author/funder, who has granted bioRxiv a license to display the preprint in perpetuity. It is made available under aCC-BY-ND 4.0 International license.

(neither for plaque counts nor mean plaque size). (B) Voxel level statistics shows no difference between female and male control mice. 
A

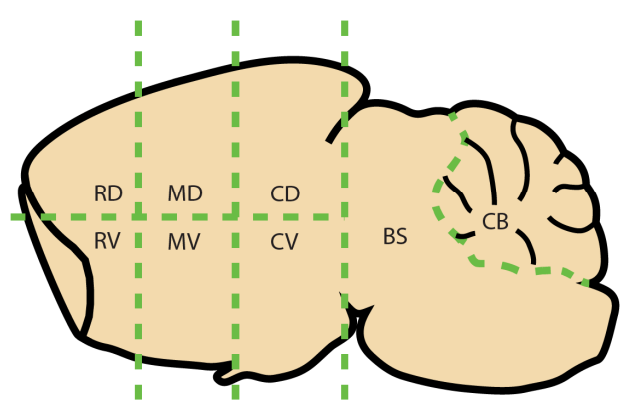

C
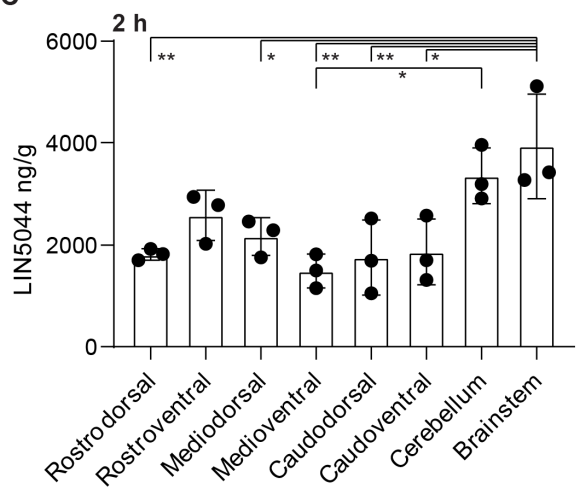

Brain region

E

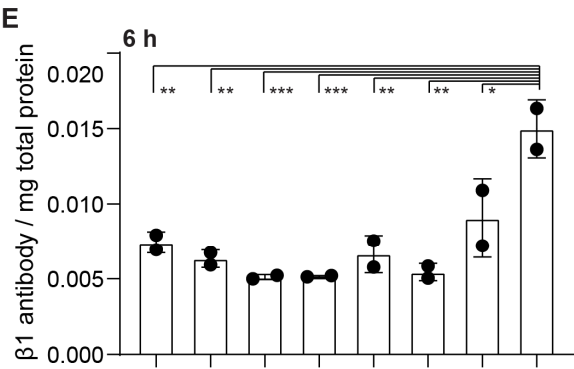

올

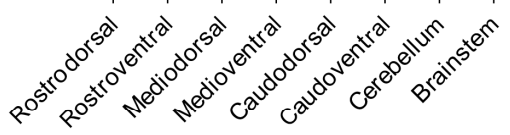

Brain region

G

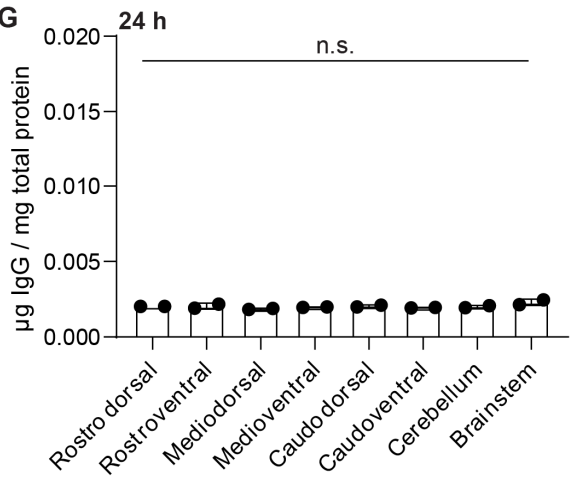

Brain region

\section{Supplementary figure 19}

B

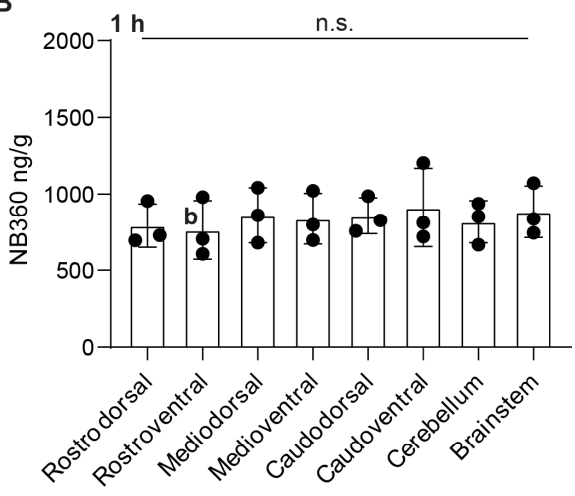

Brain region

D
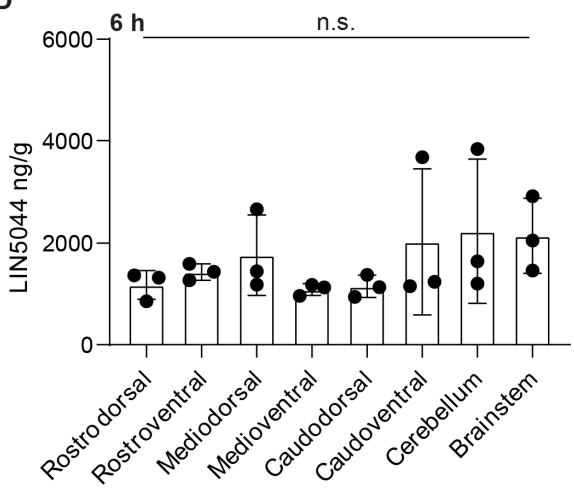

Brain region

F

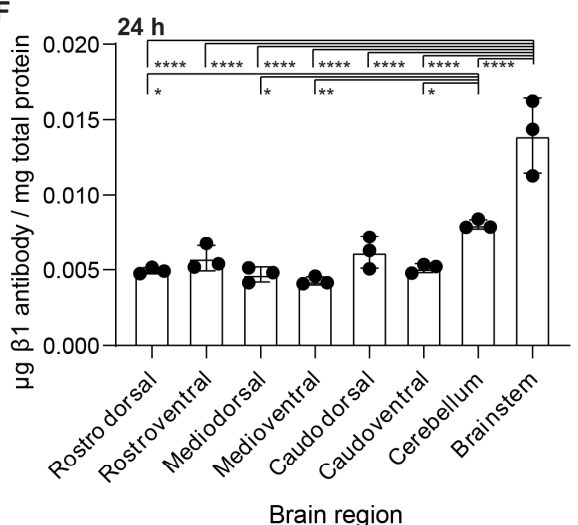




\section{Supplementary figure 19. Regional variations of bioavailability do not explain the spatial patterns of drug}

effectiveness. (A) Brains were dissected into eight regions to test regional drug distributions. (B) No regional difference in NB360 drug levels detectable after oral administration, (C) while LIN5044 shows significantly higher levels in the brainstem (ranging $0.0023<p<0.0345)$ and the cerebellum $(p=0.0241) 2$ hours after intraperitoneal injection, (D) but no difference detectable at 6 hours. (E, F) ELISA measurements of $\beta 1$ antibody levels after intraperitoneal application showed higher levels in the brainstem (for multiple brain regions ranging $p=0.0223$ to $p<9 \times 10^{-4}$ at 6 hours and $p<10^{-4}$ at 24 hours) and the cerebellum (for multiple brain regions ranging $0.0072<p<0.034$ at 24 hours) compared to other regions both at 6 and 24 hourssimilarly to LIN5044. (G) Pooled non-specific recombinant IgG shows no difference in regional distribution. 


\section{Supplementary tables}

Table S1. Number of mice in treatment cohorts.

\begin{tabular}{|l|l|l|l|l|l|l|}
\hline & $\beta 1$-old & $\begin{array}{l}\beta 1- \\
\text { young }\end{array}$ & $\begin{array}{l}\text { NB360- } \\
\text { old }\end{array}$ & $\begin{array}{l}\text { NB360- } \\
\text { young }\end{array}$ & $\begin{array}{l}\text { LIN5044 } \\
\text {-old }\end{array}$ & $\begin{array}{l}\text { LIN5044 } \\
\text {-young }\end{array}$ \\
\hline control & 5 & 4 & 4 & 5 & 4 & 6 \\
\hline treated & 3 & 6 & 5 & 3 & 4 & 6 \\
\hline
\end{tabular}

Table S1

Table S2. Neuroanatomical areas used for Allen Reference Atlas registration.

\begin{tabular}{|l|l|}
\hline Region Acronym & Region Name \\
\hline FRP & Frontal pole, cerebral cortex \\
\hline MOp & Primary motor area \\
\hline MOs & Secondary motor area \\
\hline SSp & Primary somatosensory area \\
\hline SSs & Supplemental somatosensory area \\
\hline GU & Gustatory areas \\
\hline VISC & Visceral area \\
\hline AUDd & Dorsal auditory area \\
\hline AUDp & Primary auditory area \\
\hline AUDpo & Posterior auditory area \\
\hline AUDv & Ventral auditory area \\
\hline VISal & Anterolateral visual area \\
\hline VISam & Anteromedial visual area \\
\hline VISI & Lateral visual area \\
\hline VISp & Primary visual area \\
\hline VISpl & Posterolateral visual area \\
\hline VISpm & posteromedial visual area \\
\hline VISa & Anterior area \\
\hline VISli & Laterointermediate area \\
\hline ACA & Anterior cingulate area \\
\hline PL & Infralimbic area \\
\hline ILA & Arbital area \\
\hline ORB & \\
\hline Al & Agranular insular area \\
\hline
\end{tabular}




\begin{tabular}{|c|c|}
\hline RSP & Retrosplenial area \\
\hline VISpor & Postrhinal area \\
\hline $\mathrm{VISrl}$ & Rostrolateral visual area \\
\hline TEa & Temporal association areas \\
\hline PERI & Perirhinal area \\
\hline ECT & Ectorhinal area \\
\hline OLF & Olfactory areas \\
\hline MOB & Main olfactory bulb \\
\hline $\mathrm{AOB}$ & Accessory olfactory bulb \\
\hline AON & Anterior olfactory nucleus \\
\hline TT & Taenia tecta \\
\hline $\mathrm{DP}$ & Dorsal peduncular area \\
\hline PIR & Piriform area \\
\hline NLOT & Nucleus of the lateral olfactory tract \\
\hline COA & Cortical amygdalar area \\
\hline PAA & Piriform-amygdalar area \\
\hline TR & Postpiriform transition area \\
\hline HPF & Hippocampal formation \\
\hline HIP & Hippocampal region \\
\hline ENTI & Entorhinal area, lateral part \\
\hline ENTm & Entorhinal area, medial part, dorsal zone \\
\hline PAR & Parasubiculum \\
\hline POST & Postsubiculum \\
\hline PRE & Presubiculum \\
\hline SUB & Subiculum \\
\hline Pros & Prosubiculum \\
\hline HATA & Hippocampo-amygdalar transition area \\
\hline APr & Area prostriata \\
\hline CTXsp & Cortical subplate \\
\hline CLA & Claustrum \\
\hline EP & Endopiriform nucleus \\
\hline LA & Lateral amygdalar nucleus \\
\hline BLA & Basolateral amygdalar nucleus \\
\hline BMA & Basomedial amygdalar nucleus \\
\hline PA & Posterior amygdalar nucleus \\
\hline STR & Striatum \\
\hline $\mathrm{CP}$ & Caudoputamen \\
\hline
\end{tabular}




\begin{tabular}{|c|c|}
\hline ACB & Nucleus accumbens \\
\hline FS & Fundus of striatum \\
\hline OT & Olfactory tubercle \\
\hline LSX & Lateral septal complex \\
\hline AAA & Anterior amygdalar area \\
\hline $\mathrm{BA}$ & Bed nucleus of the accessory olfactory tract \\
\hline CEA & Central amygdalar nucleus \\
\hline IA & Intercalated amygdalar nucleus \\
\hline MEA & Medial amygdalar nucleus \\
\hline PAL & Pallidum \\
\hline GPe & Globus pallidus, external segment \\
\hline GPi & Globus pallidus, internal segment \\
\hline $\mathrm{SI}$ & Substantia innominata \\
\hline MA & Magnocellular nucleus \\
\hline MSC & Medial septal complex \\
\hline TRS & Triangular nucleus of septum \\
\hline PALC & Pallidum, caudal region \\
\hline $\mathrm{TH}$ & Thalamus \\
\hline VENT & Ventral group of the dorsal thalamus \\
\hline SPF & Subparafascicular nucleus \\
\hline SPA & Subparafascicular area \\
\hline PP & Peripeduncular nucleus \\
\hline GENd & Geniculate group, dorsal thalamus \\
\hline LAT & Lateral group of the dorsal thalamus \\
\hline ATN & Anterior group of the dorsal thalamus \\
\hline MED & Medial group of the dorsal thalamus \\
\hline MTN & Midline group of the dorsal thalamus \\
\hline ILM & Intralaminar nuclei of the dorsal thalamus \\
\hline RT & Reticular nucleus of the thalamus \\
\hline GENv & Geniculate group, ventral thalamus \\
\hline $\mathrm{MH}$ & Medial habenula \\
\hline LH & Lateral habenula \\
\hline HY & Hypothalamus \\
\hline PVZ & Periventricular zone \\
\hline PVR & Periventricular region \\
\hline $\mathrm{AHN}$ & Anterior hypothalamic nucleus \\
\hline MBO & Mammillary body \\
\hline
\end{tabular}




\begin{tabular}{|c|c|}
\hline MPN & Medial preoptic nucleus \\
\hline PMd & Dorsal premammillary nucleus \\
\hline PMv & Ventral premammillary nucleus \\
\hline PVHd & Paraventricular hypothalamic nucleus, descending division \\
\hline $\mathrm{VMH}$ & Ventromedial hypothalamic nucleus \\
\hline $\mathrm{PH}$ & Posterior hypothalamic nucleus \\
\hline LHA & Lateral hypothalamic area \\
\hline LPO & Lateral preoptic area \\
\hline PST & Preparasubthalamic nucleus \\
\hline PSTN & Parasubthalamic nucleus \\
\hline PeF & Perifornical nucleus \\
\hline $\mathrm{RCH}$ & Retrochiasmatic area \\
\hline STN & Subthalamic nucleus \\
\hline TU & Tuberal nucleus \\
\hline ZI & Zona incerta \\
\hline $\mathrm{ME}$ & Median eminence \\
\hline $\mathrm{MB}$ & Midbrain \\
\hline MBsen & Midbrain, sensory related \\
\hline MBmot & Midbrain, motor related \\
\hline MBsta & Midbrain, behavioral state related \\
\hline$P$ & Pons \\
\hline NLL & Nucleus of the lateral lemniscus \\
\hline PSV & Principal sensory nucleus of the trigeminal \\
\hline PB & Parabrachial nucleus \\
\hline SOC & Superior olivary complex \\
\hline P-mot & Pons, motor related \\
\hline P-sat & Pons, behavioral state related \\
\hline MY & Medulla \\
\hline MY-sen & Medulla, sensory related \\
\hline MY-mot & Medulla, motor related \\
\hline MY-sat & Medulla, behavioral state related \\
\hline CB & Cerebellum \\
\hline VERM & Vermal regions \\
\hline HEM & Hemispheric regions \\
\hline CBN & Cerebellar nuclei \\
\hline
\end{tabular}

Table S2 
Table S3. Plaque loads in control mice of each treatment cohort show low variability.

\begin{tabular}{|l|l|r|r|r|}
\hline Treatment & Age & Count Mean & \multicolumn{1}{l|}{ Count SD } & \multicolumn{1}{c|}{ Count SE } \\
\hline AB & old & 2108735 & 292186 & 130670 \\
\hline AB & young & 1097711 & 159214 & 79607 \\
\hline BACE1 & old & 2790290 & 245900 & 122950 \\
\hline BACE1 & young & 1151097 & 159849 & 79924 \\
\hline LCP & old & 2738744 & 333892 & 166946 \\
\hline LCP & young & 1243608 & 156807 & 64016 \\
\hline$<$ all> & old & 2512293 & 426799 & 118373 \\
\hline$<$ all> & young & 1175491 & 159340 & 42585 \\
\hline
\end{tabular}

Table S3

Table S4. Significantly affected voxels (SAV) after NB360, $\beta 1$-antibody or LIN5044 treatment. After all the brain scans were registered to a brain atlas, the brains were deconstructed into standard voxels in a coordinate system. Then, for every treatment a "phantom" brain-volume was generated where each voxel represented the $p$-value of treatment effect. This was generated by two-sided t-testing all treated against all control brains (for a respective voxel). Voxels with $p$-values either $p<0.1$ or 0.05 were termed as SAV. Each treatment's phantom brain was thresholded to only contain SAVs $(p<0.1$ or 0.05$)$. The effect-overlap between treatments was defined by the voxels which were significantly affected in both of the compared treatments. Our results show that most SAVs are non-overlapping. The overlap was $<1 \%$ or $<2.65 \%$ at $p<0.05$ or $p<0.1$, respectively. 


\begin{tabular}{|c|c|c|c|c|c|c|c|}
\hline \multicolumn{8}{|c|}{$p<0.05$} \\
\hline \multicolumn{4}{|c|}{ Young } & \multicolumn{4}{|c|}{ Old } \\
\hline Density & NB360 & $\beta 1$ & LIN5044 & Density & NB360 & $\beta 1$ & LIN5044 \\
\hline NB360 & 2'649'191 & 435 & 2 & NB360 & 46 & 0 & 0 \\
\hline$\beta 1$ & 435 & $4^{\prime} 625$ & 0 & $\beta 1$ & 0 & 40 & 0 \\
\hline LIN5044 & 2 & 0 & 29 & LIN5044 & 0 & 0 & 276 \\
\hline Size & NB360 & $\beta 1$ & LIN5044 & Size & NB360 & $\beta 1$ & LIN5044 \\
\hline NB360 & $66^{\prime} 128$ & 3 & 1 & NB360 & 10 & 0 & 0 \\
\hline$\beta 1$ & 3 & 2'518 & 0 & $\beta 1$ & 0 & 18 & 1 \\
\hline LIN5044 & 1 & 0 & 80 & LIN5044 & 0 & 1 & $492^{\prime} 779$ \\
\hline Maturity & NB360 & $\beta 1$ & & Maturity & NB360 & $\beta 1$ & \\
\hline NB360 & 1'593'392 & $9^{\prime} 542$ & & NB360 & 136 & 0 & \\
\hline$\beta 1$ & 9'542 & $52 ' 893$ & & $\beta 1$ & 0 & 639 & \\
\hline \multicolumn{8}{|c|}{$p<0.1$} \\
\hline \multicolumn{4}{|c|}{ Young } & \multicolumn{4}{|c|}{ Old } \\
\hline Density & NB360 & $\beta 1$ & LIN5044 & Density & NB360 & $\beta 1$ & LIN5044 \\
\hline NB360 & 7'185'540 & $5^{\prime} 443$ & 30 & NB360 & 16304 & 0 & 0 \\
\hline$\beta 1$ & $5^{\prime} 443$ & $21^{\prime} 359$ & 0 & $\beta 1$ & 0 & 69 & 0 \\
\hline LIN5044 & 30 & 0 & 121 & LIN5044 & 0 & 0 & 486 \\
\hline Size & NB360 & $\beta 1$ & LIN5044 & Size & NB360 & $\beta 1$ & LIN5044 \\
\hline NB360 & $888^{\prime} 437$ & 282 & $1^{\prime} 302$ & NB360 & 25 & 0 & 0 \\
\hline$\beta 1$ & 282 & $8^{\prime} 661$ & 1 & $\beta 1$ & 0 & 61 & 5 \\
\hline LIN5044 & 1'302 & 1 & $20^{\prime} 530$ & LIN5044 & 0 & 5 & 2'941'884 \\
\hline Maturity & NB360 & $\beta 1$ & & Maturity & NB360 & $\beta 1$ & \\
\hline NB360 & $2^{\prime} 181^{\prime} 488$ & $19^{\prime} 777$ & & NB360 & 221 & 0 & \\
\hline$\beta 1$ & $19^{\prime} 777$ & $84^{\prime} 862$ & & $\beta 1$ & 0 & 1432 & \\
\hline
\end{tabular}

Table S4 
Table S5. Third-party libraries used for the computational pipeline.

\begin{tabular}{|l|l|}
\hline Software and Algorithms & Source \\
\hline ClearMap & $\begin{array}{l}\text { Renier, N. et al. Mapping of Brain Activity by Automated Volume } \\
\text { Analysis of Immediate Early Genes. Cell 165, 1789-1802, } \\
\text { doi:10.1016/j.cell.2016.05.007 (2016). }\end{array}$ \\
\hline Python & $\begin{array}{l}\text { Python Software Foundation. Python Language Reference, } \\
\text { version 2.7. Available at http://www.python.org }\end{array}$ \\
\hline FIJI & $\begin{array}{l}\text { Schindelin, J. et al. Fiji: An open-source platform for biological- } \\
\text { image analysis. Nat. Methods 9, 676-682 (2012). }\end{array}$ \\
\hline R & $\begin{array}{l}\text { R Core Team (2013). R: A language and environment for } \\
\text { statistical computing. R Foundation for Statistical Computing, } \\
\text { Vienna, Austria. http://www.R-project.org }\end{array}$ \\
\hline
\end{tabular}

Table S5

\section{Supplementary movie}

Movie S1. A $\beta$-therapies target distinct areas of the brain. Treatment with a BACE1 inhibitor (NB360, green) in 5-month-old mice or with the amyloid intercalator (LIN5044, magenta) in 14-month-old mice reduces the size of plaques in distinct areas of the brain. The treatment-affected areas are significantly non-overlapping (Colocalization, white) ( $p=0.03$, hypergeometric test). BACE1 inhibition affects ventro-caudal portions of the brain, while LIN5044 does so in rostro-dorsal areas and in deep cortical layers. 